\title{
Numerical Model of the Hoosic River Flood- Control Channel, Adams, MA
}

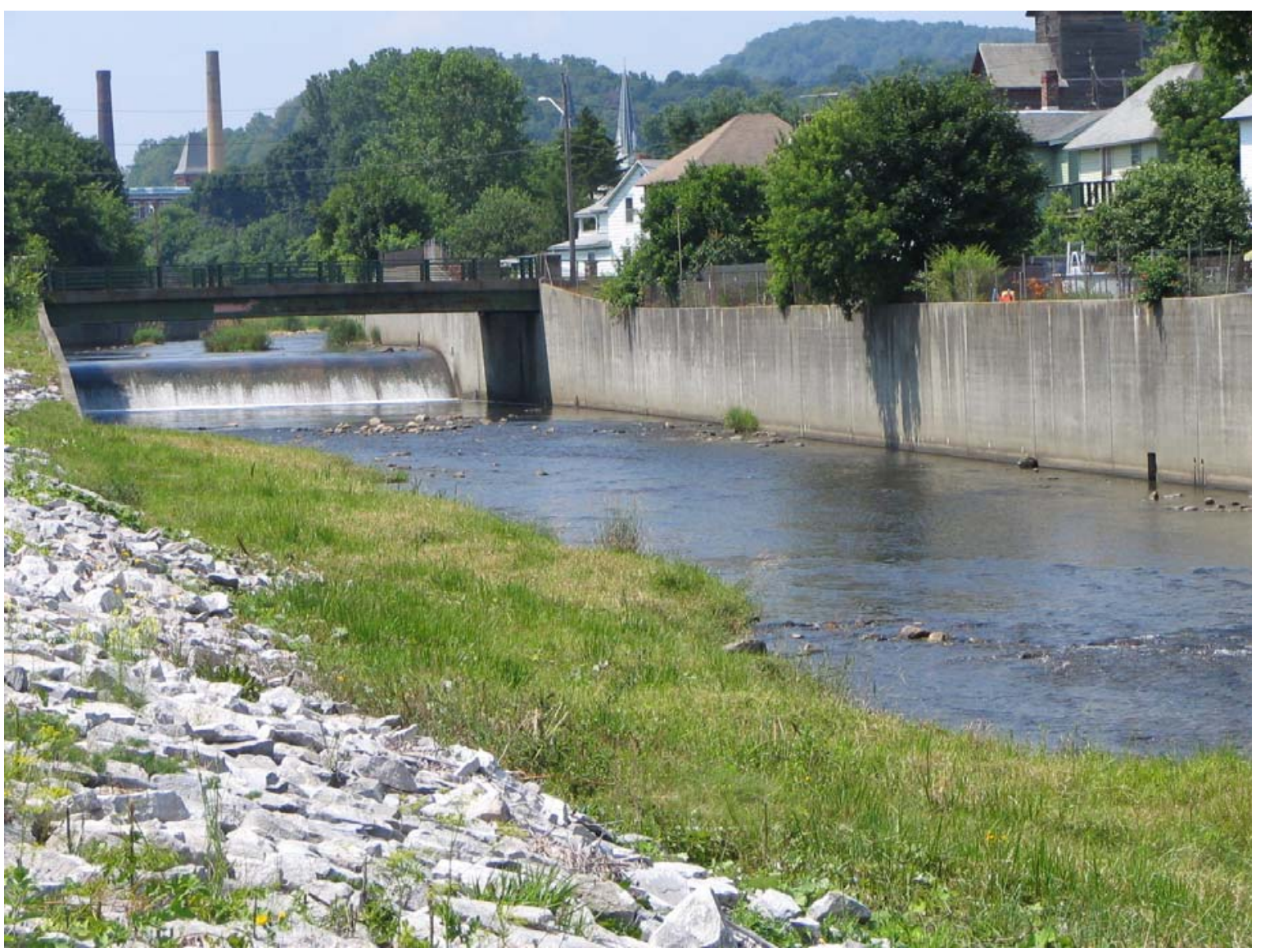




\section{Numerical Model of the Hoosic River Flood- Control Channel, Adams, MA}

Richard L. Stockstill, Jane M. Vaughan, and Keith Martin

Coastal and Hydraulics Laboratory

U.S. Army Engineer Research and Development Center

3909 Halls Ferry Road

Vicksburg, MS 39180-6199

Final report

Approved for public release; distribution is unlimited.

Prepared for U.S. Army Engineer District, New York Jacob K. Javits Federal Building

26 Federal Plaza, Room 2109

New York, NY 10278-0090 


\begin{abstract}
A numerical model study of the Hoosic River Flood-Control Channel was conducted to determine the flow conditions with the channel as it presently exists as compared with the as-built conditions. Sediment has accumulated in certain portions of the channel resulting in relatively large areas of deposited material that may inhibit flood-flow conveyance. The two-dimensional depth-averaged module of the Adaptive Hydraulics (ADH) finite element flow solver was used to obtain velocity information and water-surface elevations. Validation of the numerical modeling system was completed by comparing simulation results with published physical model data. The model was then used to evaluate the flow conditions associated with the as-built channel configuration. The existing channel conditions were then simulated to determine the water-surface elevations that are to be expected with design discharge and the channel in the present day condition. Finally, the flow conditions with two alternative channel modifications were evaluated. These modifications were proposed channel restoration configurations designed to improve habitat and aesthetics.
\end{abstract}

DISCLAIMER: The contents of this report are not to be used for advertising, publication, or promotional purposes. Citation of trade names does not constitute an official endorsement or approval of the use of such commercial products. All product names and trademarks cited are the property of their respective owners. The findings of this report are not to be construed as an official Department of the Army position unless so designated by other authorized documents. 


\section{Contents}

Figures and Tables................................................................................................................

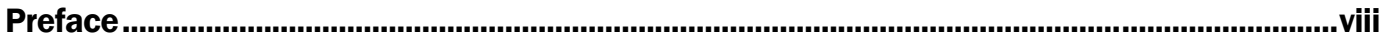

Unit Conversion Factors............................................................................................................................ix

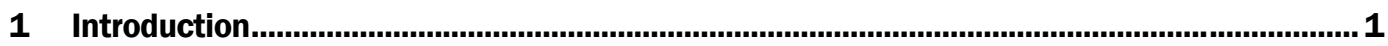

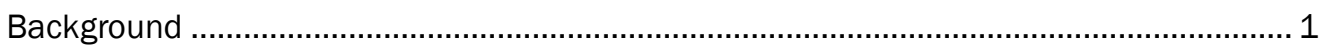

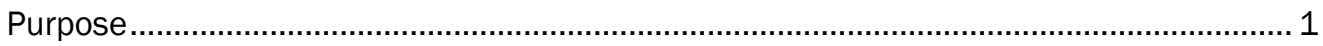

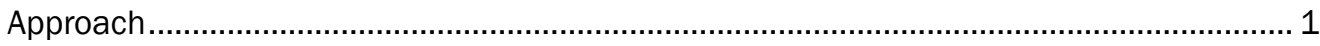

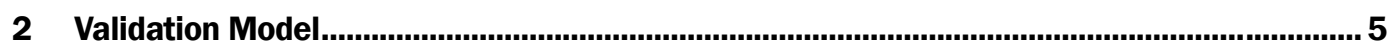

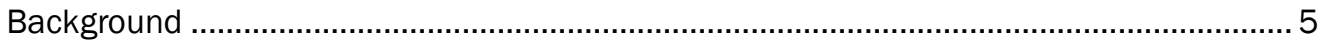

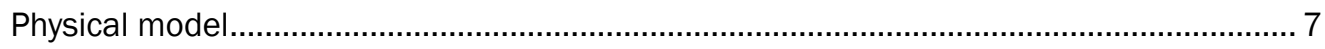

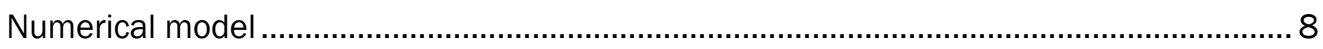

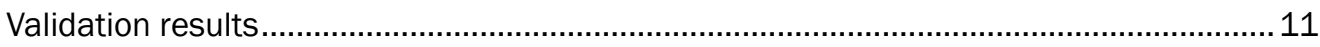

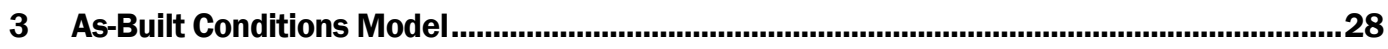

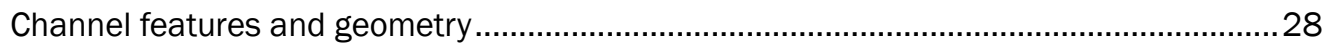

Boundary conditions and model parameters ................................................................29

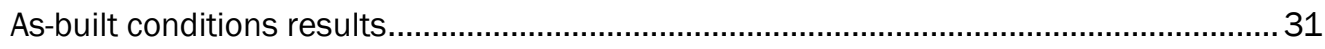

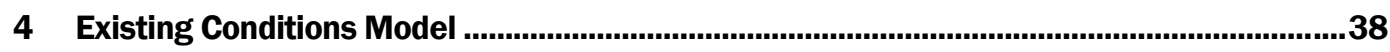

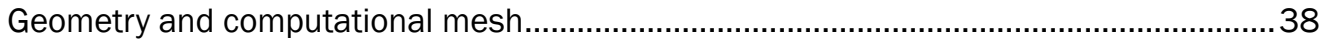

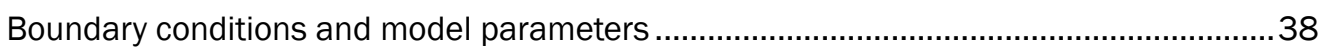

Existing conditions results ..................................................................................... 40

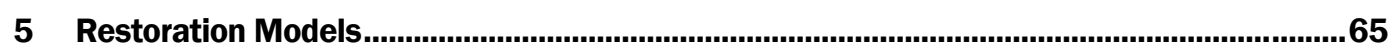

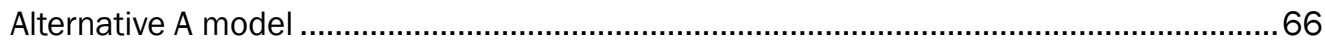

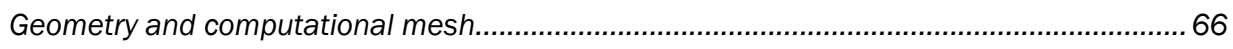

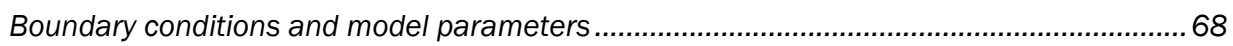

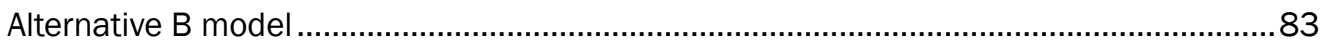

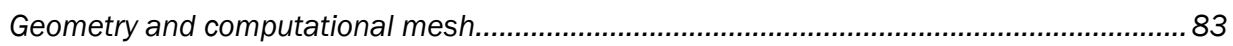

Boundary conditions and model parameters .................................................................... 84

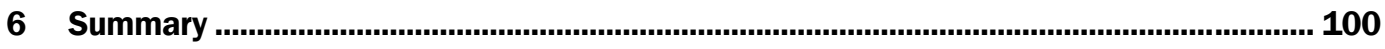

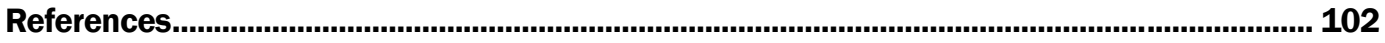

\section{Report Documentation Page}




\section{Figures and Tables}

\section{Figures}

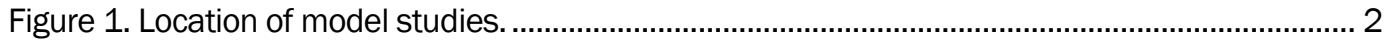

Figure 2. Hoosic River through town of Adams, MA ................................................................. 3

Figure 3. Sediment deposition and vegetation at confluence of Hoosic River and Tophet Brook.

Figure 4. Sediment deposition and vegetation in main channel downstream of Tophet

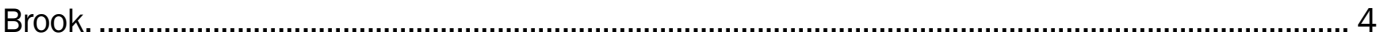

Figure 5. Model validation, physical and numerical model limits. .................................................... 6

Figure 6. Model validation, computational mesh details. ................................................................ 10

Figure 7. Model validation, numerical model results, water-surface contours downstream of the North and South Branch confluence.

Figure 8. Model validation, numerical model results at the confluence of the North and South Branches, looking downstream.

Figure 9. Model validation, numerical model results at the confluence of the North and South Branches, looking upstream.

Figure 10. Model validation, North Branch, plan and profiles, sta $205+96.03$ to $193+41.59$, left wall.

Figure 11. Model validation, North Branch, plan and profiles, sta $205+96.03$ to $193+41.59$, right wall.

Figure 12. Model validation, North Branch, plan and profiles, sta $193+41.59$ to 178+67.97, left wall.

Figure 13. Model validation, North Branch, plan and profiles, sta $193+41.59$ to 178+67.97, right wall.

Figure 14. Model validation, North Branch, plan and profiles, sta $178+67.97$ to $165+49.51$, left wall.

Figure 15. Model validation, North Branch, plan and profiles, sta $178+67.97$ to $165+49.51$, right wall.

Figure 16. Model validation, North Branch, plan and profiles, sta $165+49.51$ to 155+98.72, left wall.

Figure 17. Model validation, North Branch, plan and profiles, sta $165+49.51$ to 155+98.72, right wall.

Figure 18. Model validation, South Branch, plan and profiles, sta $183+75.00$ to 169+61.24, left wall.

Figure 19. Model validation, South Branch, plan and profiles, sta $183+75.00$ to $169+61.24$, right wall.

Figure 20. Model validation, South Branch, plan and profiles, sta 169+61.24 to $156+75.91$, left wall.

Figure 21. Model validation, South Branch, plan and profiles, sta $169+61.24$ to $156+75.91$, right wall. 
Figure 22. Model validation, South Branch, plan and profiles, sta 156+75.91 to $141+75.00$, left wall.

Figure 23. Model validation, South Branch, plan and profiles, $156+75.91$ to $141+75.00$,

right wall.

Figure 24. As-built conditions, computational mesh of Hoosic River channel and tributaries.

Figure 25. As-built conditions, velocity magnitude contours at Tophet Brook confluence, sta $53+50$ to $41+94.07$.

Figure 26 . As-built conditions, velocity magnitude contours, sta $41+17$ to $29+11$.

Figure 27. As-built conditions, velocity magnitude contours, sta $29+11$ to $17+50$...........................35

Figure 28. As-built conditions, velocity magnitude contours, sta $20+67$ to $8+38.2 \ldots \ldots \ldots \ldots \ldots \ldots . . . . . . . . . .36$

Figure 29. As-built conditions, velocity magnitude contours, sta $9+00$ to $-1+00 \ldots \ldots \ldots \ldots \ldots \ldots . . . . . . . . . . . . .37$

Figure 30. Existing conditions, computational mesh of Hoosic River channel and tributaries

Figure 31. Existing conditions, super-elevation in computed water surface through curve.

Figure 32. Existing conditions, water surface at the confluence of Tophet Brook and Hoosic River

Figure 33. Existing conditions, velocity magnitude contours at Tophet Brook confluence, sta $53+50$ to $41+94.07$.

Figure 34. Existing conditions, velocity magnitude contours, sta $41+17$ to $29+11 \ldots \ldots \ldots \ldots \ldots . . . . . . . . . . . .43$

Figure 35 . Existing conditions, velocity magnitude contours, sta $29+11$ to $17+50 \ldots \ldots \ldots \ldots \ldots \ldots . . . . . . . . .44$

Figure 36. Existing conditions, velocity magnitude contours, sta $20+67$ to $8+38.2$........................ 45

Figure 37. Existing conditions, velocity magnitude contours, sta $9+00$ to $-1+00 \ldots \ldots \ldots \ldots \ldots \ldots . . . . . . . . . . . . . . .46$

Figure 38. Existing and as-built conditions, plan and profiles, sta 121+00 to 106+73.04, left wall.

Figure 39. Existing and as-built conditions, plan and profiles, sta $121+00$ to $106+73.04$, right wall.

Figure 40. Existing and as-built conditions, plan and profiles, sta 106+73.04 to $93+37.43$, left wall.

Figure 41. Existing and as-built conditions, plan and profiles, sta $106+73.04$ to $93+37.43$, right wall. .

Figure 42. Existing and as-built conditions, plan and profiles, sta $93+37.43$ to $79+40.90$, left wall.

Figure 43. Existing and as-built conditions, plan and profiles, sta $93+37.43$ to $79+40.90$, right wall.

Figure 44. Existing and as-built conditions, plan and profiles, sta 79+40.90 68+13.34, left wall.

Figure 45. Existing and as-built conditions, plan and profiles, sta 79+40.90 68+13.34, left wall.

Figure 46. Existing and as-built conditions, plan and profiles, sta $68+13.34$ to 55+25.00, left wall.

Figure 47. Existing and as-built conditions, plan and profiles, sta $68+13.34$ to $55+25.00$, right wall......

Figure 48. Existing and as-built conditions, plan and profiles, sta 55+25.00 to $41+94.07$, left wall. 
Figure 49. Existing and as-built conditions, plan and profiles, sta $55+25.00$ to $41+94.07$, right wall.

Figure 50. Existing and as-built conditions, plan and profiles, sta $41+94.07$ to $27+19.78$, left wall.

Figure 51. Existing and as-built conditions, plan and profiles, sta $41+94.07$ to $27+19.78$, right wall.

Figure 52. Existing and as-built conditions, plan and profiles, sta $27+19.78$ to $12+14.29$, left wall.

Figure 53. Existing and as-built conditions, plan and profiles, sta $27+19.78$ to $12+14.29$, right wall. .

Figure 54. Existing and as-built conditions, plan and profiles, sta $12+14.29$ to $0+00$, left wall.

Figure 55. Existing and as-built conditions, plan and profiles, sta $12+14.29$ to $0+00$, right wall.

Figure 56. Typical drop structure modification used in the restoration alternatives........................66

Figure 57. Alternative A, computational mesh details. ..........................................................67

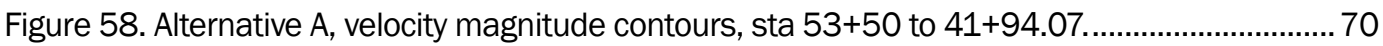

Figure 59. Alternative $A$, velocity magnitude contours, sta $41+17$ to $29+11$................................ 71

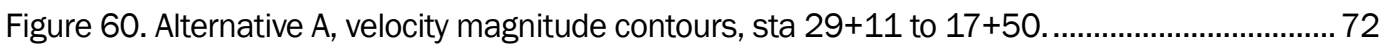

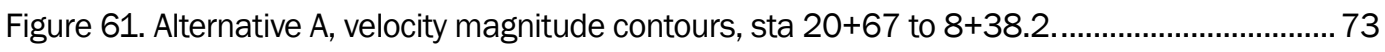

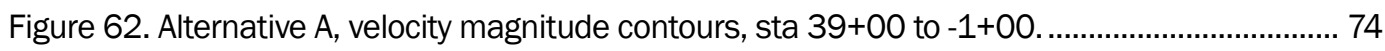

Figure 63. Alternative A, plan and profiles, sta $55+25.00$ to $41+94.07$, left wall............................. 75

Figure 64. Alternative A, plan and profiles, sta $55+25.00$ to $41+94.07$, right wall........................... 76

Figure 65. Alternative A, plan and profiles, sta $41+94.07$ to $27+19.78$, left wall............................. 77

Figure 66. Alternative A, plan and profiles, sta $41+94.07$ to $27+19.78$, right wall........................... 78

Figure 67. Alternative A, plan and profiles, sta $27+19.78$ to $12+14.29$, left wall............................. 79

Figure 68. Alternative A, plan and profiles, sta $27+19.78$ to $12+14.29$, right wall........................... 80

Figure 69. Alternative A, plan and profiles, sta $12+14.29$ to $0+00$, left wall.................................... 81

Figure 70. Alternative A, plan and profiles, sta $12+14.29$ to $0+00$, right wall.................................. 82

Figure 71. Alternative B, computational mesh details.................................................................. 85

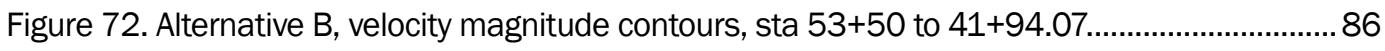

Figure 73 . Alternative $B$, velocity magnitude contours, sta $41+17$ to $29+11$.................................. 87

Figure 74 . Alternative $B$, velocity magnitude contours, sta $29+11$ to $17+50$................................ 88

Figure 75 . Alternative $B$, velocity magnitude contours, sta $20+67$ to $8+38.2$............................... 89

Figure 76. Alternative $B$, velocity magnitude contours, sta 39+00 to $-1+00$.................................. 90

Figure 77. Alternative B, plan and profiles, sta $55+25.00$ to $41+94.07$, left wall. ............................ 92

Figure 78. Alternative B, plan and profiles, sta $55+25.00$ to $41+94.07$, right wall. ........................ 93

Figure 79. Alternative B, plan and profiles, sta $41+94.07$ to $27+19.78$, left wall............................ 94

Figure 80. Alternative B, plan and profiles, sta $41+94.07$ to $27+19.78$, right wall...........................95

Figure 81. Alternative B, plan and profiles, sta $27+19.78$ to $12+14.29$, left wall.............................96

Figure 82. Alternative B, plan and profiles, sta $27+19.78$ to $12+14.29$, right wall. ........................ 97

Figure 83. Alternative B, plan and profiles, sta $12+14.29$ to $0+00$, left wall ...................................98 
Figure 84. Alternative B, plan and profiles, sta $12+14.29$ to $0+00$, right wall. ...............................99

Tables

Table 1. Design discharges (100-year frequency)................................................................................ 31 


\section{Preface}

The model investigation presented in this report was authorized and funded by the U.S. Army Engineer District, New York (NAN). This work was conducted in the Coastal and Hydraulics Laboratory (CHL) of the U.S. Army Engineer Research and Development Center (ERDC) during the period of June 2006 to August 2009 under the direction of Thomas W. Richardson, former Director, CHL; Dr. William Martin, Director, CHL; Dr. Rose Kress, Chief, Navigation Division, CHL; and Dennis W. Webb, Chief, Navigation Branch, CHL.

This investigation of flow conditions in the Hoosic River Flood-Control Channel was conducted by Dr. Richard L. Stockstill and Jane M. Vaughan of the Navigation Branch. Keith Martin of the Estuarine Engineering Branch, under the supervision of Dr. Robert McAdory, conducted the validation modeling.

Juan C. Escajadillo, Abraham Medina-Vega, and Allan Ford of the NAN, surveyed the Hoosic River and Tophet Brook from June 18 to June 22, 2007. They collected bed elevations, described bed materials, and photographed various portions of the lower end of the study reach. The existing conditions model was constructed using their field data. Some photographs in this report are taken from their report.

COL Gary E. Johnston was Commander and Executive Director of ERDC. Dr. James R. Houston was Director. 


\section{Unit Conversion Factors}

\begin{tabular}{|l|c|l|}
\hline Multiply & By & To Obtain \\
\hline cubic feet & 0.02831685 & cubic meters \\
\hline feet & 0.3048 & meters \\
\hline miles (U.S. statute) & $1,609.347$ & meters \\
\hline
\end{tabular}




\section{Introduction}

\section{Background}

The Hoosic River begins in western Massachusetts and flows generally north and northwest, crossing the southwest corner of Vermont to the vicinity of Eagle Bridge, New York, where it turns west and joins the Hudson River about 16 miles above Troy, New York (Figure 1). It is 66 miles long and has a drainage area of 713 square miles. Adams, Massachusetts is situated on the south branch of the Hoosic River, about 8 miles below the source of the river. The flood-control project for Adams provides a man-made channel through the town. The upstream reach of the project consists of a rectangular concrete channel varying from 40 to $75 \mathrm{ft}$ in width (Figure 2). The downstream reach is a trapezoidal earth channel having a base width varying from 65 to $90 \mathrm{ft}$.

\section{Purpose}

The purpose of this study was to determine the flow conditions in the transitions and curves in the supercritical channel, at the confluences with the Fiske Brook and Tophet Brook Channels, at the drop structures, and in the reach where the flow transitions from supercritical to subcritical flow. Particular attention was directed to evaluating the consequences of the channel changes that have occurred since initial construction. These changes are predominately the deposition of sediment in the lower portion of the modeled reach. The study was primarily for the purpose of evaluating various modifications to the lower end as part of a channel restoration project. The model was to determine if restoration alterations would change watersurface elevations associated with the design discharge.

\section{Approach}

The first phase of the study tested the numerical model's ability to reproduce the hydraulic conditions observed in a previously published physical model study. After the numerical model was validated, the as-built conditions were simulated to establish water-surface elevations associated with the initial design and construction. After as-built flow conditions were established, flow conditions produced with the existing conditions of the 


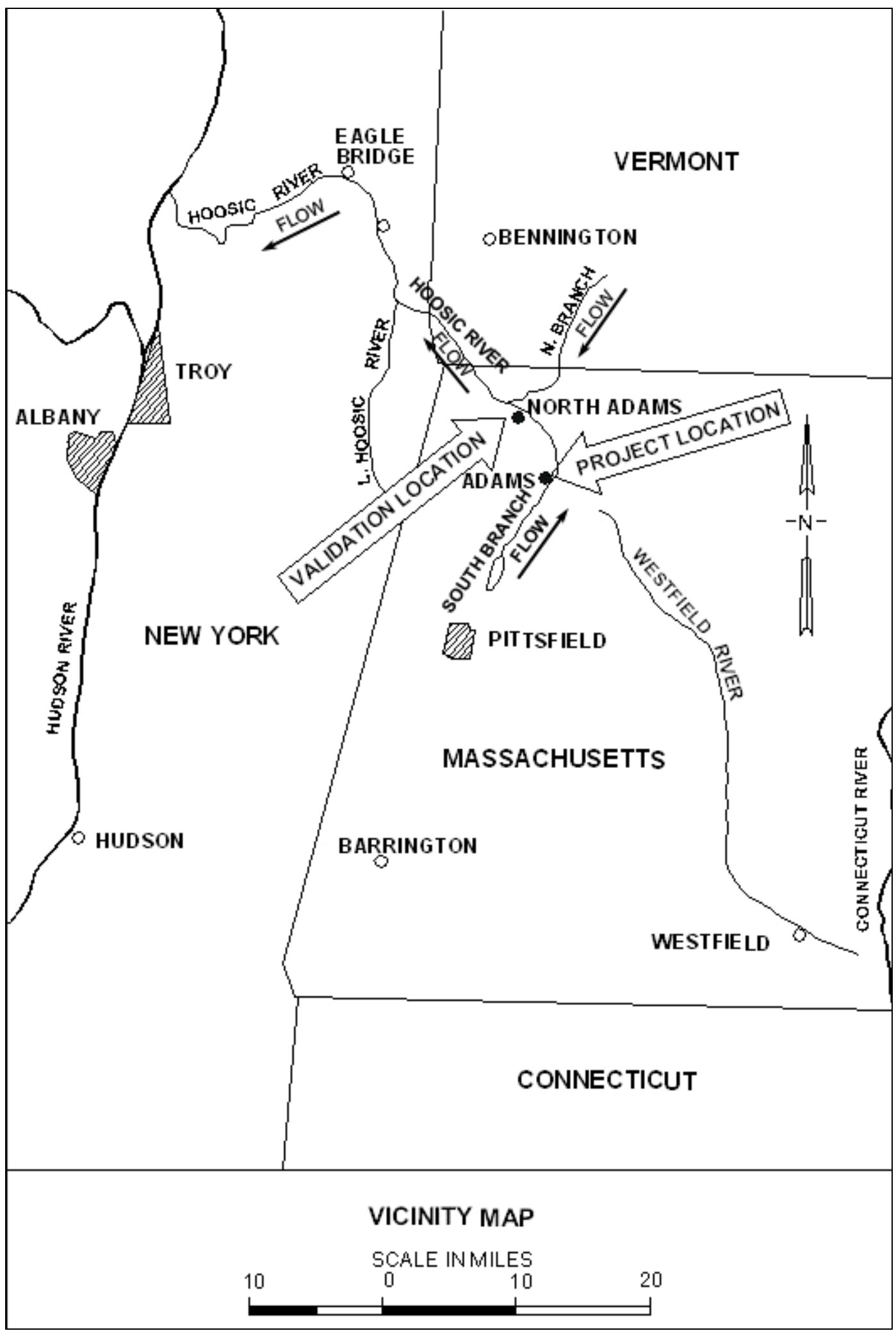

Figure 1. Location of model studies. 


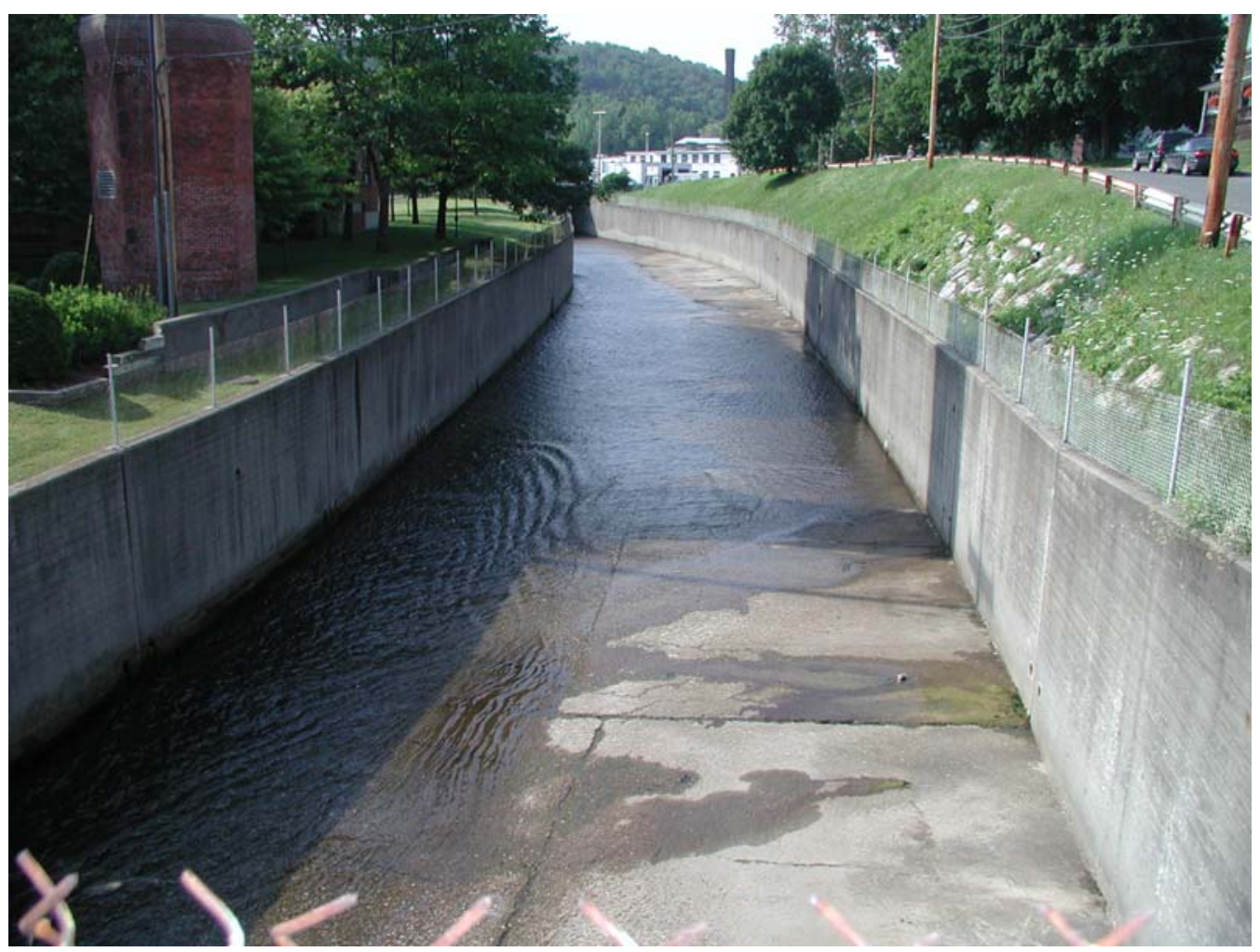

Figure 2. Hoosic River through town of Adams, MA.

channel were computed. The existing conditions include large deposits of sediments at various locations within the channel (see Figures 3 and 4), so there was a question as to how this may change water-surface elevations during flood events. The final phase of the study was the hydraulic evaluation of restoration alternatives to determine their impacts on watersurface elevations. 


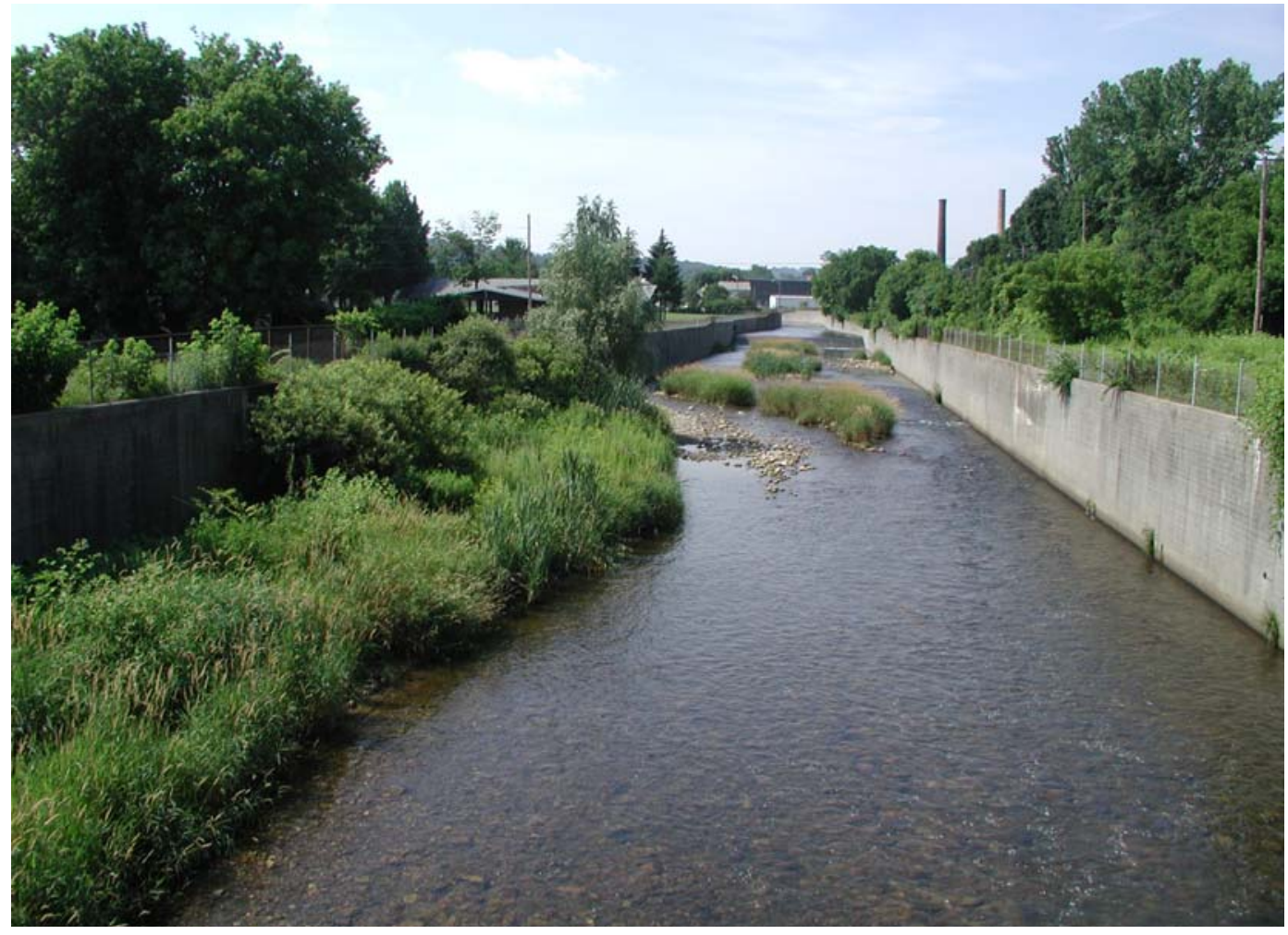

Figure 3. Sediment deposition and vegetation at confluence of Hoosic River and Tophet Brook.

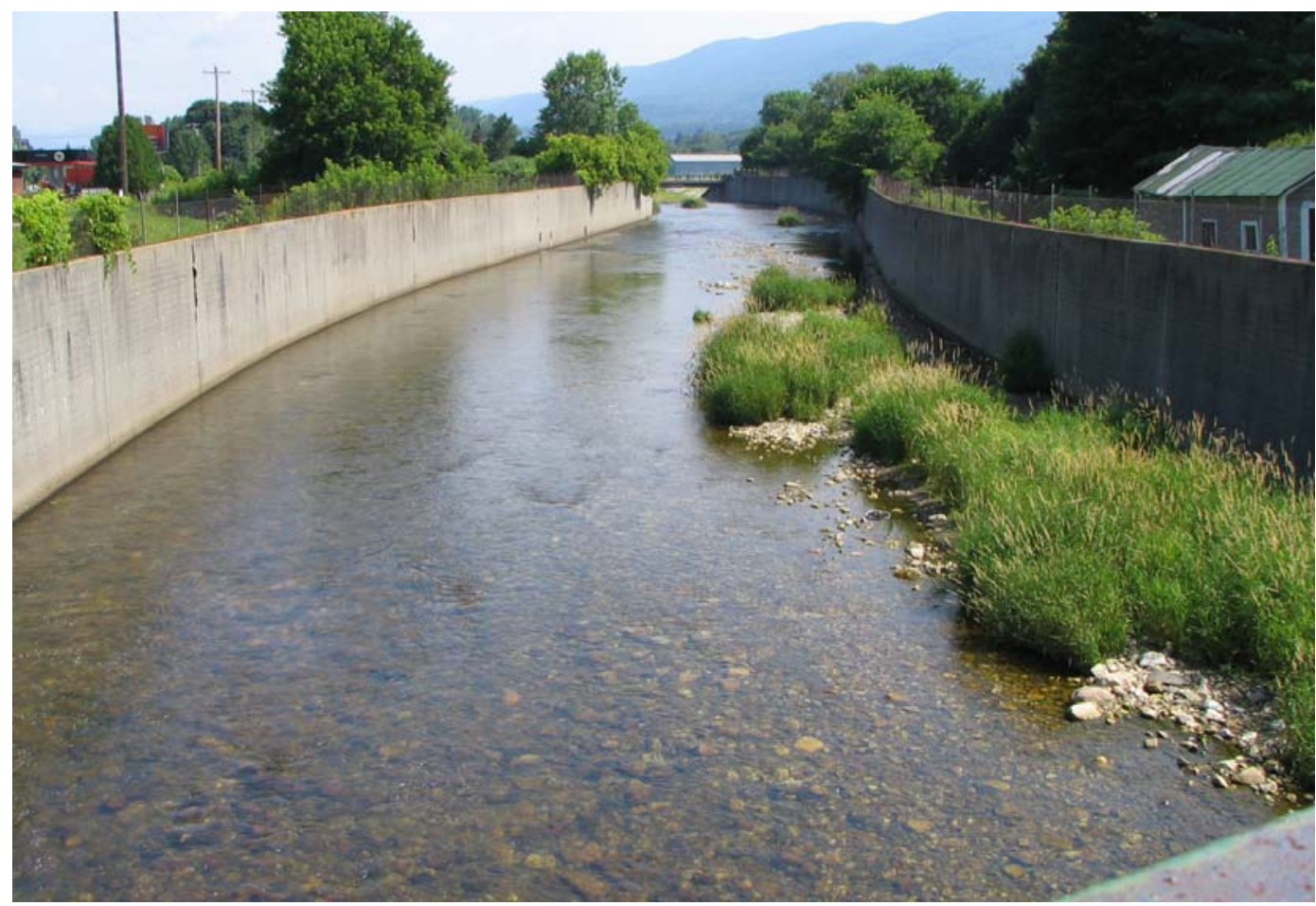

Figure 4. Sediment deposition and vegetation in main channel downstream of Tophet Brook. 


\section{Validation Model}

\section{Background}

The two-dimensional (2-D) model was tested to see how well it could reproduce the water-surface elevations within a concrete high-velocity channel having complex geometric features including spiral curves, invert banking, and very few tangents.

Validation required a data set of observed flow conditions. A portion of the Hoosic River flood-control project through North Adams, MA (Figure 1) was previously tested in a physical model (U.S. Army Engineer Waterways Experiment Station 1952). The 2-D numerical model was validated by comparing computed water-surface elevations with those measured in the physical model. The actual portion of the Hoosic River that was modeled for validation purposes is just as complicated; perhaps more so, than the study reach through Adams. The project was a good case to test the numerical model's ability to simulate the complicated flow throughout the study reach. The validation (North Adams) reach contained 23 curves with compound spirals and invert banking, a confluence of two supercritical channels, and a twin stilling basin used to contain hydraulic jumps prior to introducing the flow to a soft-bottom channel. The longest tangent between compound curves was less than 5 times the channel width. Most curves are adjoined in that the spiral-to-tangent (ST) ending one curve and the tangent-to-spiral (TS) beginning the next curve share the same station.

The validation project is the North Branch and South Branch within North Adams (see Figure 5). Both channels have a channel width of $45 \mathrm{ft}$ along most of their length. The South Branch model was more that 4,000 $\mathrm{ft}$ long and fell more than $20 \mathrm{ft}$ in elevation. The slope varied, but the overall slope of the South Branch was 0.005. The average Froude number for this reach was 1.7 and at the discharge of 10,300 cfs, the normal depth was $8.4 \mathrm{ft}$ and the cross-sectional averaged velocity was $27 \mathrm{fps}$. Normal depth rarely occurs along the reach of the channel due to numerous curves, but knowing that the velocity was expected to be about $27 \mathrm{fps}$ at a depth of $8.4 \mathrm{ft}$ provided a general description of the flow conditions. 


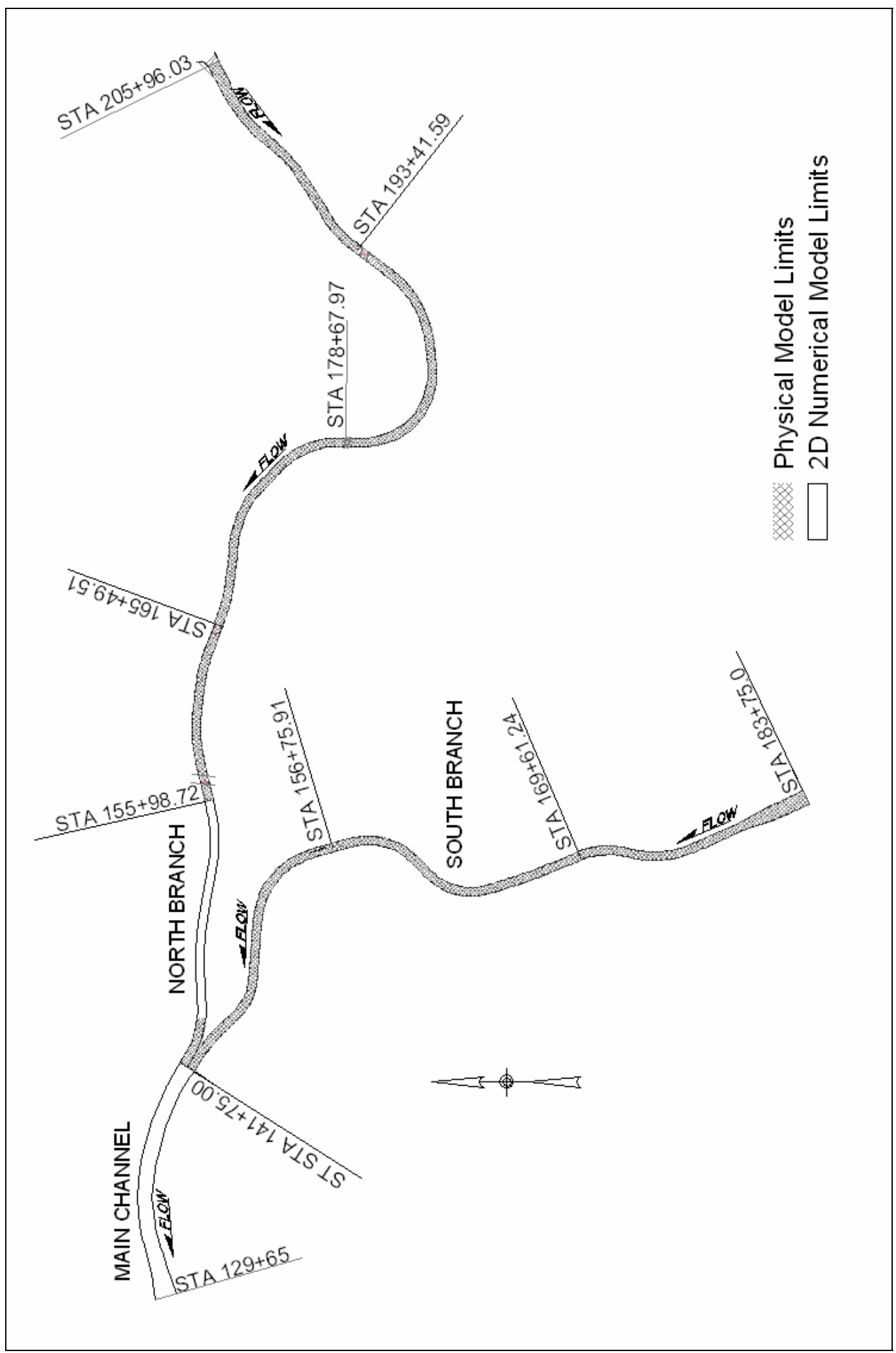

Figure 5. Model validation, physical and numerical model limits. 
The North Branch dropped more than $90 \mathrm{ft}$ in elevation over the 4,600 ft modeled, resulting in an overall bed slope of 0.014 . This very steep slope on the North Branch resulted in an average Froude number of 2.8. Conveying the design discharge (at the time of the physical model study) of 14,600 cfs resulted in a normal depth of $7.5 \mathrm{ft}$ and a cross-sectional averaged velocity of $43 \mathrm{fps}$ at normal depth. The actual flow was always varying due to the changes in alignments, but knowing that the velocity should be greater than $40 \mathrm{fps}$ at a depth of $7.5 \mathrm{ft}$ gave insight into the flow characteristics to be expected.

\section{Physical model}

The physical model was a 1:30-scale flume of the North and South Branches of the Hoosic River running through North Adams, Massachusetts. The model study was conducted in increments between 1950 and 1957 at the U.S. Army Engineer Waterways Experiment Station. Channel configurations (plans and profiles) were taken from the physical model report (U.S. Army Engineer Waterways Experiment Station 1952). Flow depths were scaled from the values plotted in the report. The recommended design was reproduced in the numerical model.

The 1:30-scale hydraulic model, which was constructed of plywood, was hydraulically too rough. The friction differences are attributed to the differences in the model and prototype Reynolds numbers. In an attempt to better simulate the prototype roughness, the slope of the physical model was increased. The physical-model report mentioned that the model's bed slope was increased, but it does not provide the actual resulting slopes.

Data consisted of velocity and depth measurements at various locations along the North and South Branches. These depth measurements were used to develop water-surface profiles along the walls. The turbulence in the high-velocity flow produces only a quasi-steady flow condition. The depth at a particular location varies in time. Generally, the physical model study reported maximum values of depth, although particular tests recorded temporally averaged values. Because the physical model test reported maximum depths, it was expected that the computed depths, which are time averaged over turbulence scales, would be somewhat less than those recorded in the physical model study. 


\section{Numerical model}

The channel configuration is shown in Figure 5 . More than $6,000 \mathrm{ft}$ of the North Branch was reproduced from sta 205+96.03 to the confluence with the South Branch at sta 141+75. Forty two hundred feet of the South Branch was reproduced from the upstream limit at sta $183+75$ to the confluence at sta $141+75$. The main channel reach extended from downstream of the confluence to the stilling basin, a total of $1,210 \mathrm{ft}$.

The shallow-water (or long-wave) equations are a result of the vertical integration of the equations of mass and momentum conservation for incompressible flow under the hydrostatic pressure assumption. The flow depth (h), the x-component of velocity $(\mathrm{u})$, and the y-component of velocity (v) define the dependent variables of the fluid motion. If the fluid pressure at the surface is taken as zero and the free-surface stresses are neglected, the shallow-water equations are given as:

$$
\frac{\partial U}{\partial t}+\frac{\partial F}{\partial x}+\frac{\partial G}{\partial y}+H=0
$$

where:

$$
\begin{gathered}
U=\left\{\begin{array}{c}
\mathrm{h} \\
\mathrm{uh} \\
\mathrm{vh}
\end{array}\right\} \\
\mathrm{F}=\left\{\begin{array}{c}
\mathrm{hu} \\
h u^{2}+\frac{1}{2} g h^{2}-\mathrm{h} \frac{\sigma_{\mathrm{xx}}}{\rho} \\
h u v-\mathrm{h} \frac{\sigma_{\mathrm{yx}}}{\rho}
\end{array}\right\}
\end{gathered}
$$




$$
G=\left\{\begin{array}{c}
h v \\
h u v-h \frac{\sigma_{x y}}{\rho} \\
h v^{2}+\frac{1}{2} g h^{2}-h \frac{\sigma_{y y}}{\rho}
\end{array}\right\}
$$

and:

$$
H=\left\{\begin{array}{c}
0 \\
g h \frac{\partial z_{b}}{\partial x}+n^{2} g \frac{u \sqrt{u^{2}+v^{2}}}{C_{0} h^{1 / 3}} \\
g h \frac{\partial z_{b}}{\partial y}+n^{2} g \frac{v \sqrt{u^{2}+v^{2}}}{C_{0} h^{1 / 3}}
\end{array}\right\}
$$

here:

$$
\begin{aligned}
\rho= & \text { fluid density } \\
\mathrm{g}= & \text { gravitational acceleration } \\
\mathrm{Z}_{\mathrm{b}}= & \text { channel bed elevation } \\
\mathrm{n}= & \text { Manning's roughness coefficient } \\
\mathrm{C}_{\mathrm{o}}= & \text { a dimensional constant }\left(\mathrm{C}_{\mathrm{o}}=1 \text { for SI units and } 2.208\right. \text { for } \\
& \text { U.S. Customary units) }
\end{aligned}
$$

and:

$$
\begin{aligned}
\sigma \text { 's }= & \text { Reynolds stresses due to turbulence, where the first subscript } \\
& \text { indicates the direction, and the second indicates the face on } \\
& \text { which the stress acts. }
\end{aligned}
$$

The equations are discretized using the finite element method in which $\mathrm{u}$, $\mathrm{v}$, and $\mathrm{h}$ are represented as linear polynomials on each triangular element. The numerical model is the Adaptive Hydraulics (ADH) code (http://adh.usace.army.mil). This code features mesh adaption whereby the computational mesh is automatically refined in areas where needed to provide an accurate solution. 
The computational mesh developed to model the validation flow conditions, consisted of 4548 nodes and 7963 triangular elements (Figure 6).

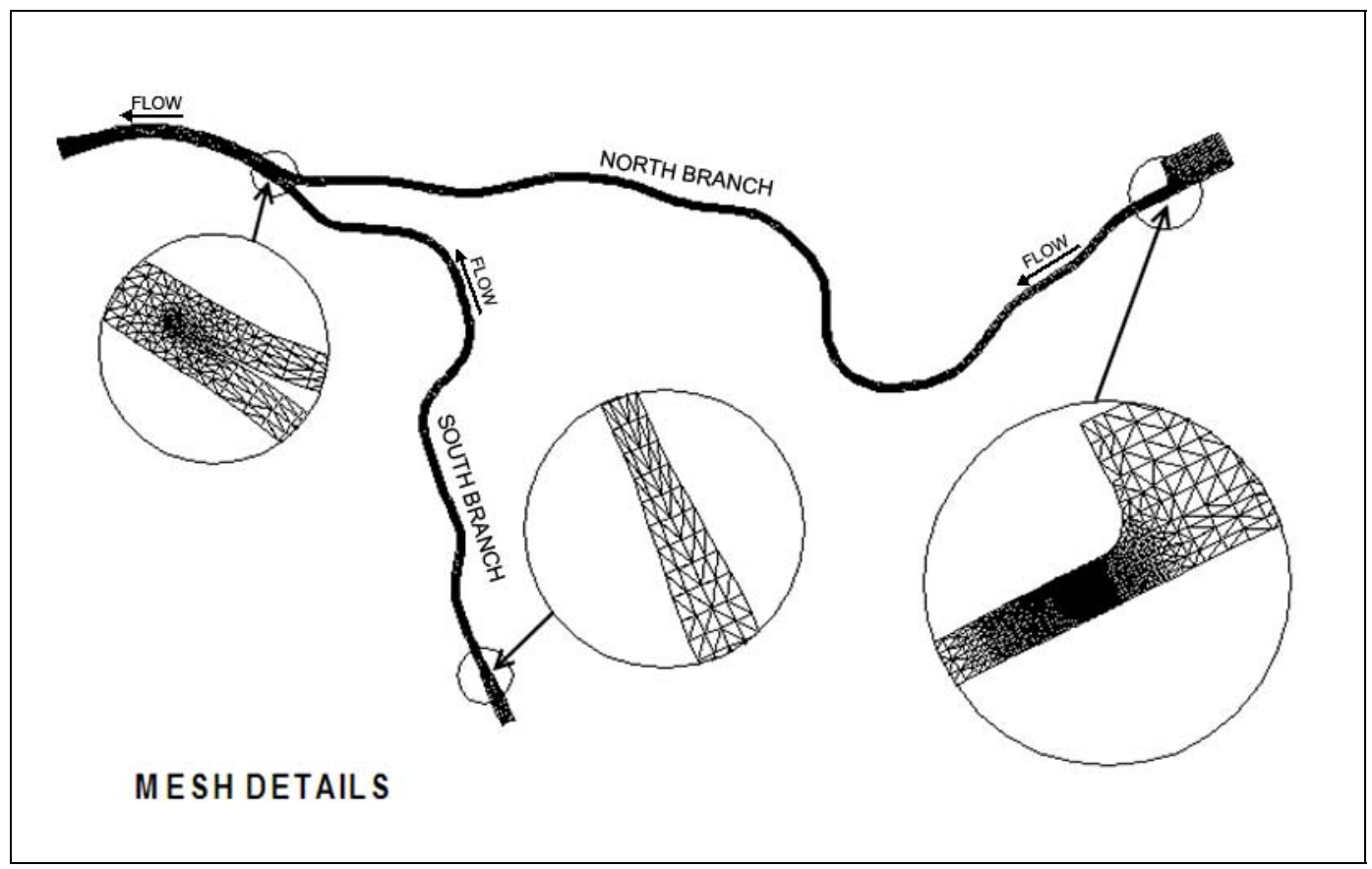

Figure 6. Model validation, computational mesh details.

The majority of the mesh was built with elements that were approximately $33 \mathrm{ft}$ by $11 \mathrm{ft}$ in the longitudinal and lateral direction, respectively. Greater resolution (smaller elements) was used in the vicinity of the submerged weir in the northern branch, the confluence of the northern and southern branches, and the spillways in the main channel. ADH was set to refine the mesh one level. Refinement automatically splits the elements where the computed residual exceeds a specified threshold.

The tailwater was set at el $677.0^{1}$ at the outflow boundary which was at the western end of the main channel. The flow at the upstream end of each branch was subcritical so a subcritical inflow boundary condition was specified for each branch. Inflow discharges of $14,600 \mathrm{cfs}$ and $10,300 \mathrm{cfs}$ were applied to the boundaries of the northern and southern branches, respectively. The flow accelerated to supercritical due to the steepness of the channel slope. The transition from subcritical to supercritical flow occurred in the channel contraction on the South Branch and at the submerged weir on the North Branch.

1 All elevations (el) are in feet referenced to the National Geodetic Vertical Datum of 1929. 
The model was run from an initial condition assuming zero velocity and uniform depth to steady state by advancing in time. A Manning's coefficient, $\mathrm{n}$, was set in the model based on channel conditions. Each channel was given an $n$ value of 0.016 .

The water-surface profile was obtained from the numerical model results by extracting depth values from the steady-state solution at the boundary nodes along the model walls. These values were then plotted and compared to the profiles published in the physical model report (U.S. Army Engineer Waterways Experiment Station 1952).

\section{Validation results}

The primary objective of a flood-control channel is containing flood flows. So, the primary objective in modeling these channels was accurately computing the depth of flow throughout the flow domain. Comparisons of the physical model data with numerical model results provided an evaluation of the numerical model's ability to reproduce the observed flow depths.

Physical model invert elevations along the right and left bank were taken from the physical model report. Depths were scaled from the report and transferred to water-surface elevations using the invert elevations. Both water-surface and bed elevation profiles were then plotted at an exaggerated (10:1) vertical scale.

The validation run was performed to compare the numerical computations to the flow depths measured in the physical model. Examples of results from the numerical model are provided in Figures 7-9. Comparison of the numerical model results and the physical model data are provided in Figures 10-23. These figures show water-surface profiles along the physically modeled reaches of the North and South Branches of the Hoosic Rivers in North Adams. Each figure provides both observed and computed profiles along the right and left walls (referenced to looking downstream).

The figures illustrate that the model accurately reproduced the watersurface elevations along the walls of the North Branch. The computed depths are slightly lower than those recorded in the physical model along the lower end of the South Branch (sta 169+oo to 148+00). However, the differences are small and, as previously noted, the physical model tests recorded maximum depths in the turbulent supercritical flow. The model does simulate the super-elevation of the water surface in the banked bends. 
These simulation results show that the 2-D ADH model is an appropriate tool to use in evaluating flow conditions in the Hoosic River Flood-Control Channel.

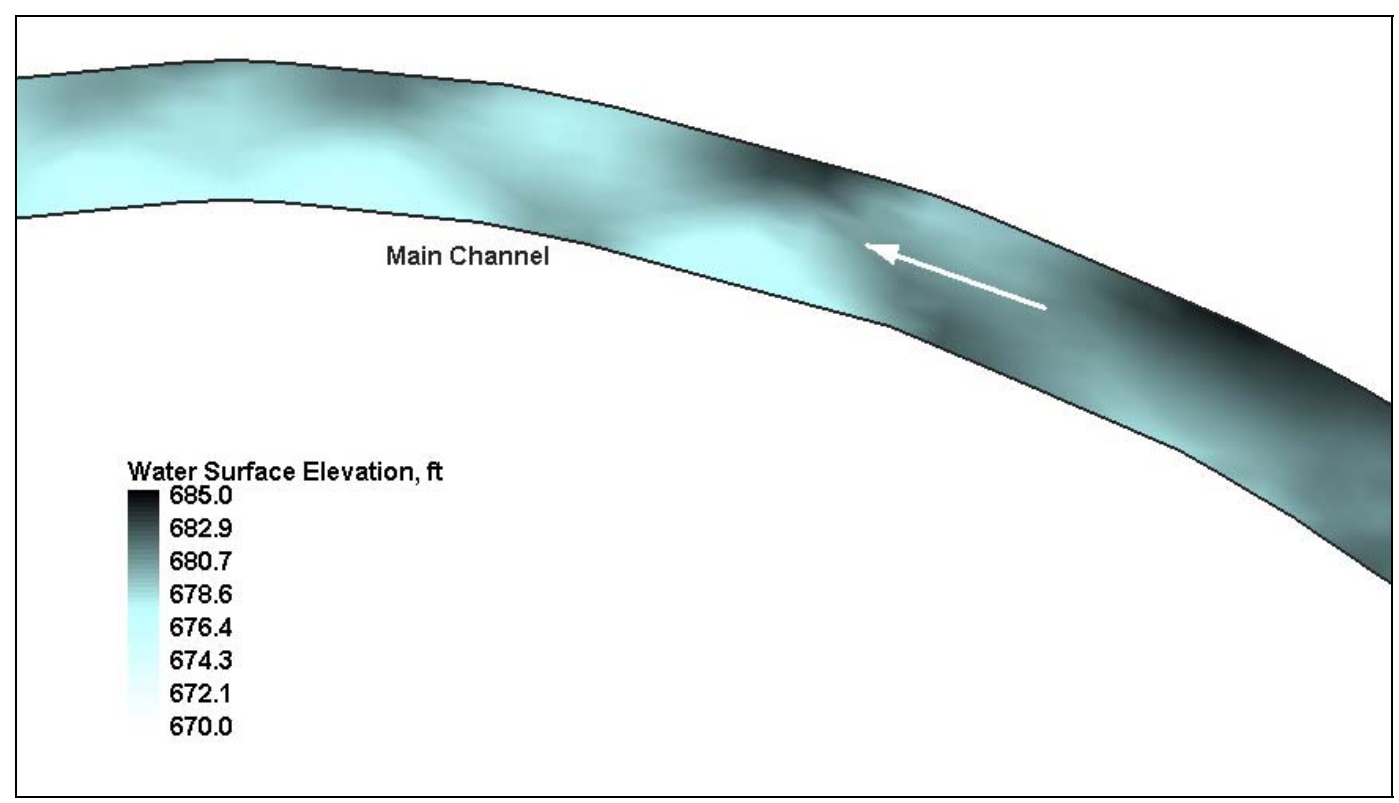

Figure 7. Model validation, numerical model results, water-surface contours downstream of the North and South Branch confluence.

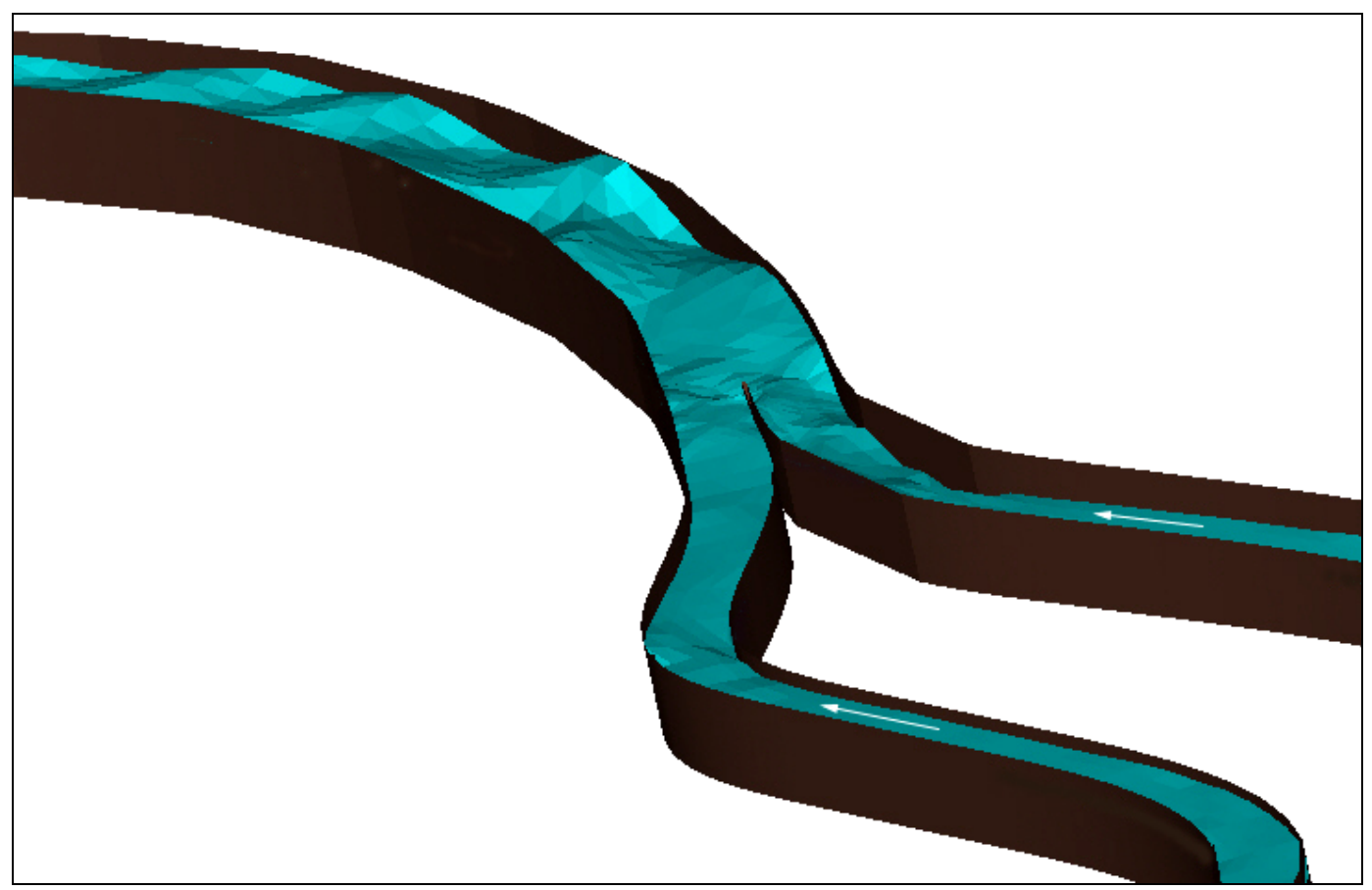

Figure 8. Model validation, numerical model results at the confluence of the North and South Branches, looking downstream. 


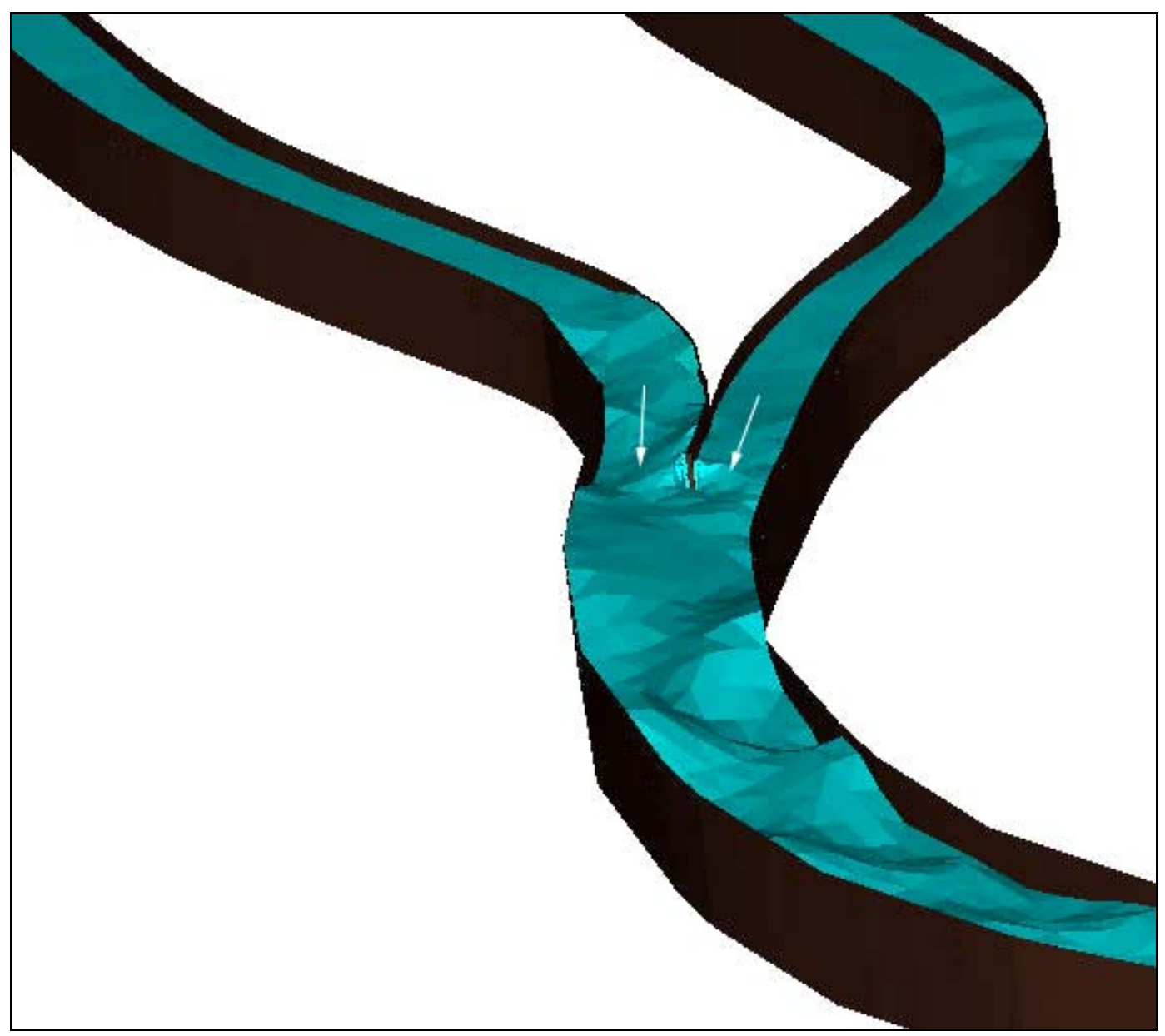

Figure 9. Model validation, numerical model results at the confluence of the North and South Branches, looking upstream. 

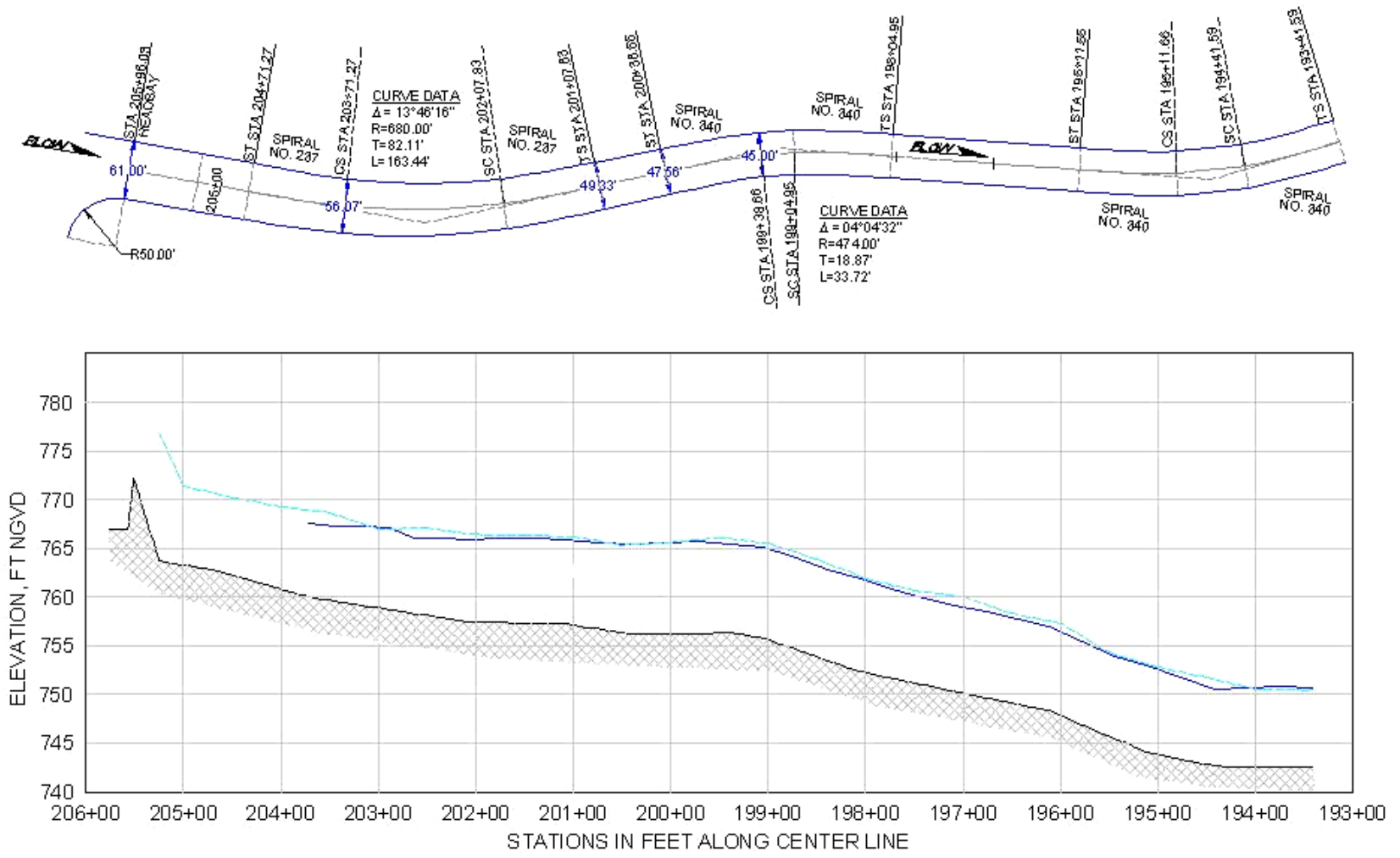

WSE, Left Wall, 2D Computational Model

NOTE: SIDES OF CHANNEL ARE REFERENCED TO LOOKING DOMNSTREAM

Plan and Left Side Profiles

North Branch

STA $205+96.03$ TO $193+41.59$

Figure 10. Model validation, North Branch, plan and profiles, sta $205+96.03$ to $193+41.59$, left wall. 

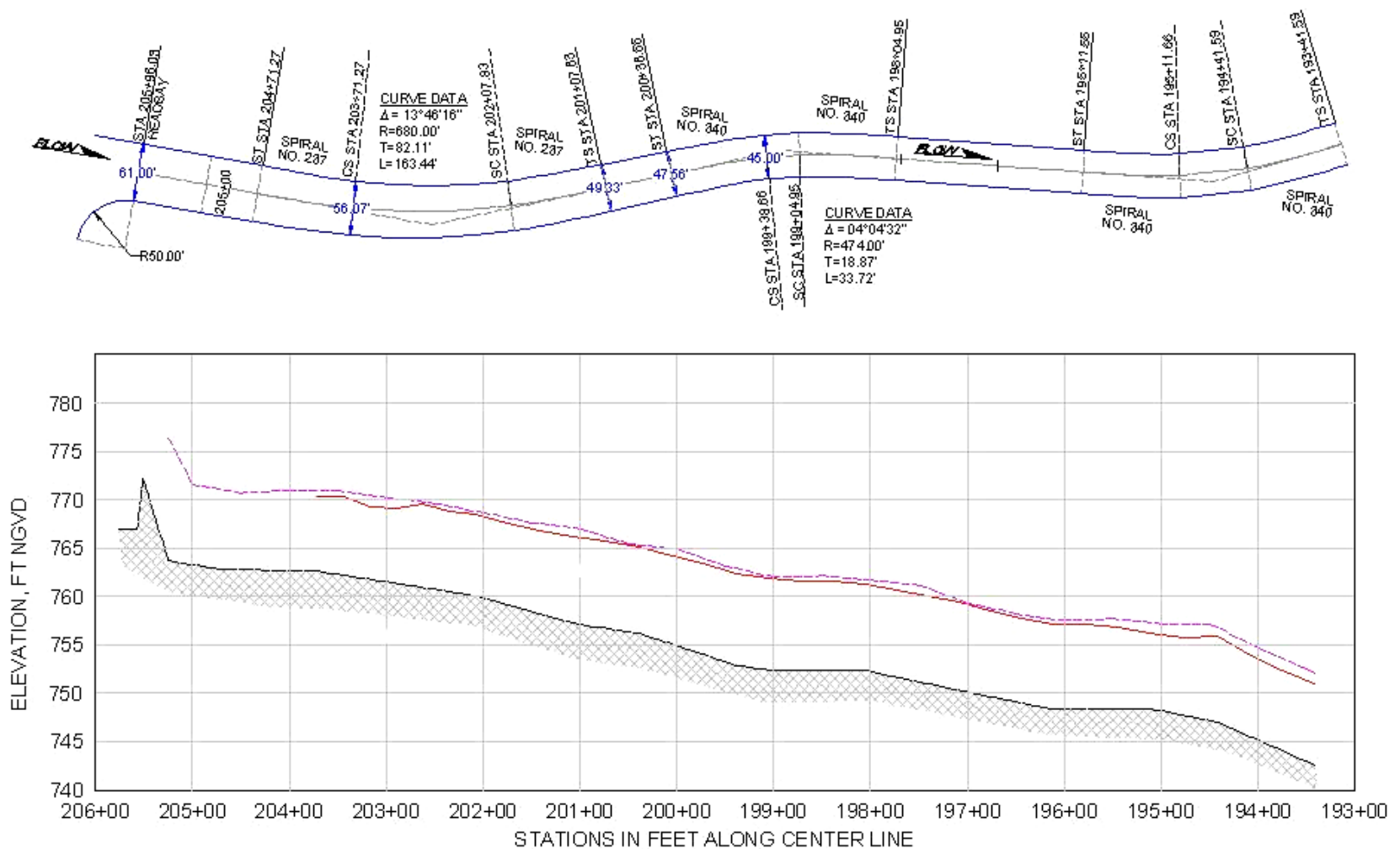

LEGEND

Right Floor Elevation

WSE, Right Wall, Physical Model

WSE, Right Wall, 2D Computational Model

Plan and Right Side Profiles

North Branch

NOTE: SIDES OF CHANNEL ARE REFERENCED TO LOOKING DOMNSTREAM

STA $205+96.03$ TO $193+41.59$

Figure 11. Model validation, North Branch, plan and profiles, sta $205+96.03$ to $193+41.59$, right wall. 


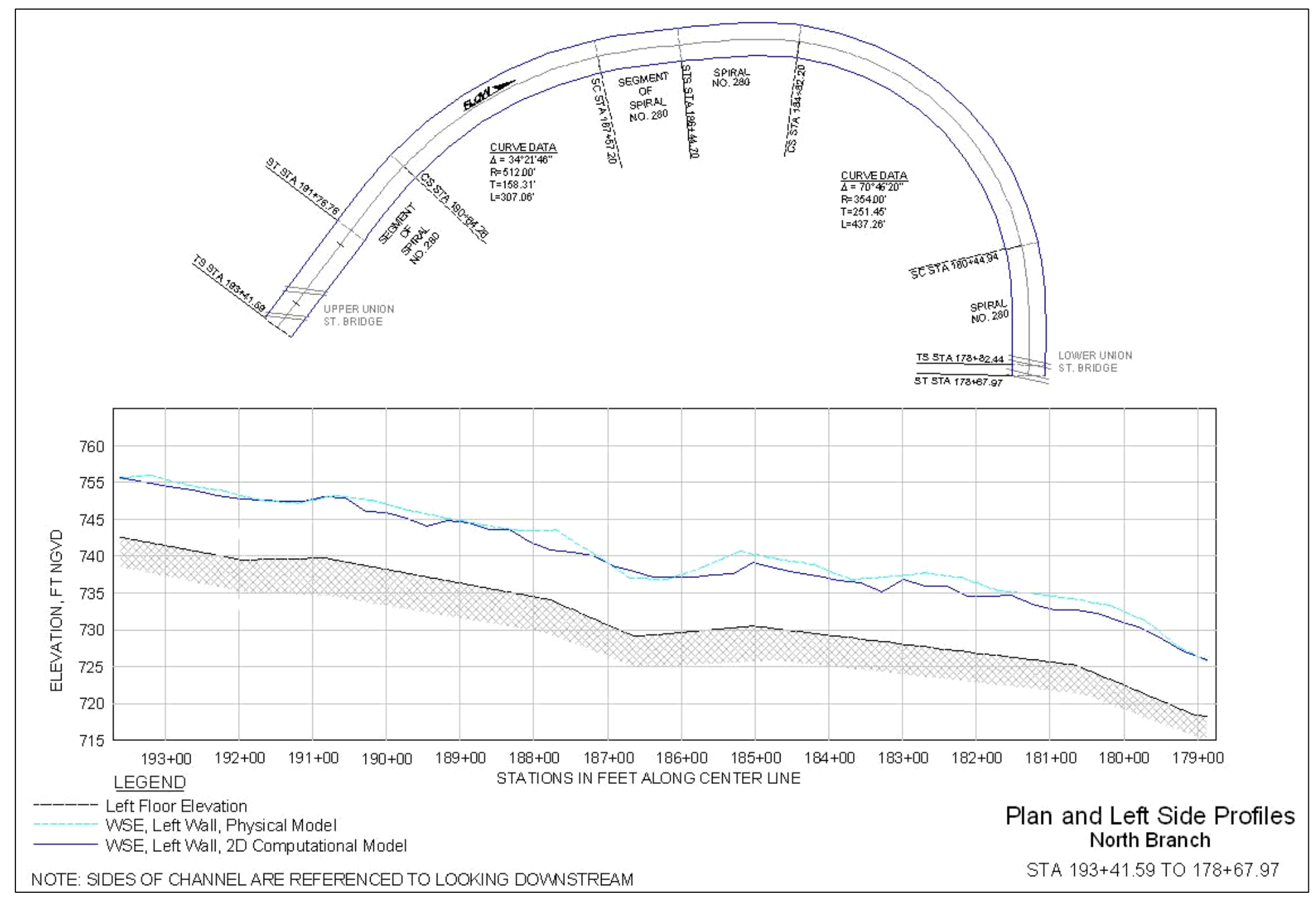

Figure 12. Model validation, North Branch, plan and profiles, sta $193+41.59$ to $178+67.97$, left wall. 


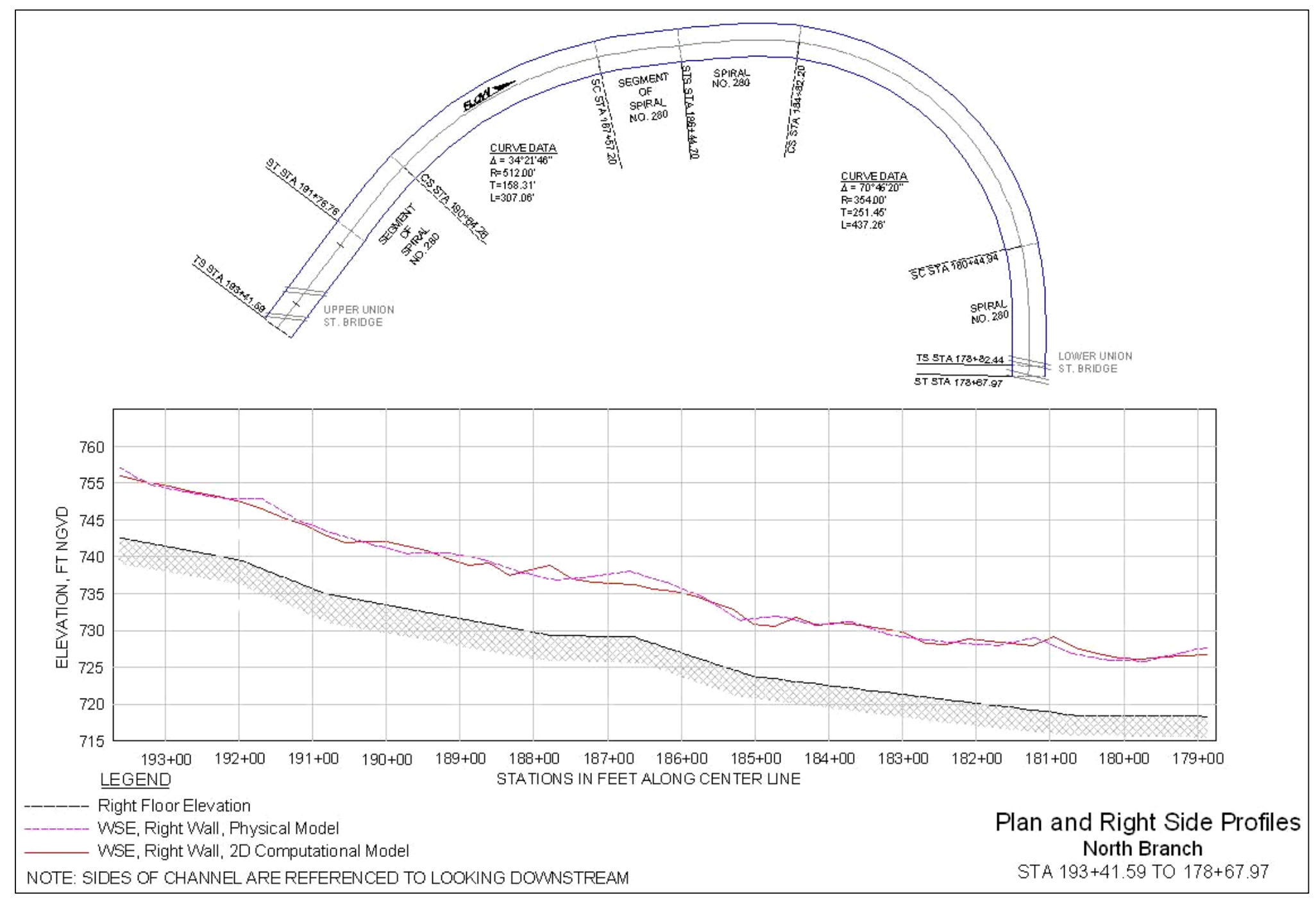

Figure 13. Model validation, North Branch, plan and profiles, sta $193+41.59$ to $178+67.97$, right wall. 


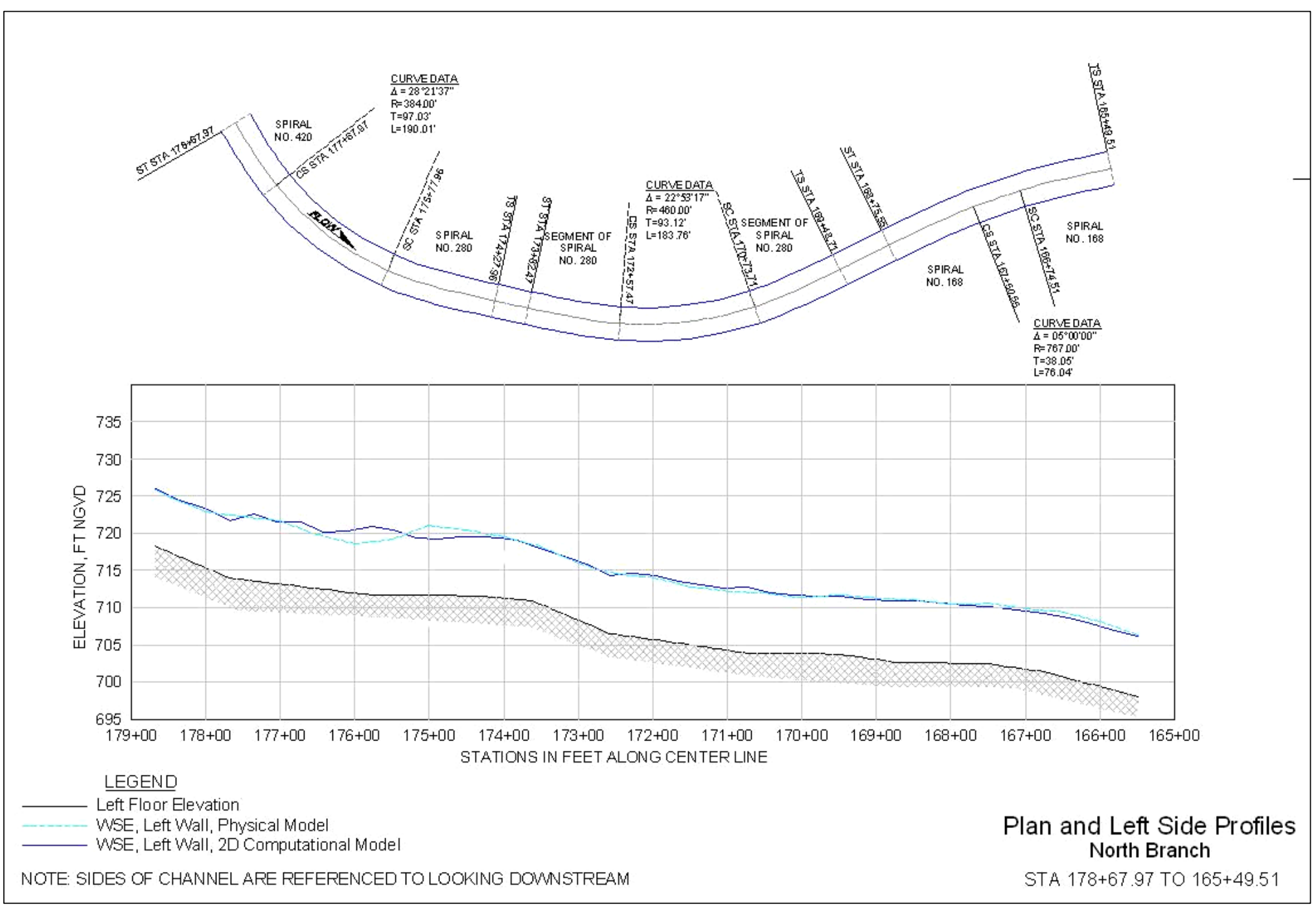

Figure 14. Model validation, North Branch, plan and profiles, sta $178+67.97$ to $165+49.51$, left wall. 


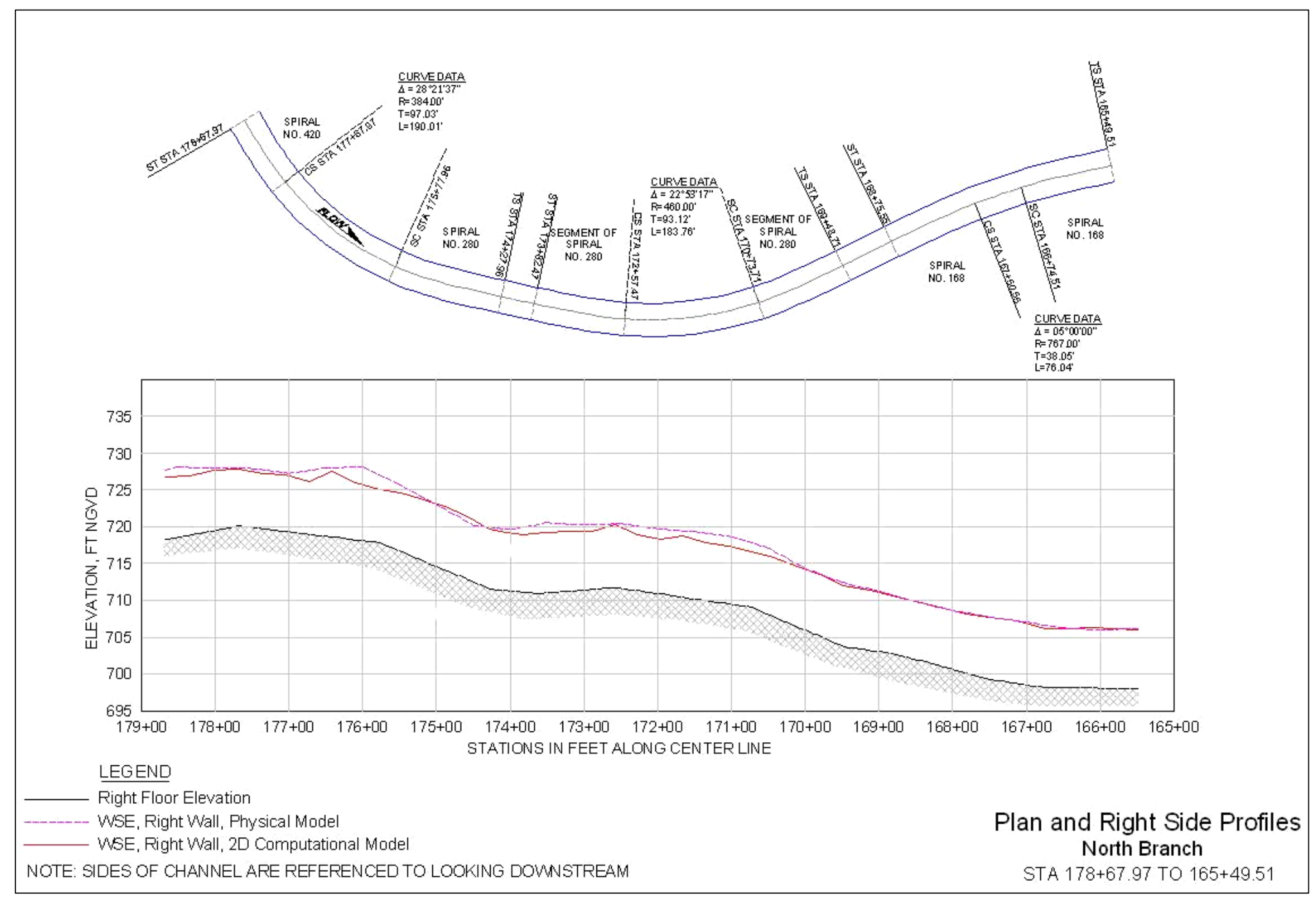

Figure 15. Model validation, North Branch, plan and profiles, sta $178+67.97$ to $165+49.51$, right wall. 

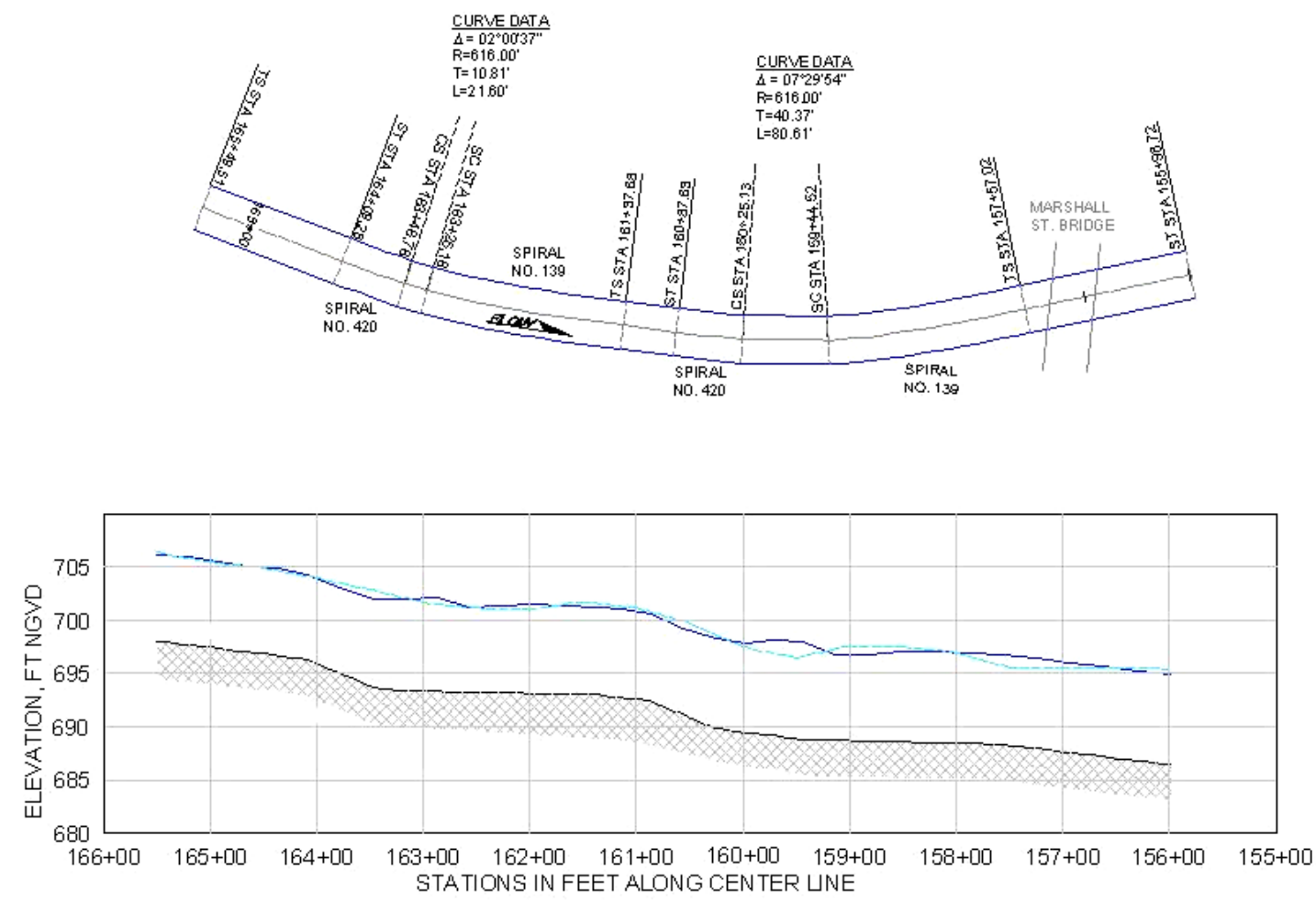

Figure 16. Model validation, North Branch, plan and profiles, sta $165+49.51$ to $155+98.72$, left wall. 

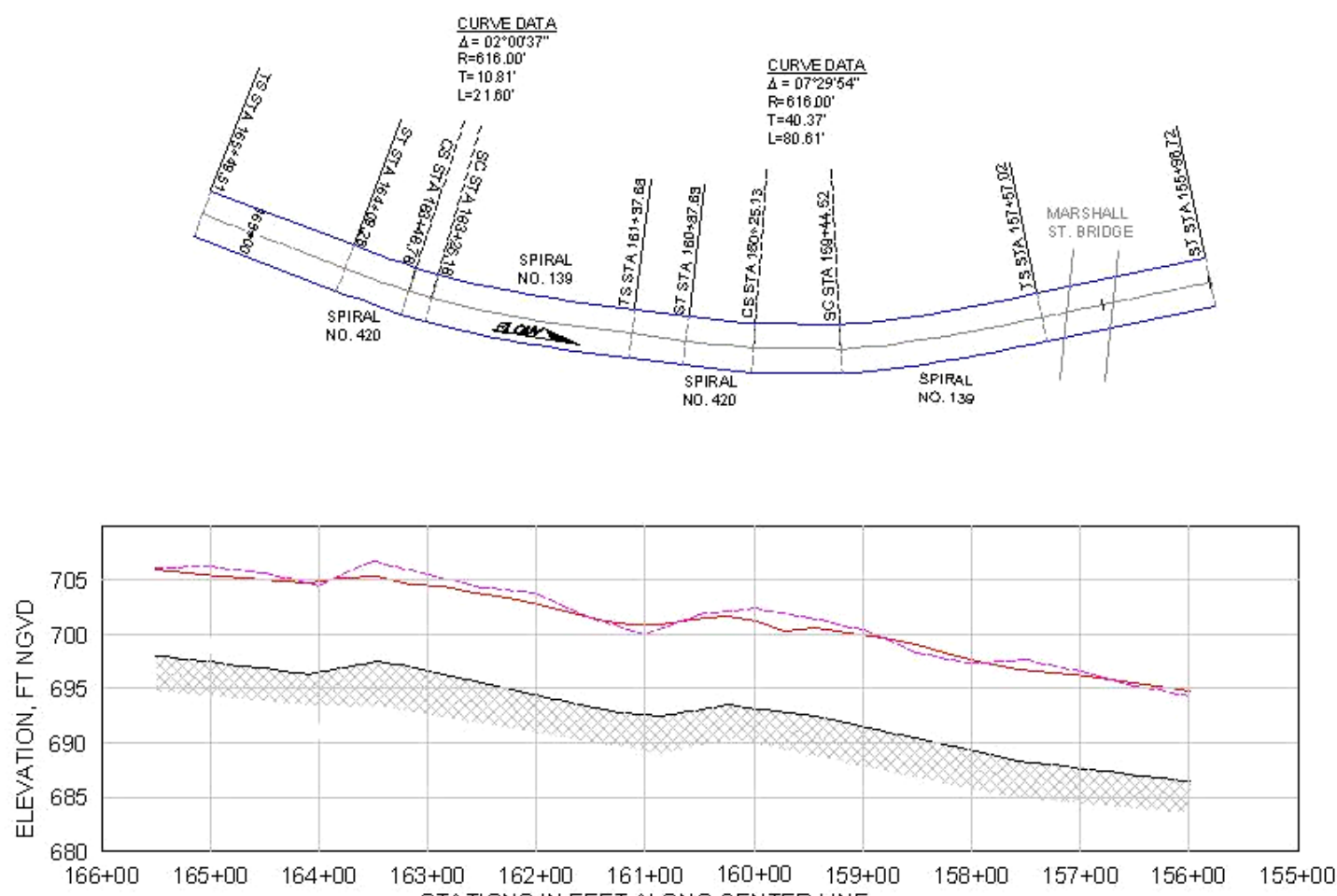

LEGEND

Right Floor Elevation

MSE, Right Wall, Physical Mode

WSE, Right Wall, 2D Computational Model

Plan and Right Side Profiles

North Branch

NOTE: SIDES OF CHANNEL ARE REFERENCED TOLOOKING DOMNSTREAM STA 165+49.51 TO 155+98.72

Figure 17. Model validation, North Branch, plan and profiles, sta $165+49.51$ to $155+98.72$, right wall. 


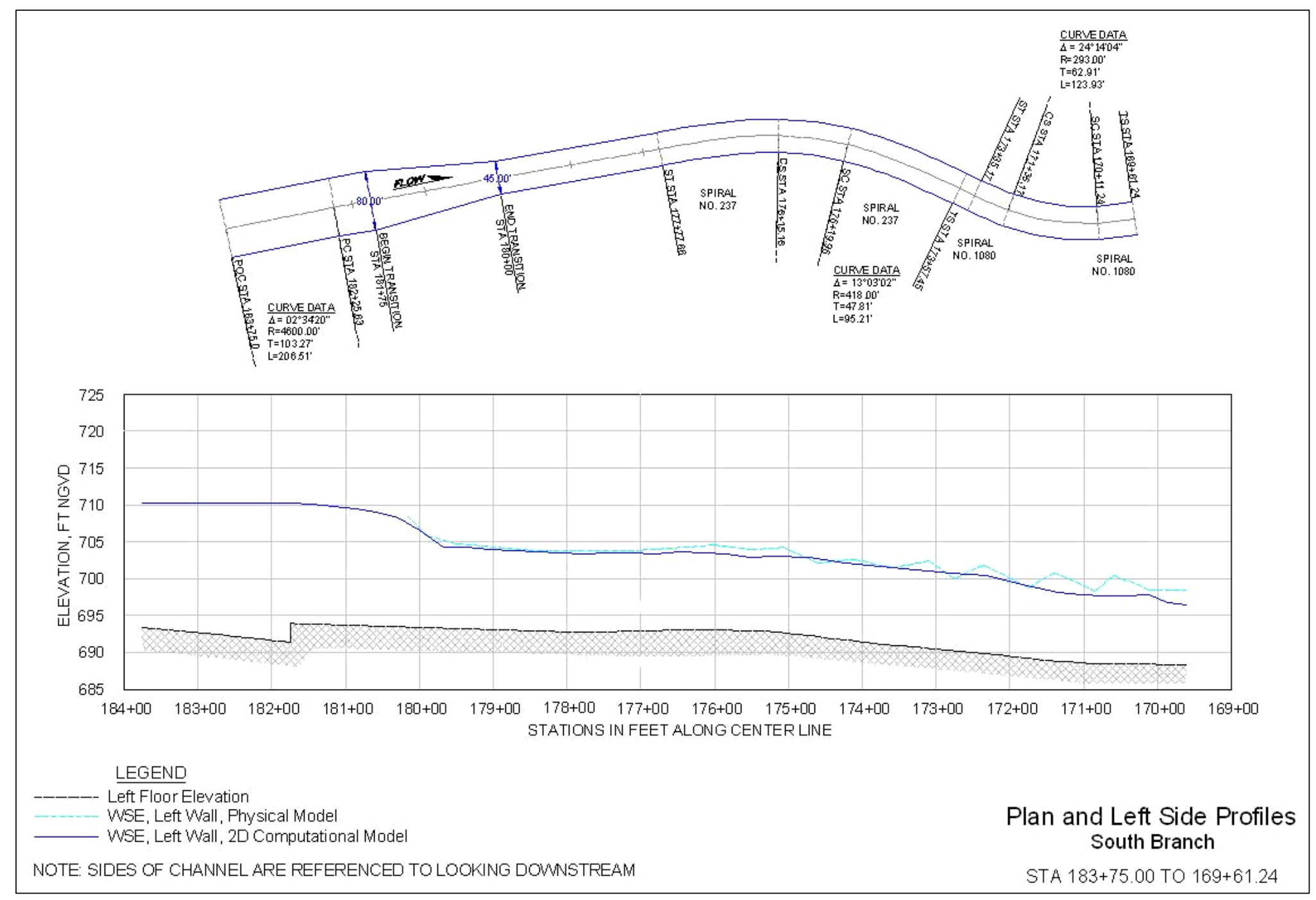

Figure 18. Model validation, South Branch, plan and profiles, sta $183+75.00$ to $169+61.24$, left wall. 


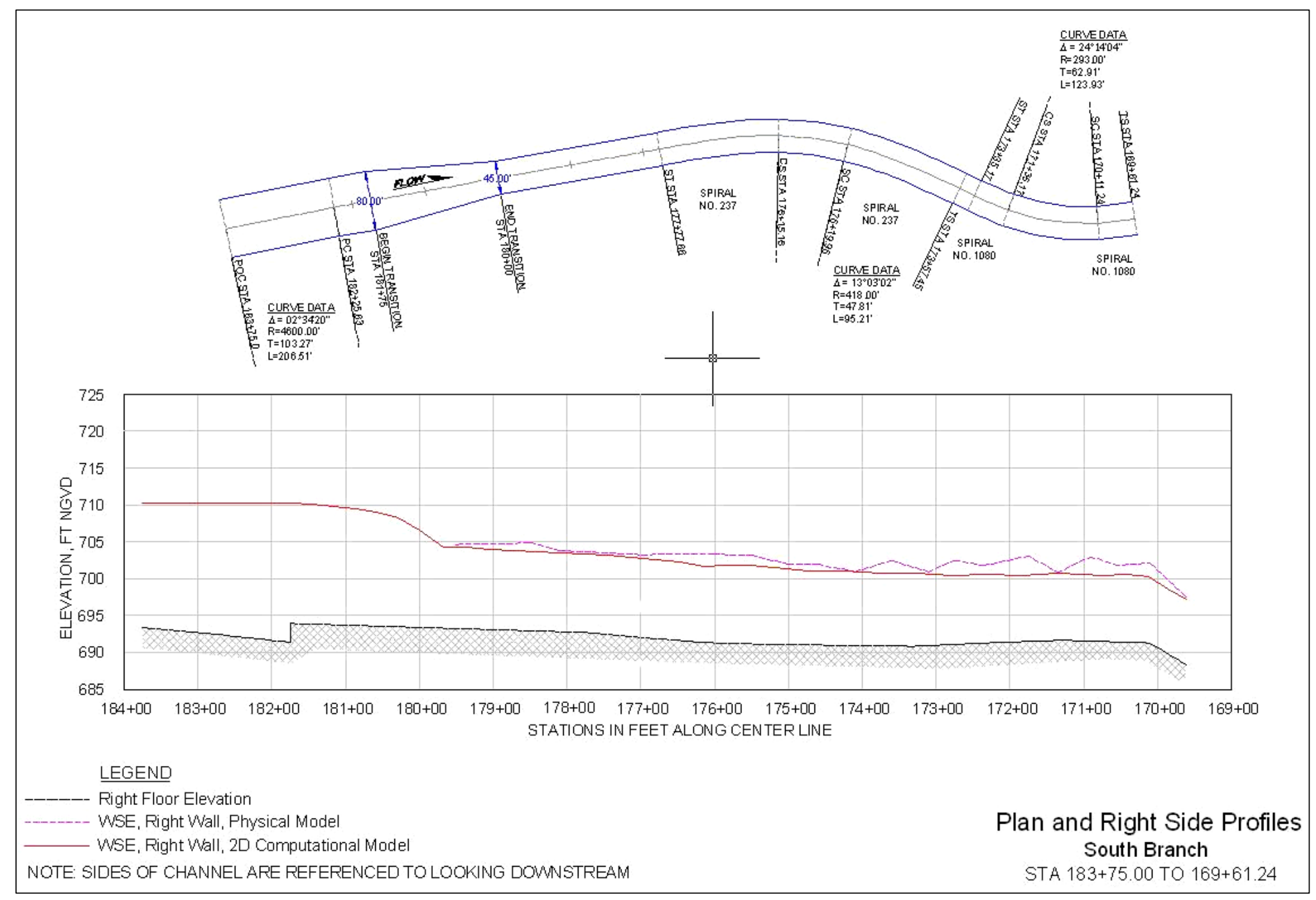

Figure 19. Model validation, South Branch, plan and profiles, sta $183+75.00$ to $169+61.24$, right wall. 


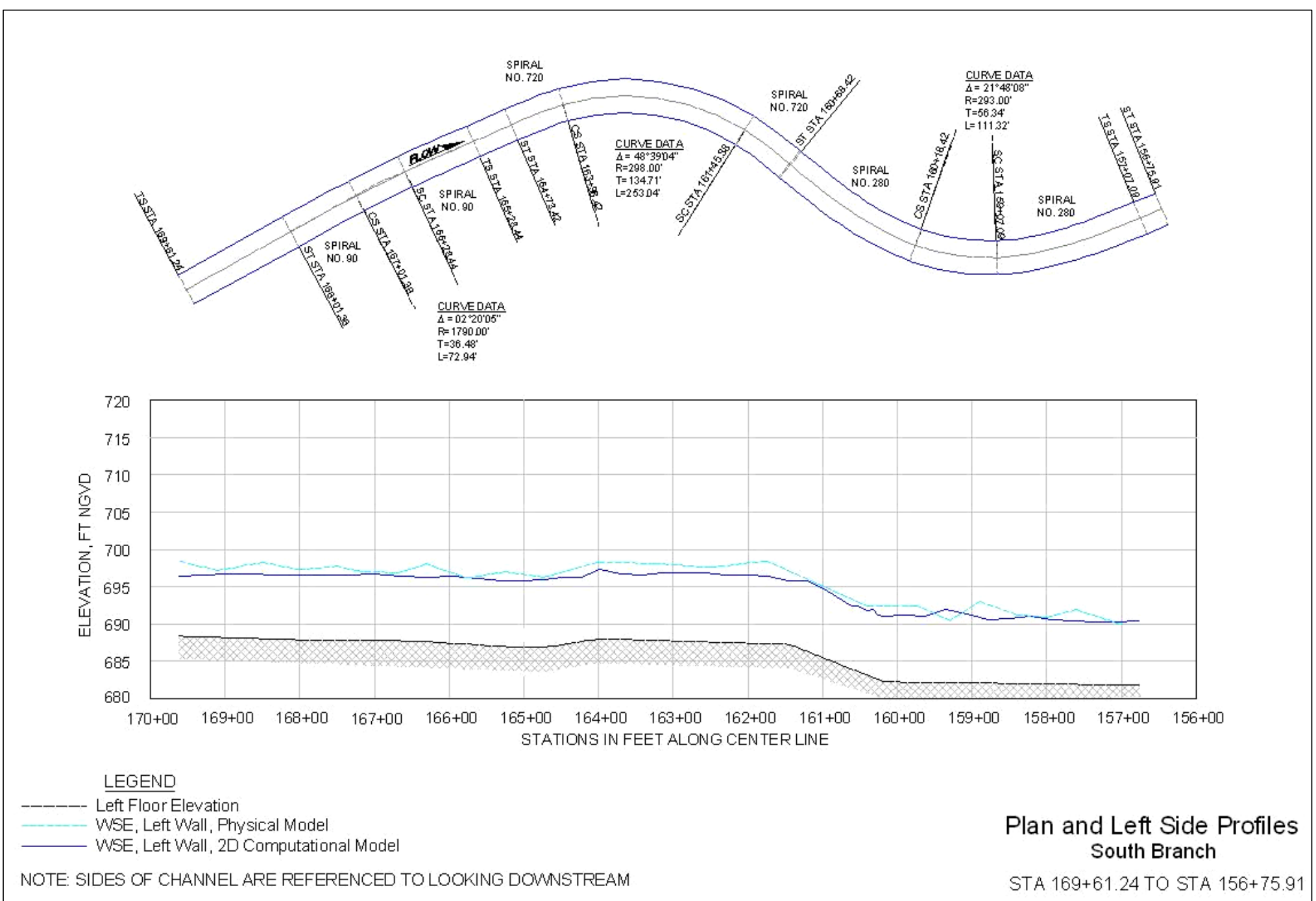

Figure 20. Model validation, South Branch, plan and profiles, sta $169+61.24$ to $156+75.91$, left wall. 


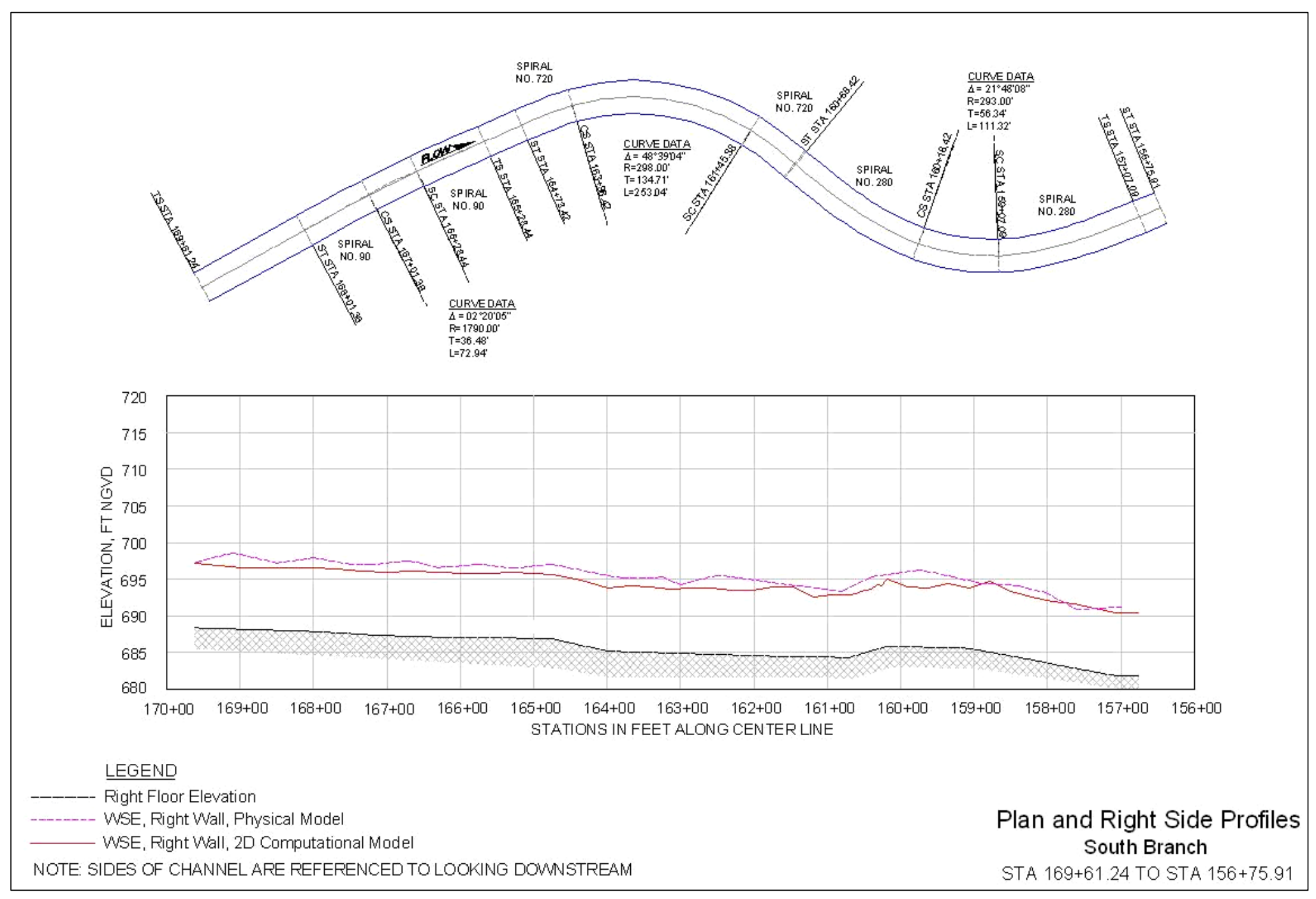

Figure 21. Model validation, South Branch, plan and profiles, sta $169+61.24$ to $156+75.91$, right wall. 


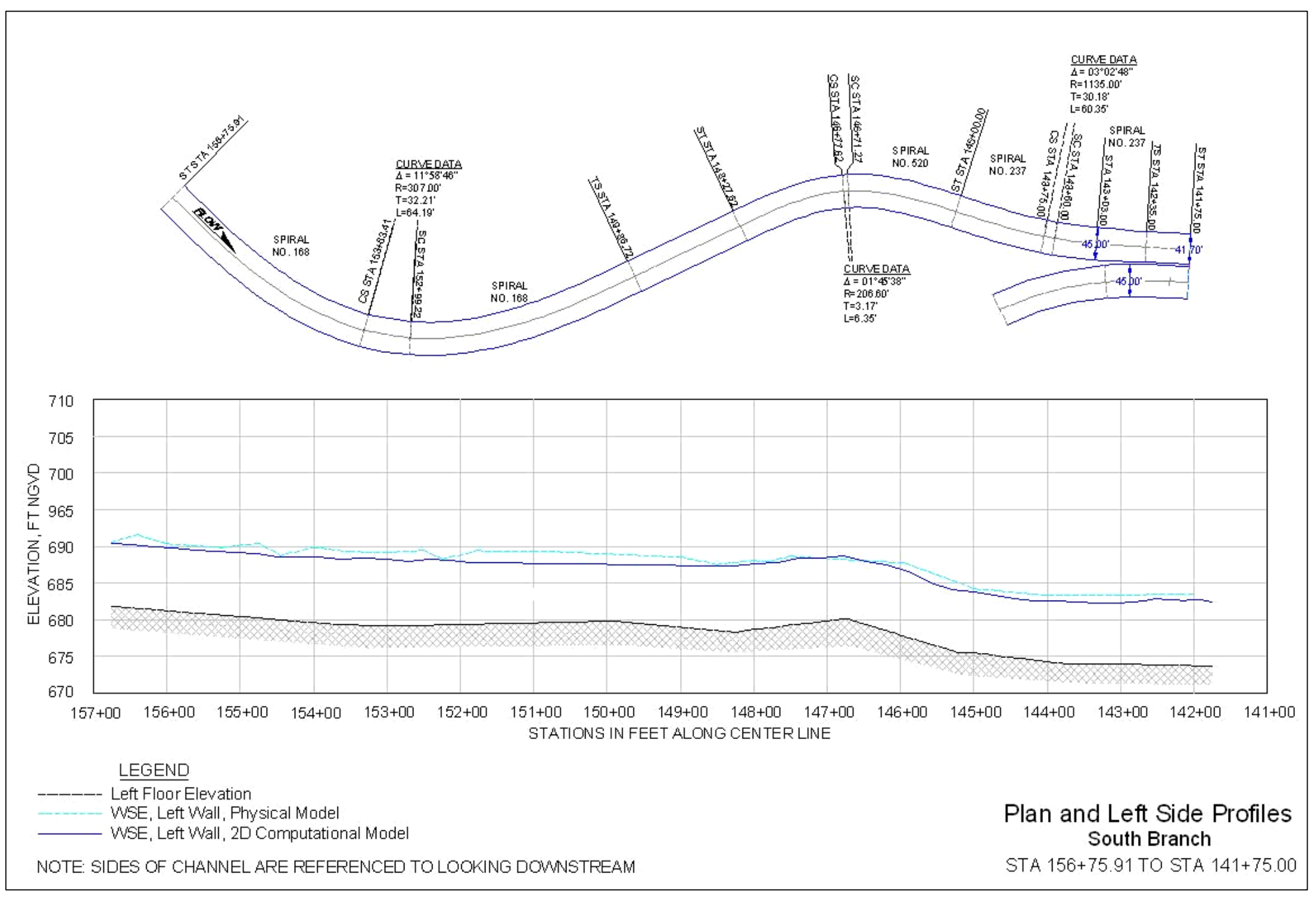

Figure 22. Model validation, South Branch, plan and profiles, sta $156+75.91$ to $141+75.00$, left wall. 


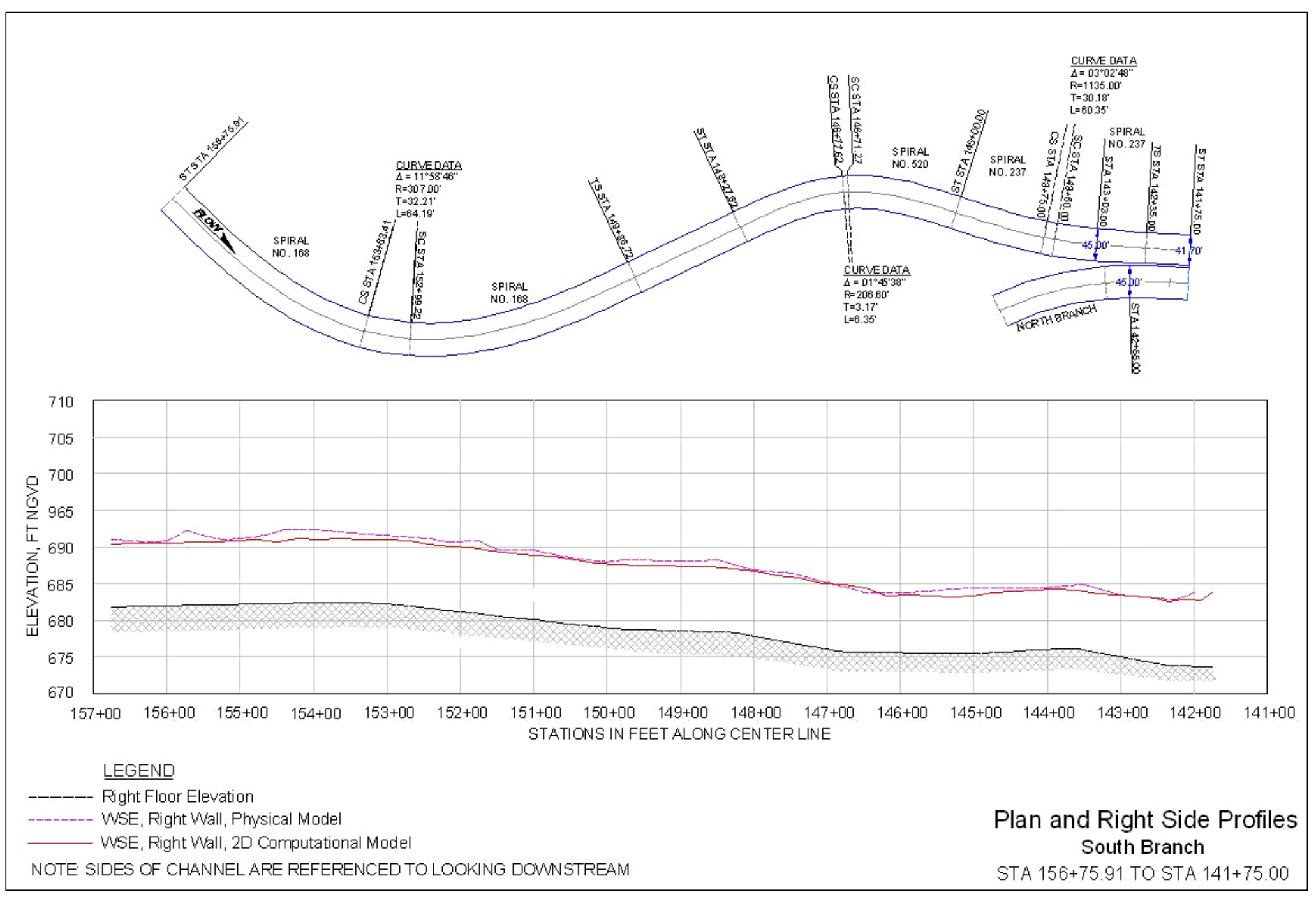

Figure 23. Model validation, South Branch, plan and profiles, $156+75.91$ to $141+75.00$, right wall. 


\section{As-Built Conditions Model}

\section{Channel features and geometry}

The model reproduced the main channel of the Hoosic River from below Plunkett Dam (sta 121+0o) to $100 \mathrm{ft}$ downstream of Lime Street (sta $0+00$ ), a distance of 12,100 ft. The lower $125 \mathrm{ft}$ of Fiske Brook was reproduced. The Tophet Brook modeled reach extended from the confluence up to sta $3+89$. The detailed junctions where these channels merge with the main channel were also included in the model.

Channel features include the weir at sta $113+34$ where the flow accelerates from subcritical to supercritical, three drop structures, each incorporating a stilling basin, nine channel bends that have spiral curves that transition the flow into and out of circular curves, with invert banking in which the invert is rotated about the center line. The spiral curve layout is in accordance with the Hydraulic Design Criteria (Hydraulic Design Chart 6602/2 and sheets 660-2 to 660-2/4) from research conducted by the Los Angeles District (U.S. Army Engineer District, Los Angeles, 1948). Invert banking design was developed in the original Hoosic River physical model study (U.S. Army Engineer Waterways Experiment Station 1952). The invert banking is given by:

$$
\Delta \mathrm{z}=\mathrm{C} \frac{\mathrm{V}^{2} \mathrm{~W}}{\mathrm{gr}}
$$

here:

$$
\begin{aligned}
\Delta \mathrm{z}= & \text { change in invert elevation at the wall from center-line invert } \\
& \text { elevation } \\
\mathrm{C}= & \text { a coefficient } \\
\mathrm{V}= & \text { mean channel velocity of flow approaching the curve } \\
\mathrm{W}= & \text { channel width } \\
\mathrm{g}= & \text { gravitational acceleration } \\
\mathrm{r}= & \text { radius of channel center-line curvature }
\end{aligned}
$$

The coefficient, C, used in the design of the Hoosic River channel in the reach through Adams was 1.2. This value was developed during the North Adams physical model study (U.S. Army Engineer Waterways Experiment 
Station 1952). These criteria are now the accepted hydraulic design criteria found in EM 1110-2-1601.

The lower reach of the modeled Hoosic River channel, downstream of sta $35+47.83$, is composed of various cross-sectional shapes: trapezoidal, rectangular, and compound with a vertical wall on one side and a sloping side on the other. This reach has a base width of $75 \mathrm{ft}$ and the side slopes are laid $1 \mathrm{~V}$ on $3 \mathrm{H}$. The flow in this lower reach is subcritical. The bed is composed of gravel, riprap, and derrick stone. The bends are simple circular curves. The mild longitudinal slope needed to sustain subcritical flow is established and maintained with the drop structures at sta 51+50, sta $36+54$, and sta $20+67$.

\section{Computational mesh}

A mesh was developed using as-built plans (line drawings) provided by the U.S. Army Engineer District, New York (NAN). The line drawings were used to create a CAD figure of the channel alignment. The mesh was generated from this CAD drawing. The finite element mesh had 12,868 nodes and 23,272 triangular elements.

The computational mesh of the as-built conditions model is shown in Figure 24. The flow direction is from lower left to upper right of the mesh. Details of the mesh at each drop structure are shown on the figure. A minimum of 5 elements were used to describe the high-velocity channel. Typical element sizes were approximately $15 \mathrm{ft}$ by $25 \mathrm{ft}$, with much smaller elements (greater resolution) at junctions, piers, drop structures, and stilling basins.

\section{Boundary conditions and model parameters}

Discharges associated with the 100-year frequency flow event were used as the design flows. Discharge values were furnished by the NAN. Peak flows for each channel reach are shown in Table 1. It was assumed that the peak discharges at the upstream ends of the Hoosic River channel, Fiske Brook, and Tophet Brook occur simultaneously, although the hydrographs show slight differences at the times of peak at these inflows.

The inflow boundary condition for the main Hoosic River channel was specified as subcritical. A discharge of $4,271 \mathrm{cfs}$ was applied at the upstream end of the model. Supercritical inflow of $958 \mathrm{cfs}$ was specified 


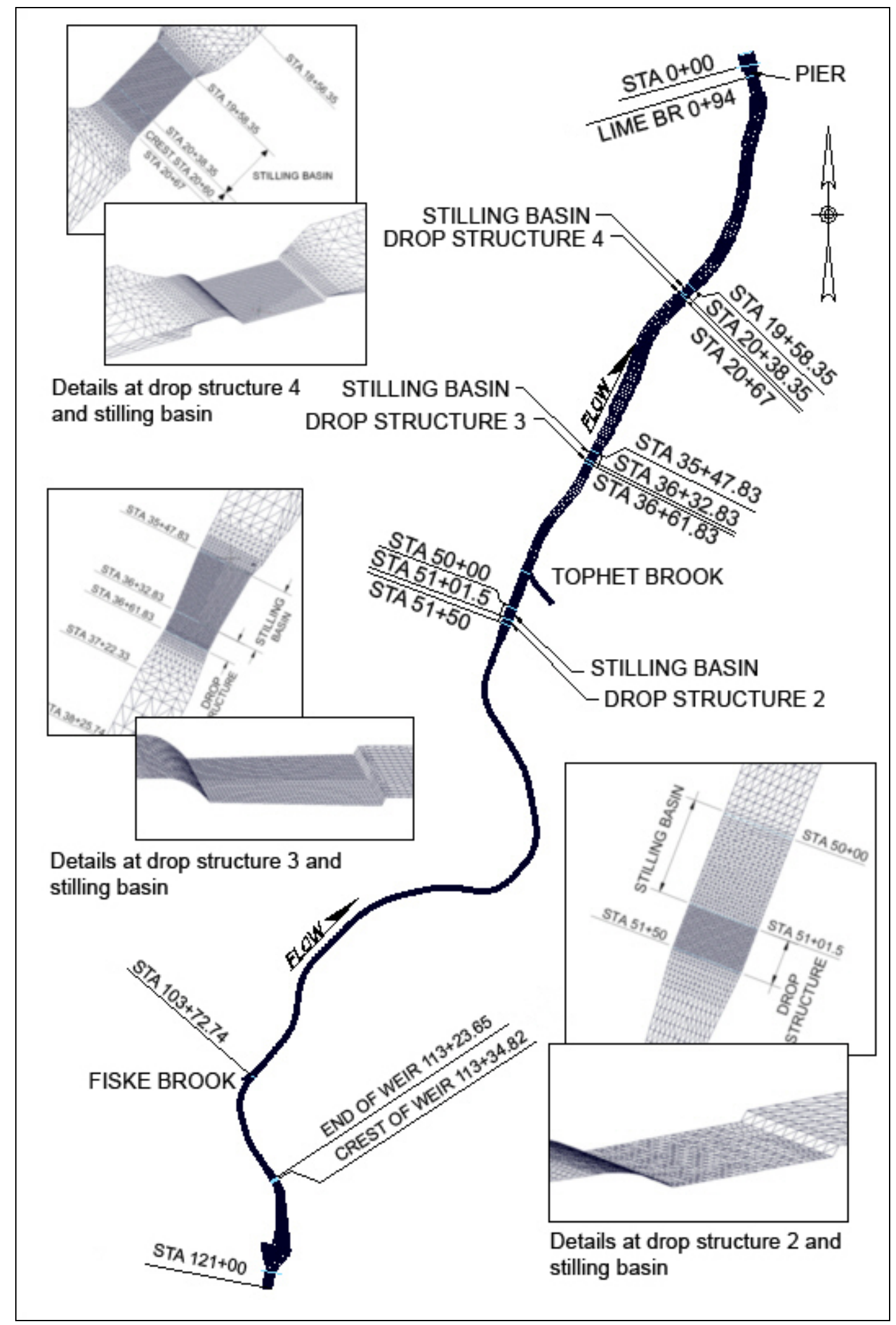

Figure 24. As-built conditions, computational mesh of Hoosic River channel and tributaries. 
Table 1. Design discharges (100-year frequency).

\begin{tabular}{|l|l|l|}
\hline Inflow Boundary & $\begin{array}{l}\text { Inflow Discharge } \\
\text { cfs }\end{array}$ & $\begin{array}{l}\text { Combined Discharge } \\
\text { cfs }\end{array}$ \\
\hline Hoosic River & 4271 & 4271 \\
\hline Fiske Brook & 958 & 5229 \\
\hline Tophet Brook & 1544 & 6773 \\
\hline
\end{tabular}

at the upper end of Fiske Brook. The Tophet Brook inflow was supercritical and the discharge was $1,544 \mathrm{cfs}$. A subcritical outflow boundary condition was set at the downstream end of the channel. The outflow discharge of $6,773 \mathrm{cfs}$ was the total of the three inflows. Normal depth, which is $8.2 \mathrm{ft}$ at $6,773 \mathrm{cfs}$, was assumed to occur at the outflow section and since the centerline bed elevation was 734.8 a tailwater of el 743.0 was specified as the outflow boundary.

The discharges used to evaluate the Hoosic River channel were 4,271 cfs at the upstream end of the Hoosic River at sta 121+oo down to the confluence of Fiske Brook near sta 103+50. Downstream of Fiske Brook the flow rate was 5,229 cfs until the addition of Tophet Brook flow. The Tophet Brook confluence was near sta $46+50$ where the flow discharge increased to the total of $6,773 \mathrm{cfs}$.

The upper reach of the channel was concrete and the lower end varied from small cobbles and derrick stone to riprap. The bed roughness was uniform on the invert of the high-velocity channel, but varied along the model's lower reach. A Manning's roughness coefficient, n, of 0.014 was used for concrete, 0.025 for soil and derrick stone, and 0.030 for riprap.

\section{As-built conditions results}

Flow features that would produce adverse flow conditions were modified during the physical model study reported in U.S. Army Engineer Waterways Experiment Station (1957). The physical model study's recommendations were primarily incorporated into the constructed (as-built) channel. The numerical model simulation results confirmed the acceptable performance of the channel as originally designed and constructed. The velocity in the high-velocity channel reach varied from about $23 \mathrm{fps}$ to about $29 \mathrm{fps}$. The velocity of the flow over the drop structure near sta $51+50$ was greater than $30 \mathrm{fps}$. Velocities in the area considered for channel 
modifications are shown in Figures 25-29. Note that the contour interval is different on each figure. These contours of velocity magnitude show the transition from supercritical flow upstream of the first drop structure at sta $51+50$, to subcritical flow along the lower reach. The drop structures downstream of Tophet Brook maintained the mild slopes needed to ensure subcritical flow.

The as-built conditions water-surface profiles are plotted with the results of the existing conditions which will be discussed in the next section. The profiles will be used to examine the effects of the material that is deposited in the existing channel. 


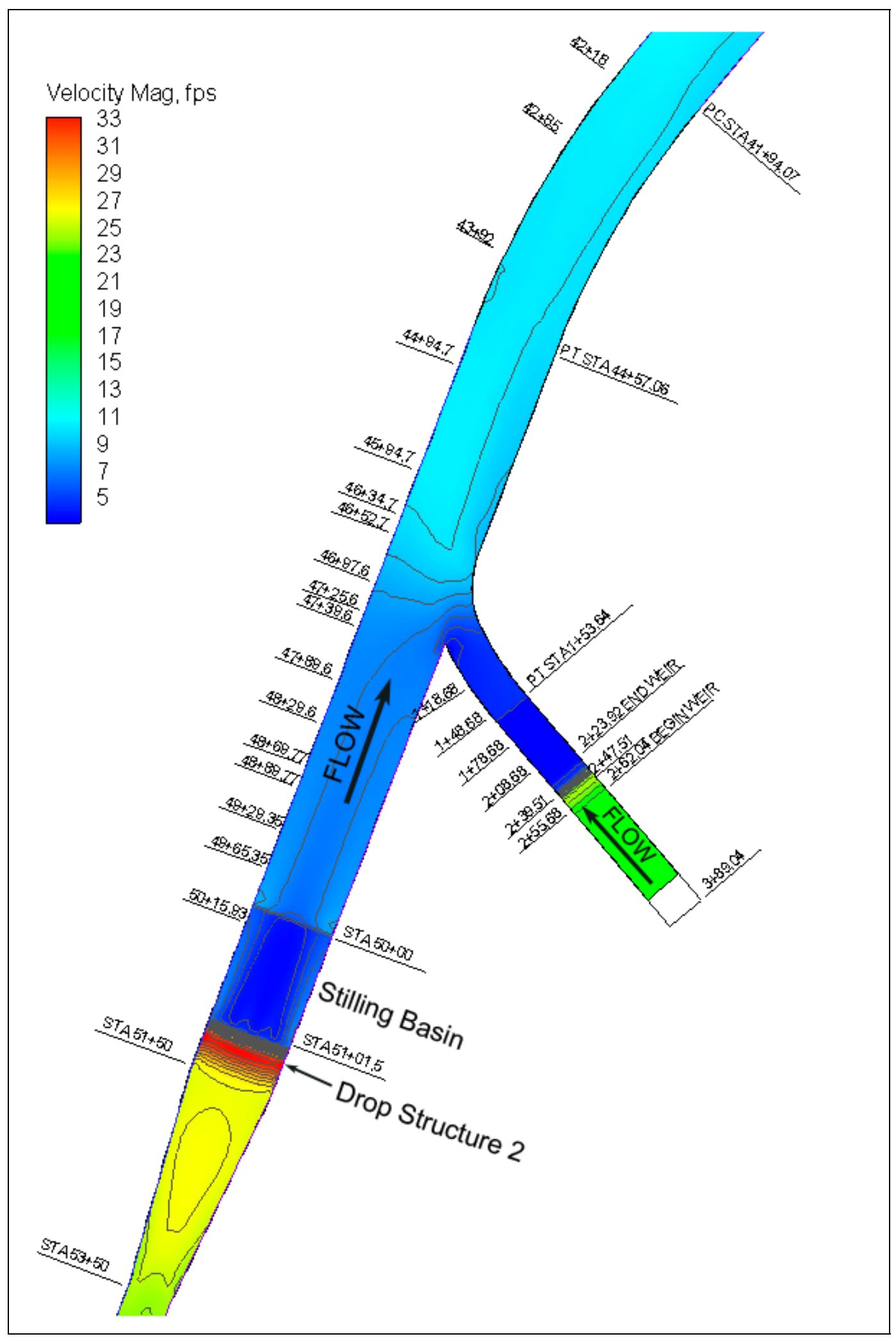

Figure 25. As-built conditions, velocity magnitude contours at Tophet Brook confluence, sta $53+50$ to $41+94.07$. 


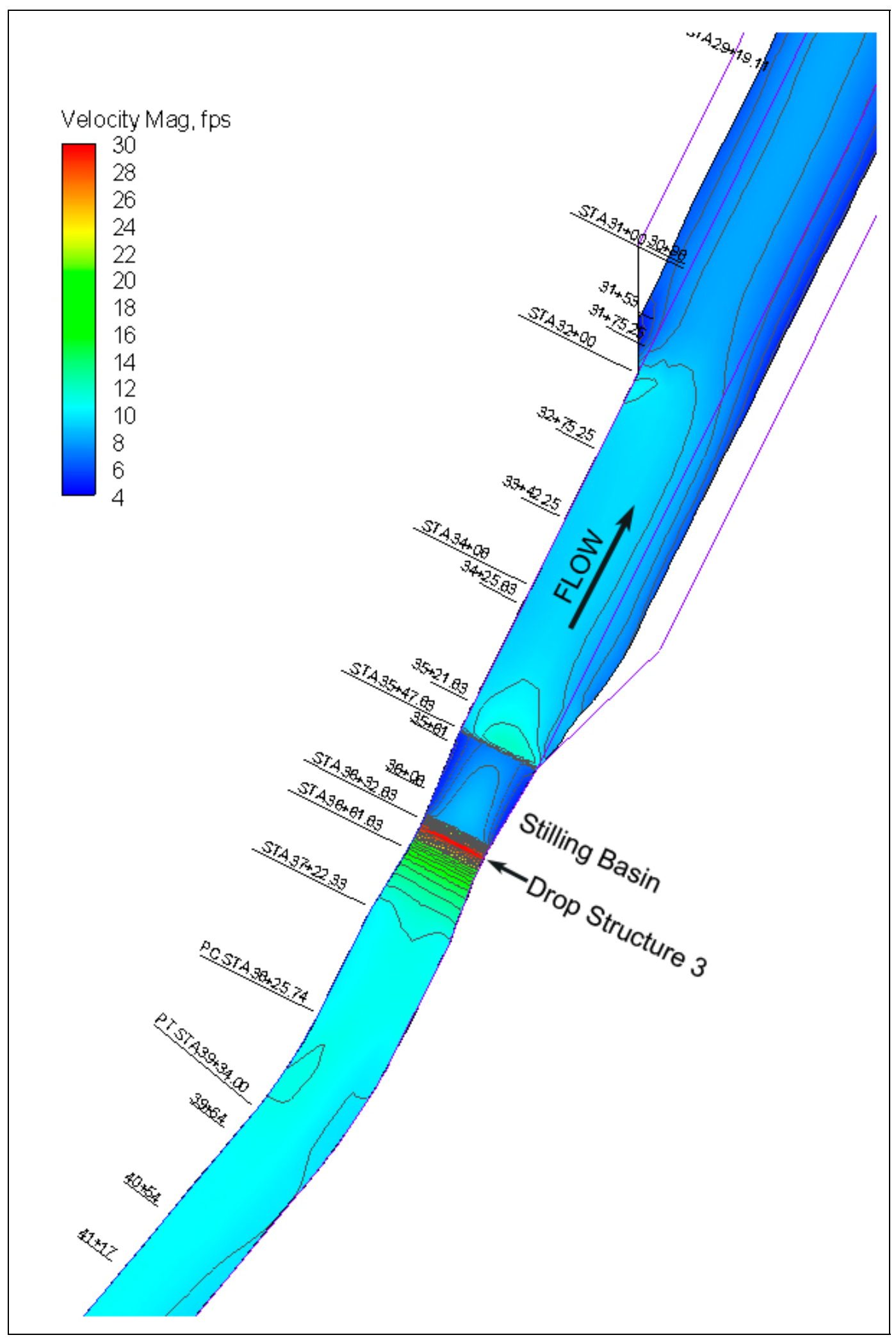

Figure 26 . As-built conditions, velocity magnitude contours, sta $41+17$ to $29+11$. 


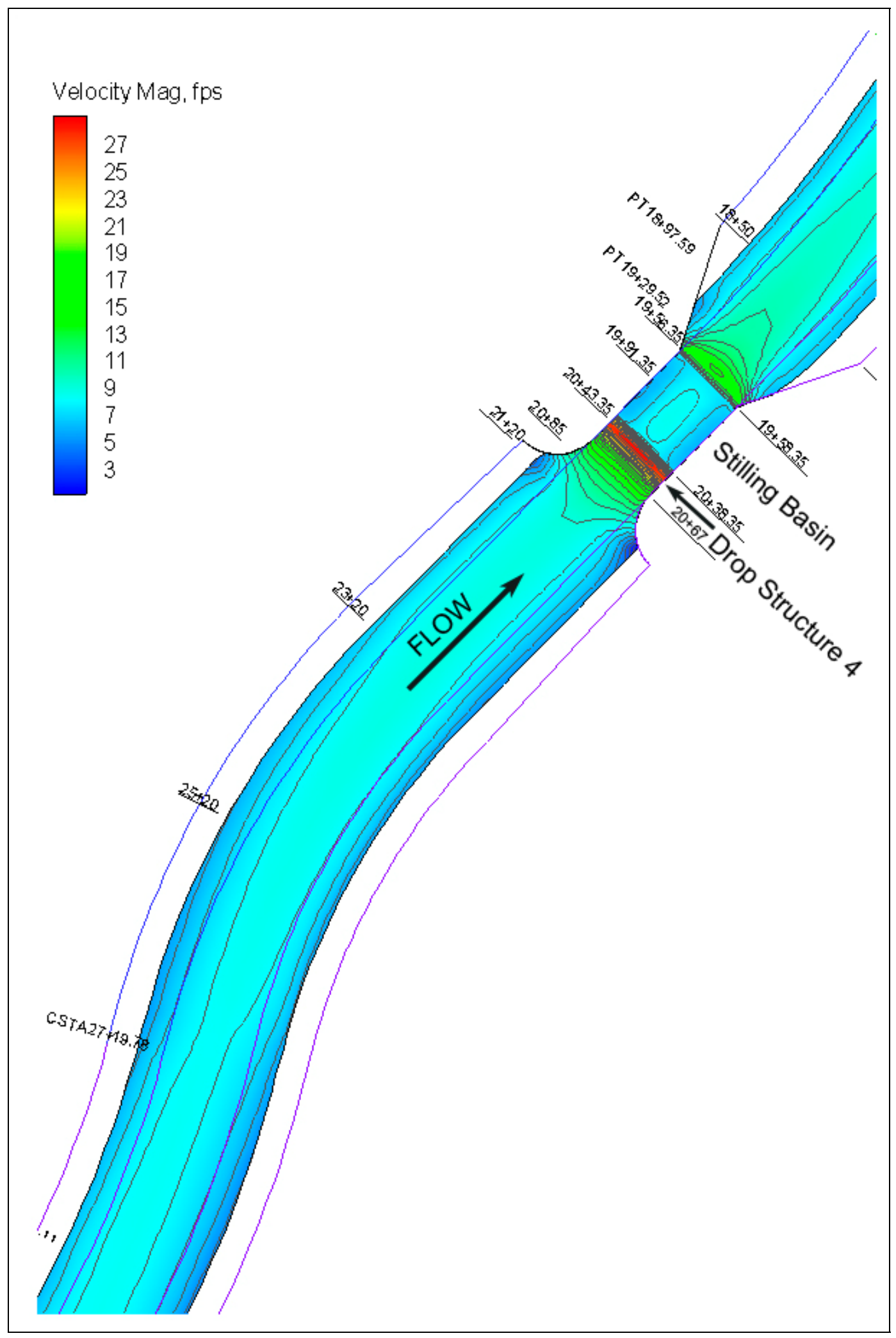

Figure 27 . As-built conditions, velocity magnitude contours, sta $29+11$ to $17+50$. 


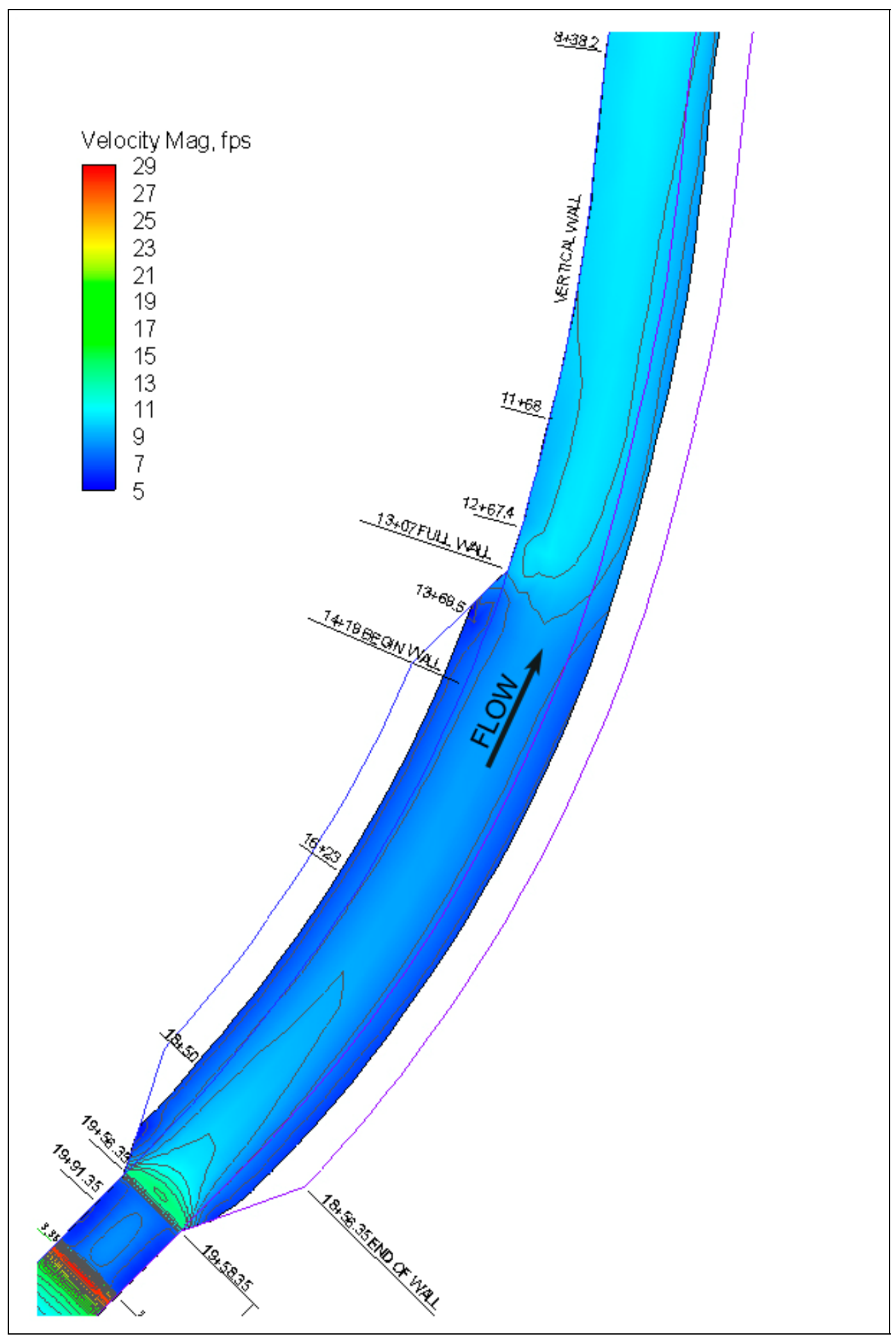

Figure 28. As-built conditions, velocity magnitude contours, sta $20+67$ to $8+38.2$. 


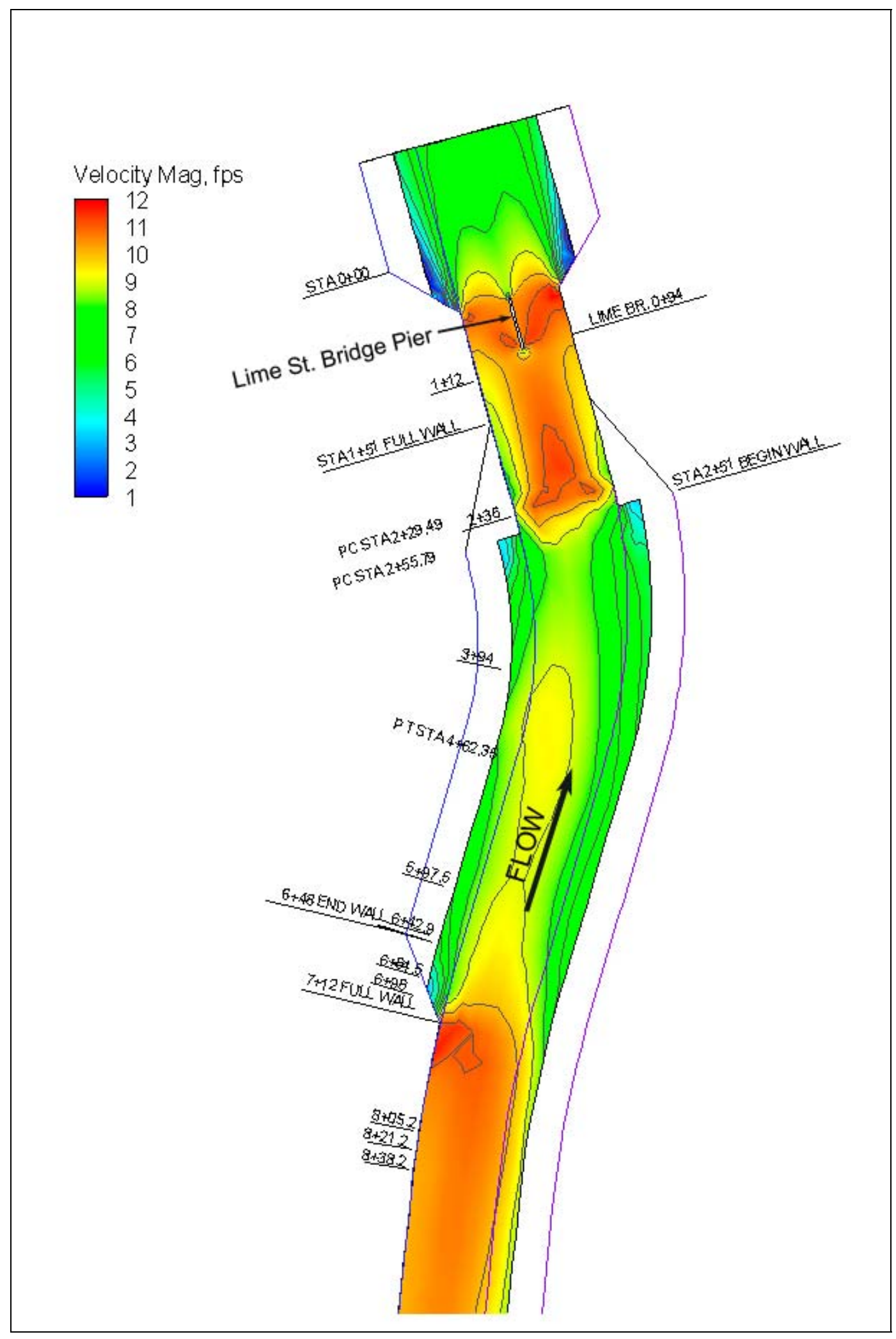

Figure 29. As-built conditions, velocity magnitude contours, sta 9+00 to $-1+00$. 


\section{Existing Conditions Model}

\section{Geometry and computational mesh}

The channel has changed over the years since construction was completed in the 1950's. Gravel and rocks have washed into the stream and accumulated on the bed. Also, vegetation has grown up in the area of interest. The bed elevations in the as-built conditions model were changed to simulate present day conditions.

The NAN conducted an engineering survey on 18-22 June 2007. The survey data described the existing bathymetry in the Hoosic River from sta $1+12$ to sta $50+15.93$ and that of Tophet Brook from sta $0+77.26$ to sta $2+56.68$. The data included bed elevations, photographs, and descriptions of the surveyed reaches. The survey data were used to update the asbuilt conditions computational mesh to reflect the changes reported in the survey. The photographs were used to visually check the mesh for areas that had not changed from the as-built conditions (such as concrete channel with no sediment buildup and drop structure crests). The pier at the Lime Street Bridge has changed since the Hoosic Channel was first constructed. Initially, the bridge had a single pier within the channel. The bridge was modified in 1996 to free spanning. Therefore, the as-built conditions model had a bridge pier at Lime Street and the existing conditions model did not.

The existing conditions mesh had 12,255 nodes and 22,105 triangular elements. Element sizes and mesh resolution were similar to those used to model the as-built conditions. Details of the existing conditions mesh are shown in Figure 30.

\section{Boundary conditions and model parameters}

The boundary conditions (inflow discharges and tailwater elevation) were identical to those used for the as-built conditions model. The roughness coefficients were also similar to the as-built conditions model. The primary difference in the setup of the as-built conditions and existing conditions models was inclusion of material that had been deposited within the channel. 


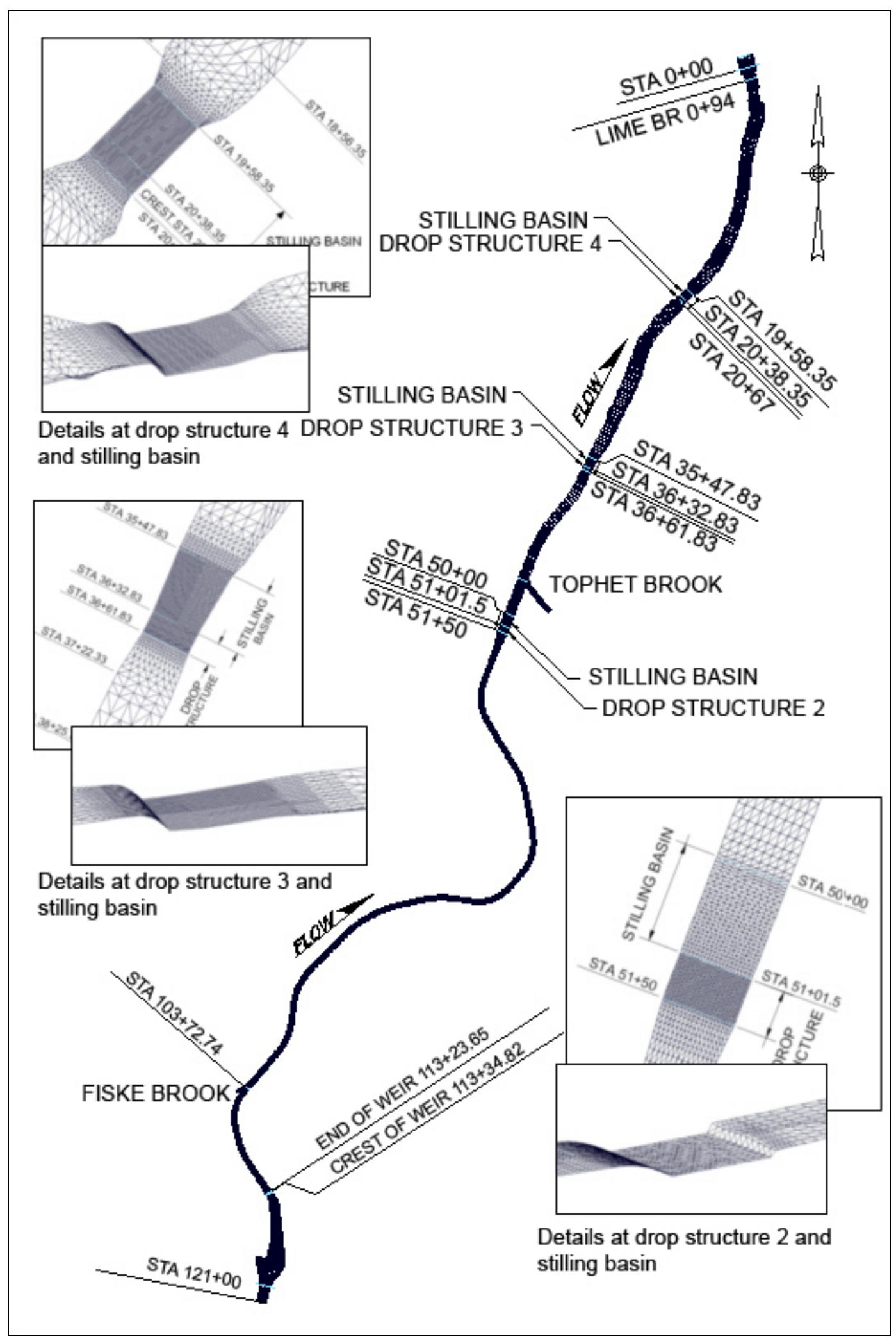

Figure 30. Existing conditions, computational mesh of Hoosic River channel and tributaries. 


\section{Existing conditions results}

The numerical model results are illustrated on the three-dimensional perspectives provided in Figures 31 and 32. Figure 31 shows the superelevation of the water surface as flow passed around a bend. The hydraulic jumps downstream of the drop structure in the main channel (near sta 51+50) and Tophet Brook are shown in Figure 32. The jumps were contained within the stilling basins as they were designed to perform.

Velocities in the lower end of the modeled reach where restoration efforts will be directed are shown in Figures 33-37. Note that the contour intervals are different on each figure. The range and intervals of contours are different to accentuate the differences across the reach depicted on each figure.

Detailed water-surface profiles resulting from the design discharge are provided in Figures $38-55$. The plan and profile drawings show the channel alignment, invert elevation, and water-surface profiles for the as-built and existing conditions. The profiles are provided along both the right and left walls (looking downstream). The water-surface profiles down to the drop structure near $51+50$ were similar for the as-built and existing conditions. This is because the models were identical throughout this reach. This recalculation of as-built conditions was made simply for convenience of model setup.

The material deposited on the bed is shown in the bed profiles downstream of sta $51+00$. The existing conditions increase the water-surface elevation more than $2 \mathrm{ft}$ from near sta $51+50$ (Figures 50 and 51) down to sta 26+0o (Figures 52 and 53). The water-surface elevation downstream of sta $26+00$ with the existing conditions is more than $1 \mathrm{ft}$ higher than the as-built conditions as shown in Figures $52-55$. 


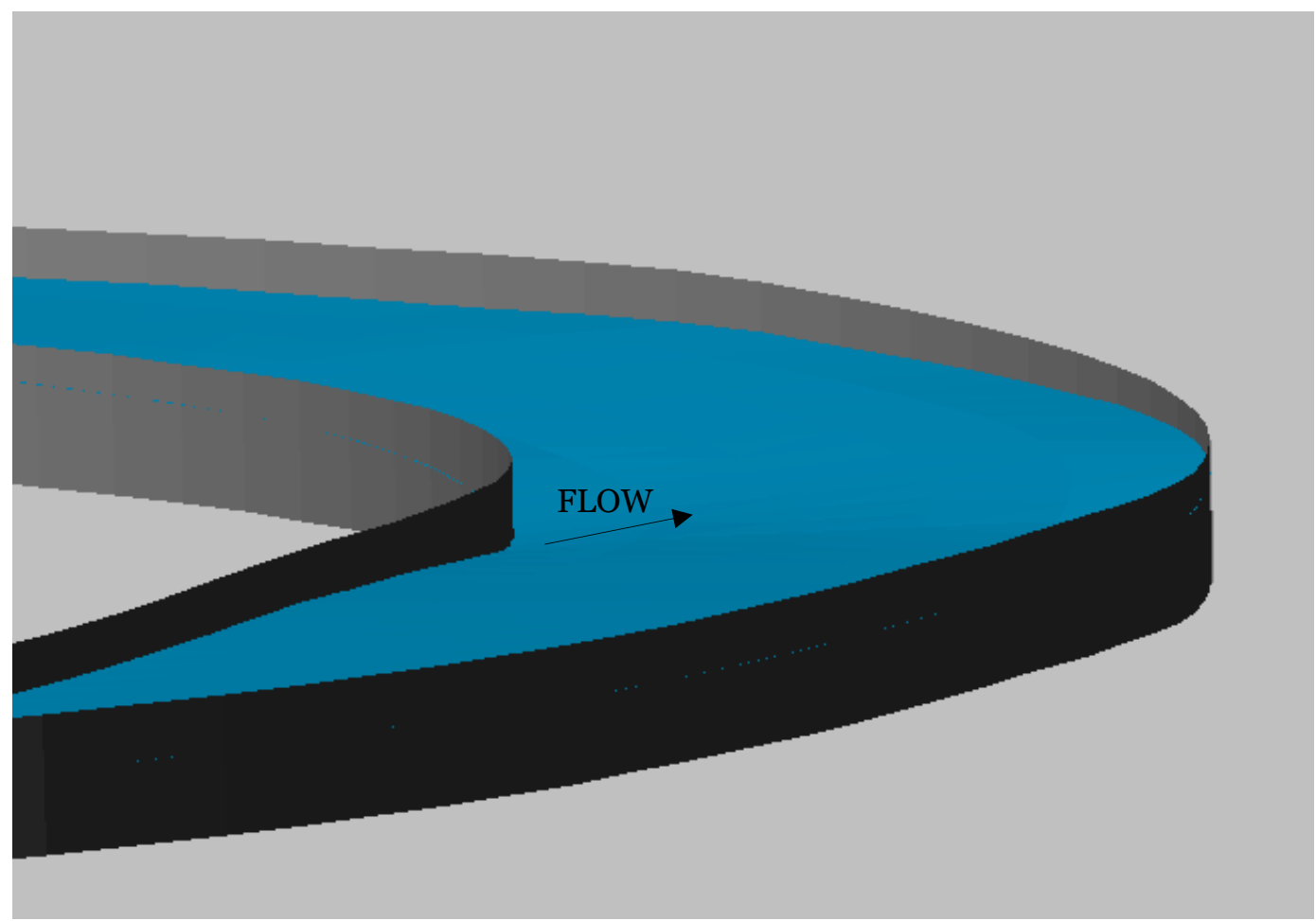

Figure 31. Existing conditions, super-elevation in computed water surface through curve.

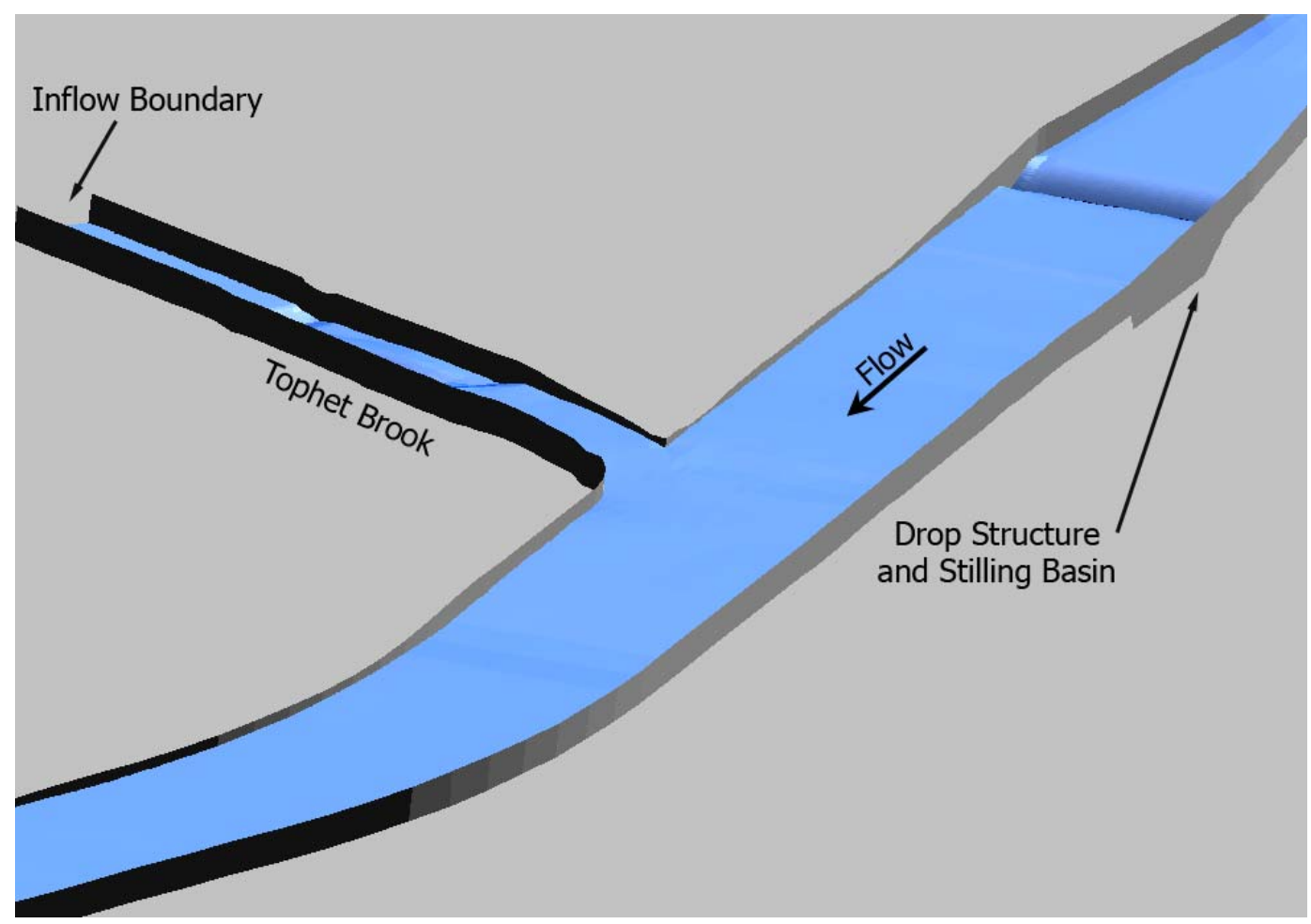

Figure 32. Existing conditions, water surface at the confluence of Tophet Brook and Hoosic River. 


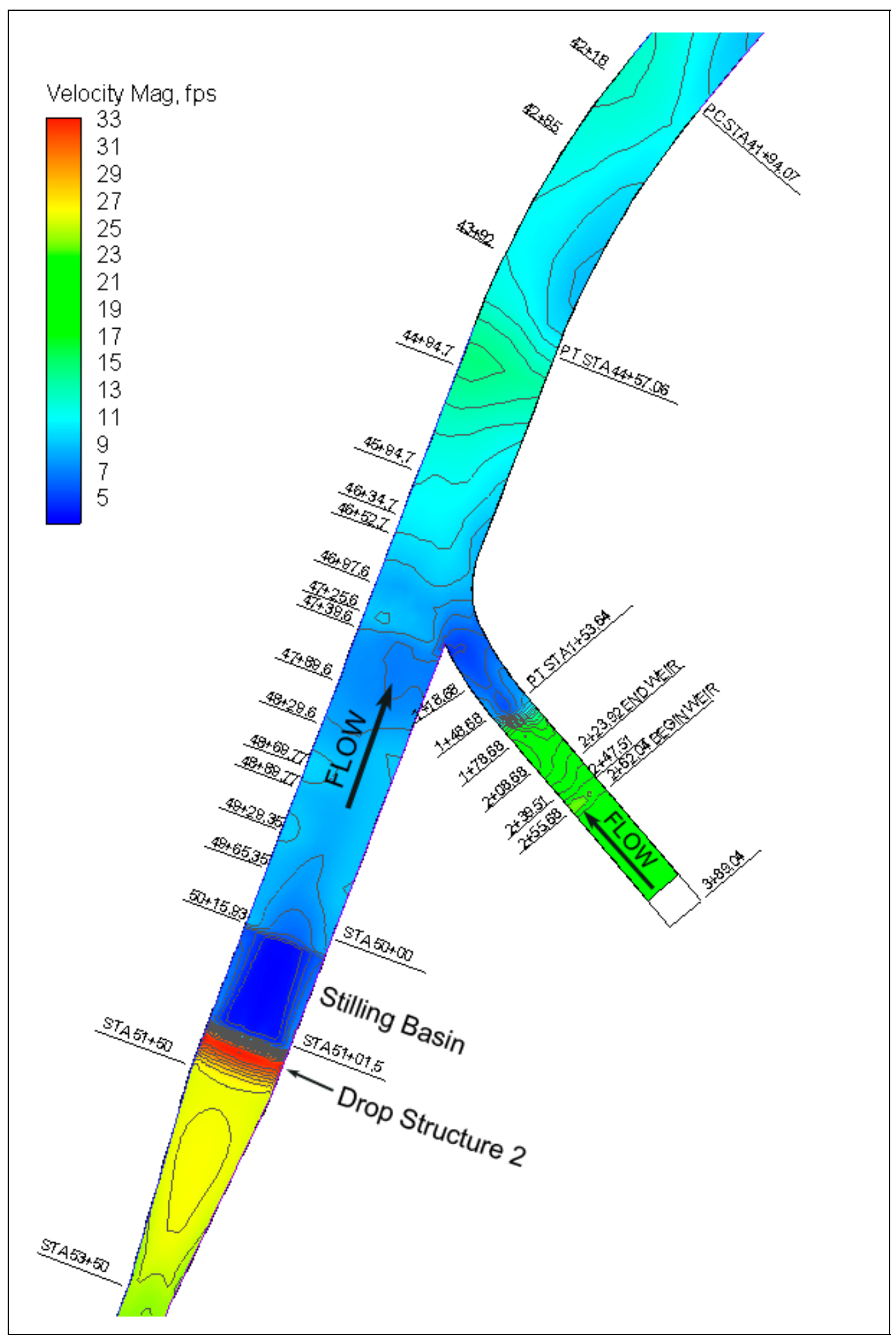

Figure 33. Existing conditions, velocity magnitude contours at Tophet Brook confluence, sta $53+50$ to $41+94.07$. 


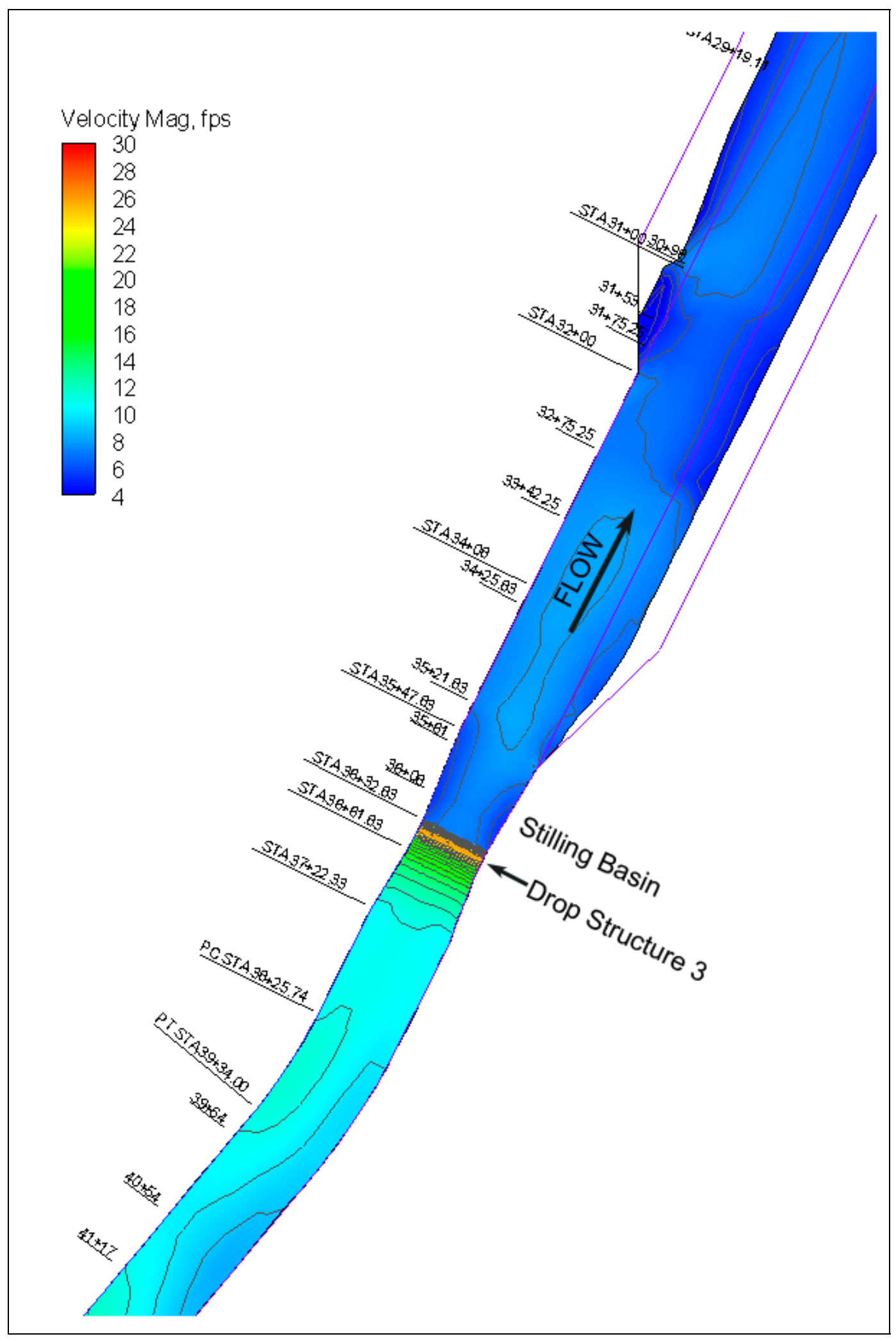

Figure 34 . Existing conditions, velocity magnitude contours, sta $41+17$ to $29+11$. 


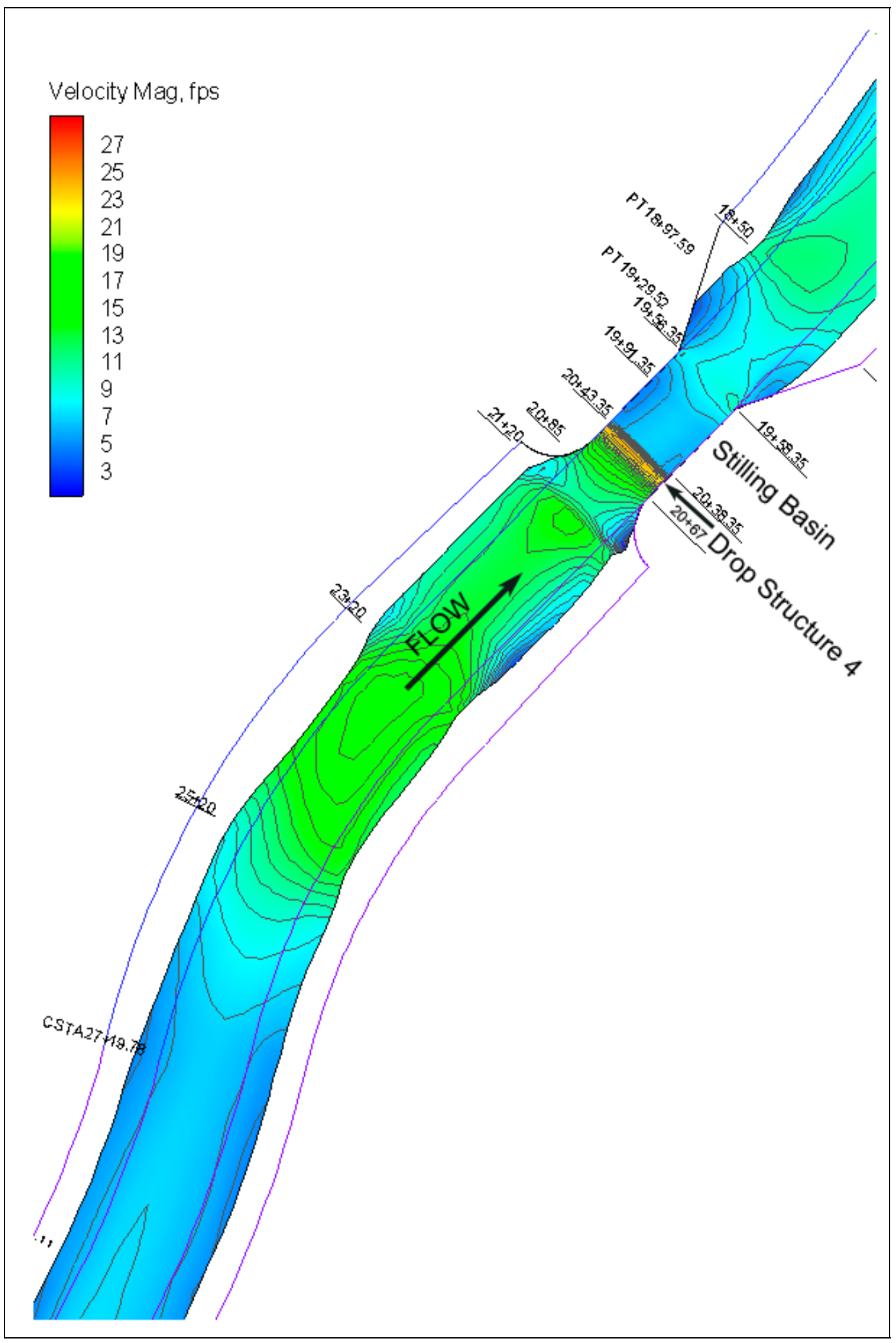

Figure 35 . Existing conditions, velocity magnitude contours, sta $29+11$ to $17+50$. 


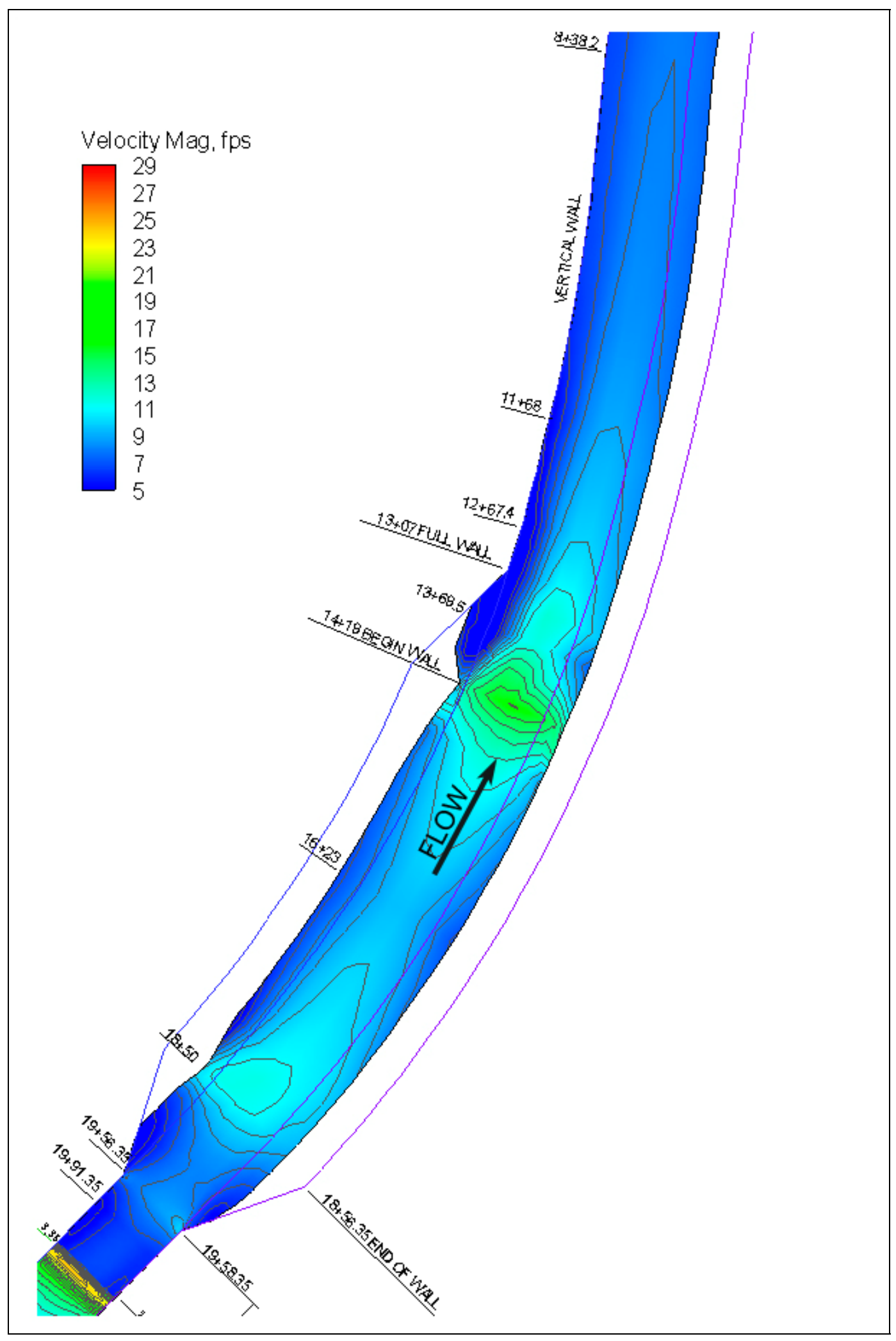

Figure 36 . Existing conditions, velocity magnitude contours, sta $20+67$ to $8+38.2$. 


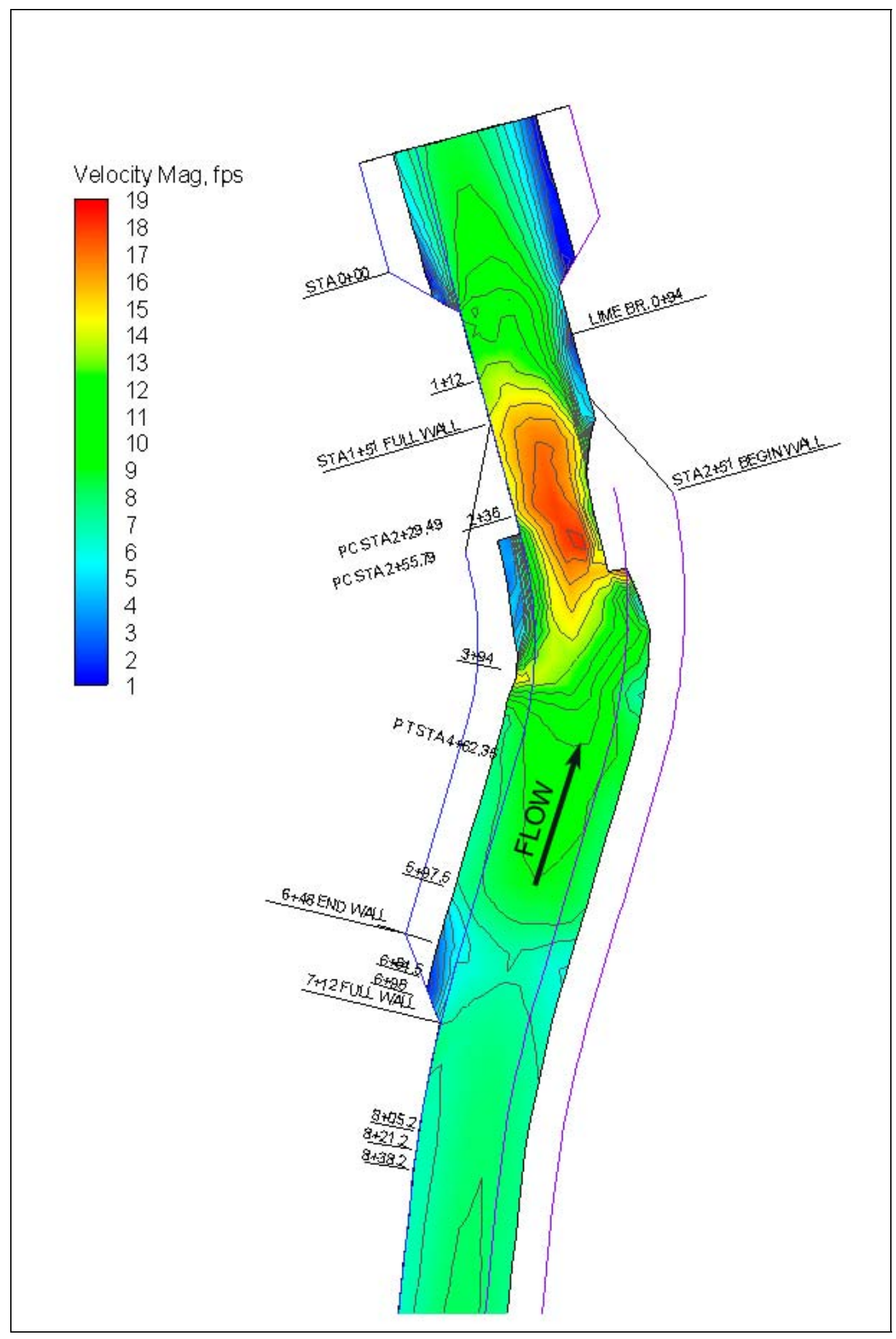

Figure 37 . Existing conditions, velocity magnitude contours, sta $9+00$ to $-1+00$. 


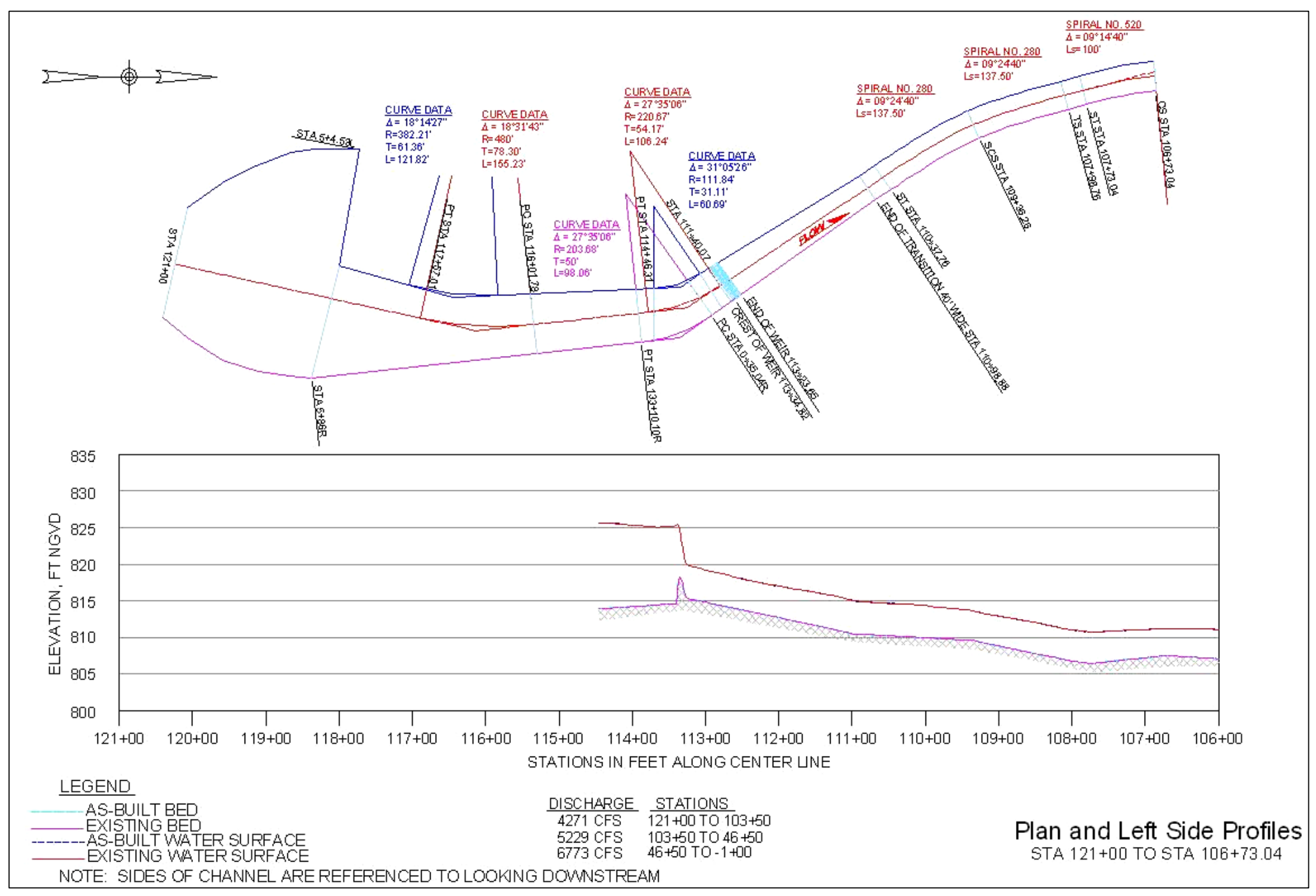

Figure 38. Existing and as-built conditions, plan and profiles, sta $121+00$ to $106+73.04$, left wall. 


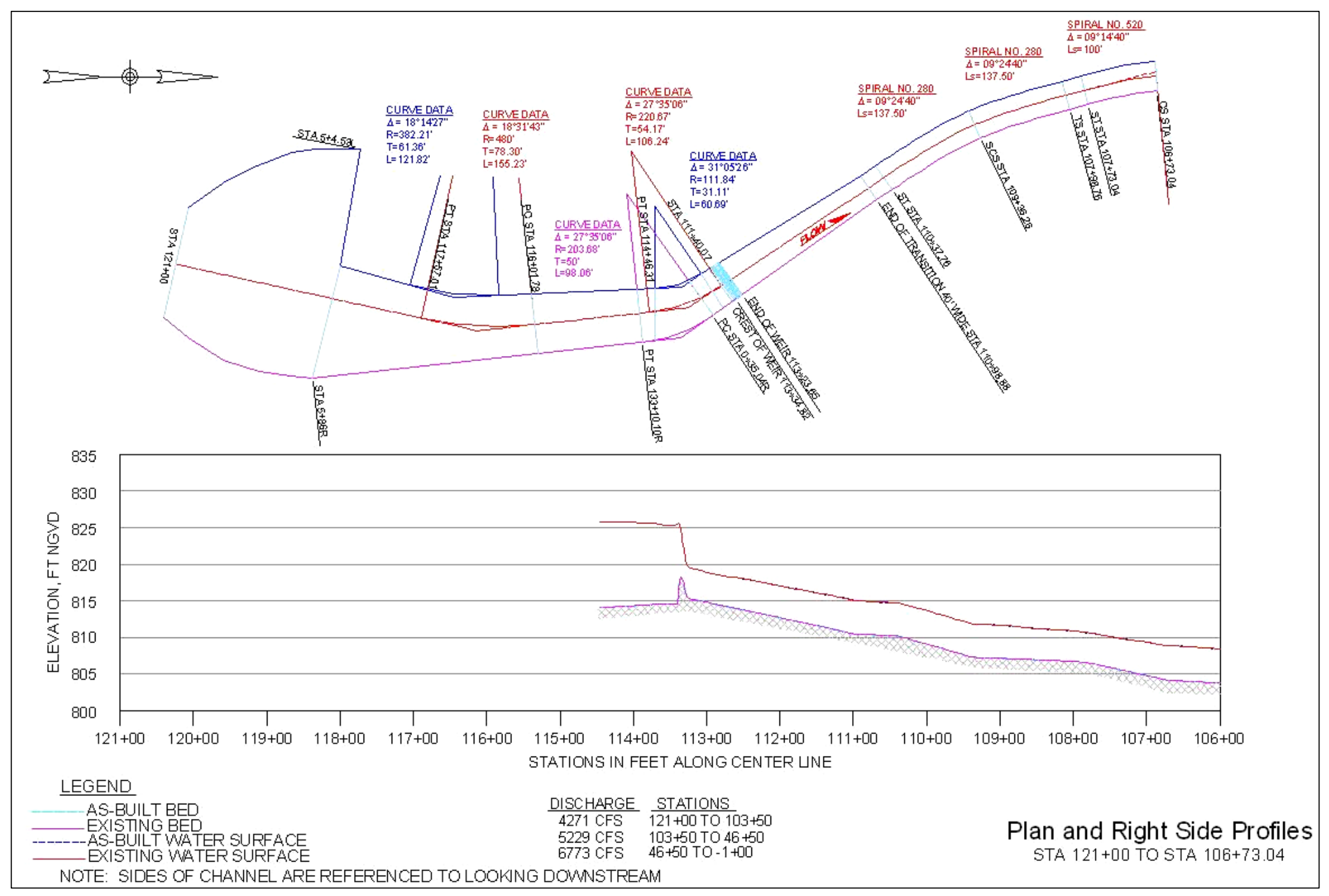

Figure 39. Existing and as-built conditions, plan and profiles, sta $121+00$ to $106+73.04$, right wall. 


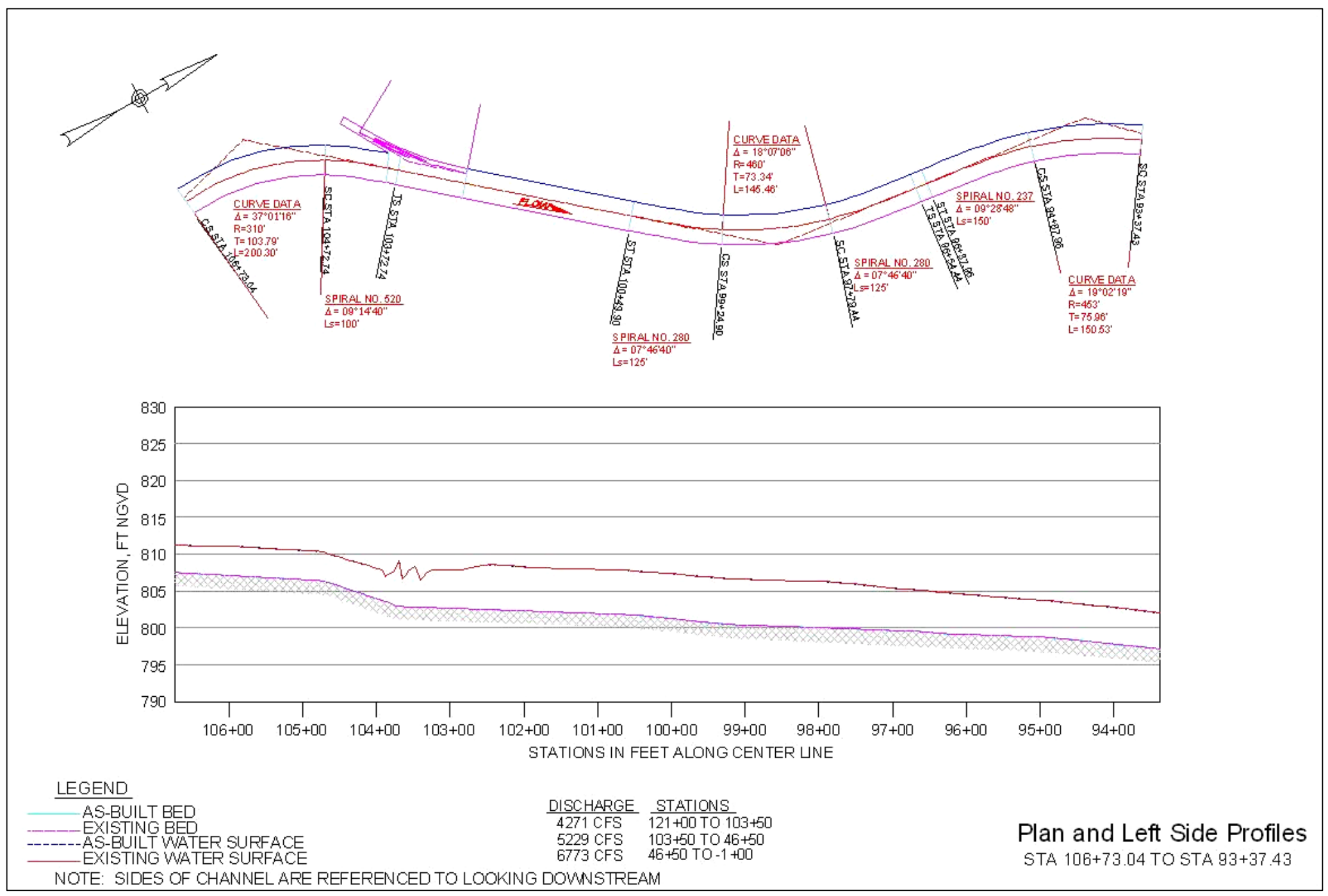

Figure 40. Existing and as-built conditions, plan and profiles, sta $106+73.04$ to $93+37.43$, left wall. 


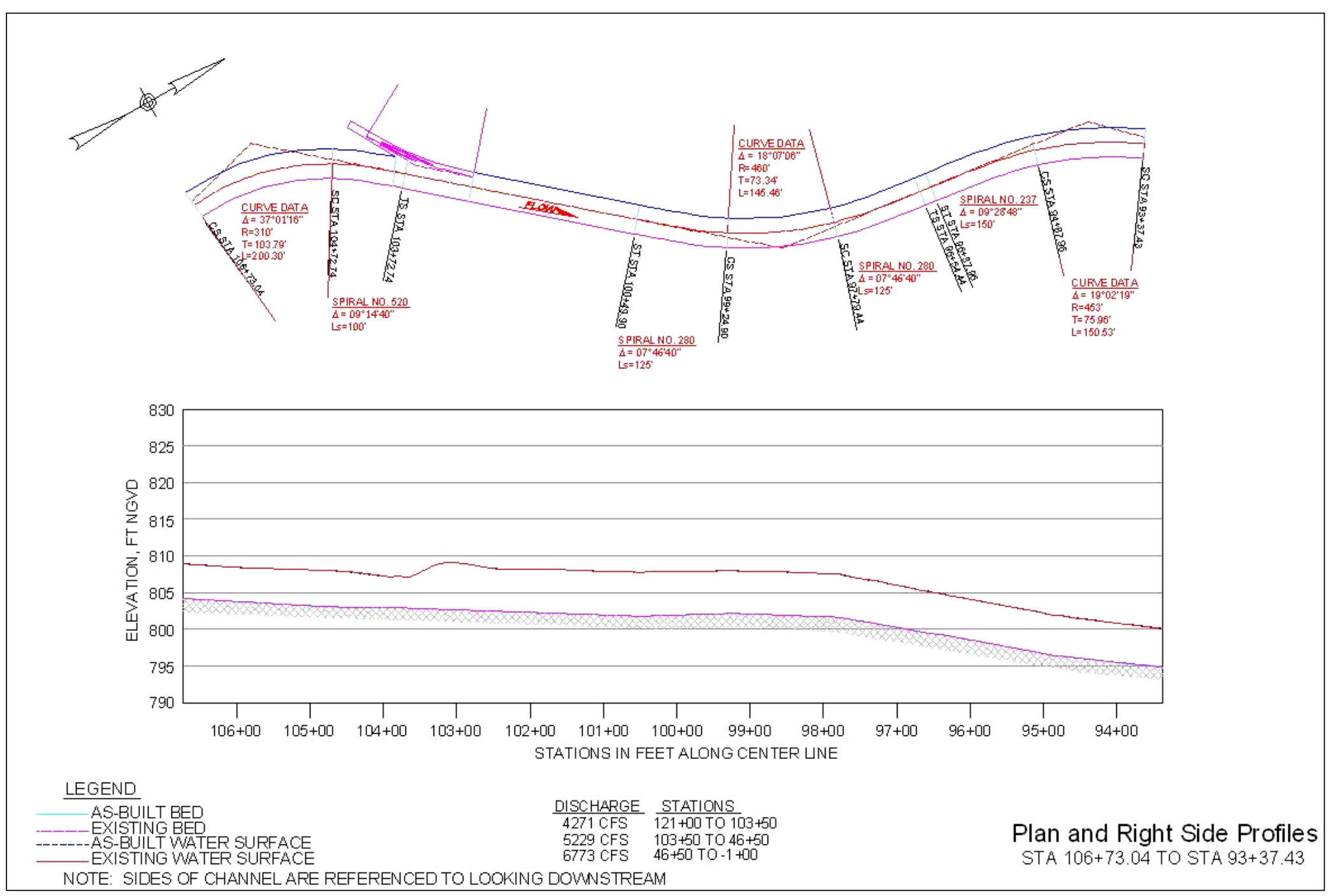

Figure 41. Existing and as-built conditions, plan and profiles, sta $106+73.04$ to $93+37.43$, right wall. 


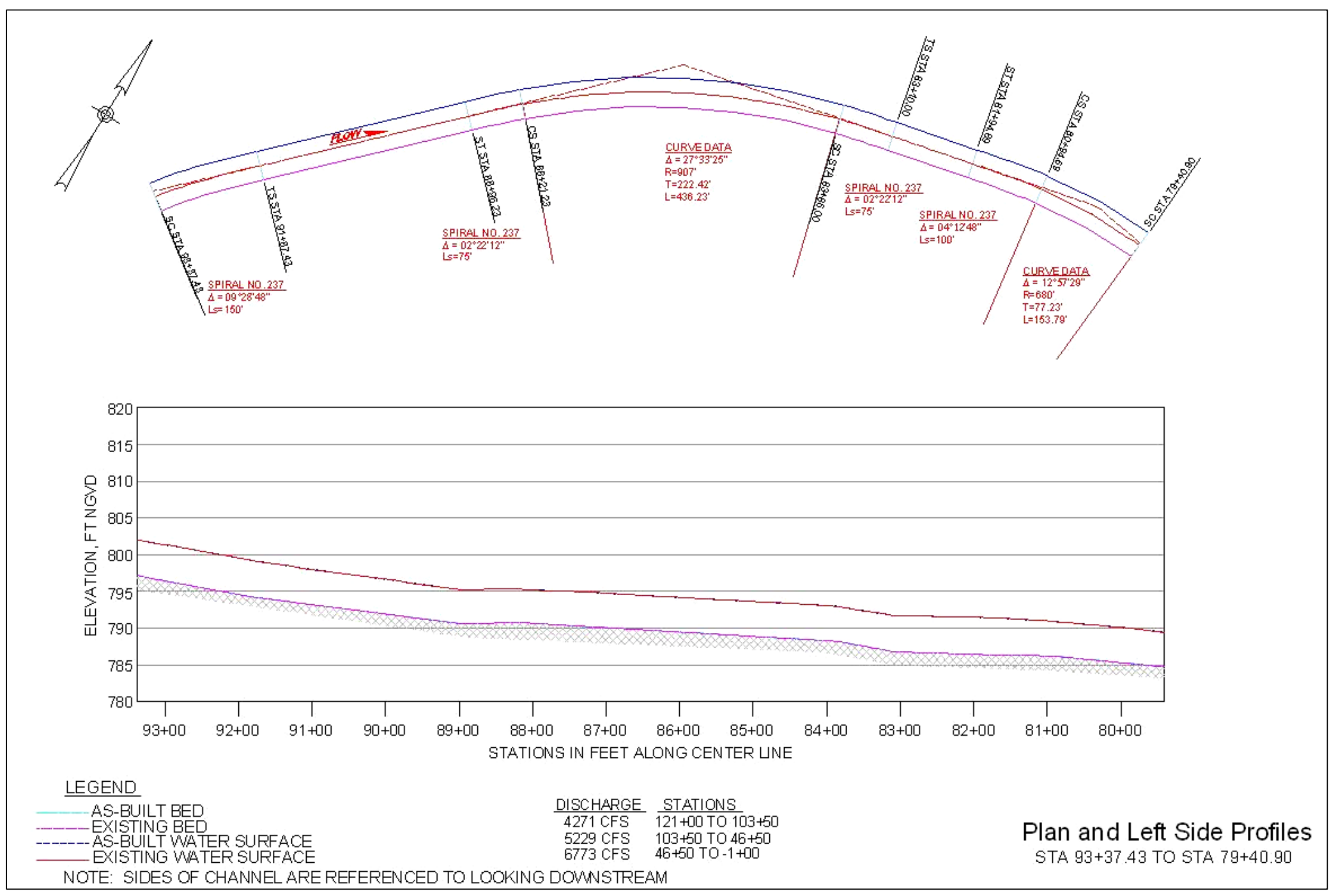

Figure 42. Existing and as-built conditions, plan and profiles, sta $93+37.43$ to $79+40.90$, left wall. 


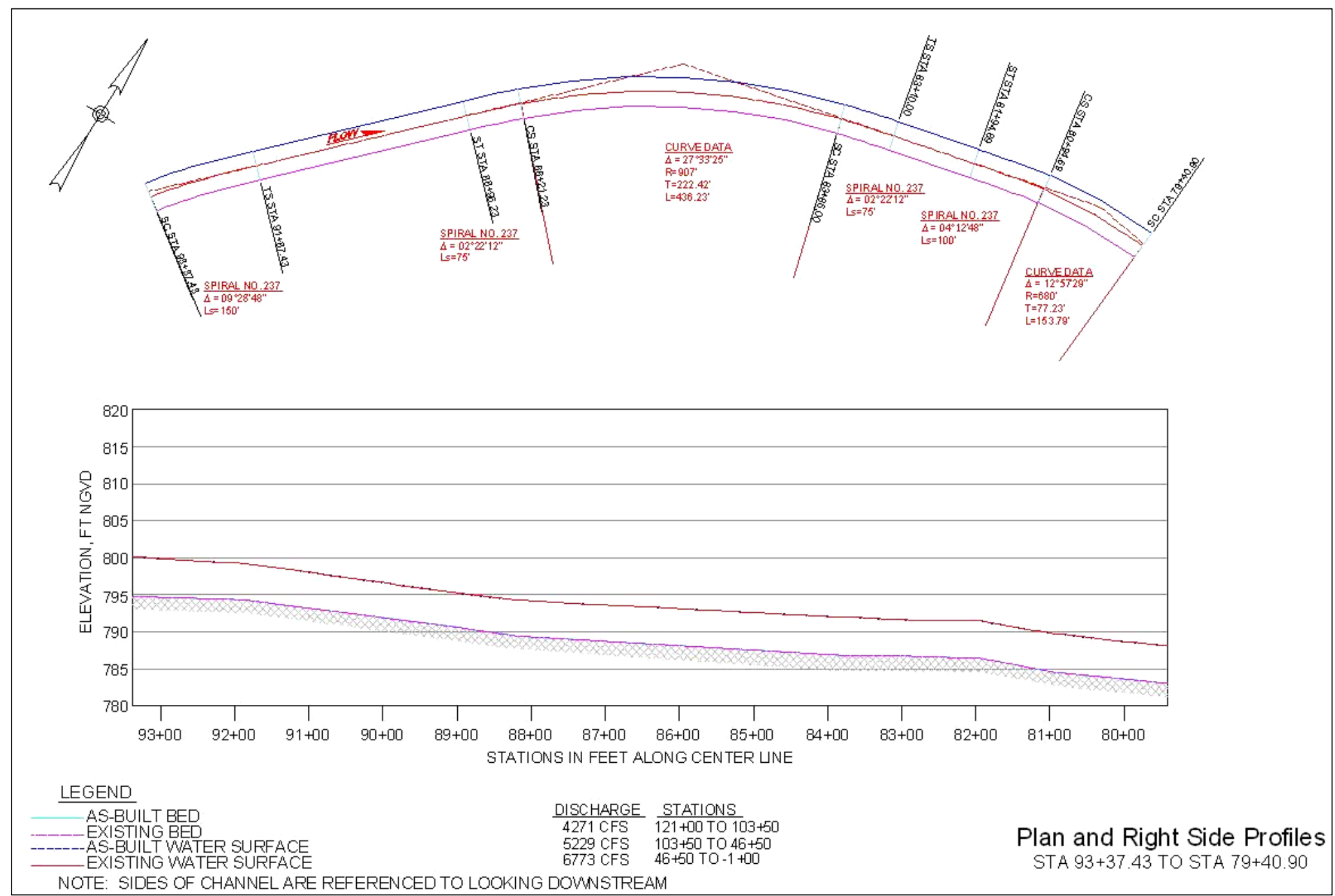

Figure 43. Existing and as-built conditions, plan and profiles, sta $93+37.43$ to $79+40.90$, right wall. 


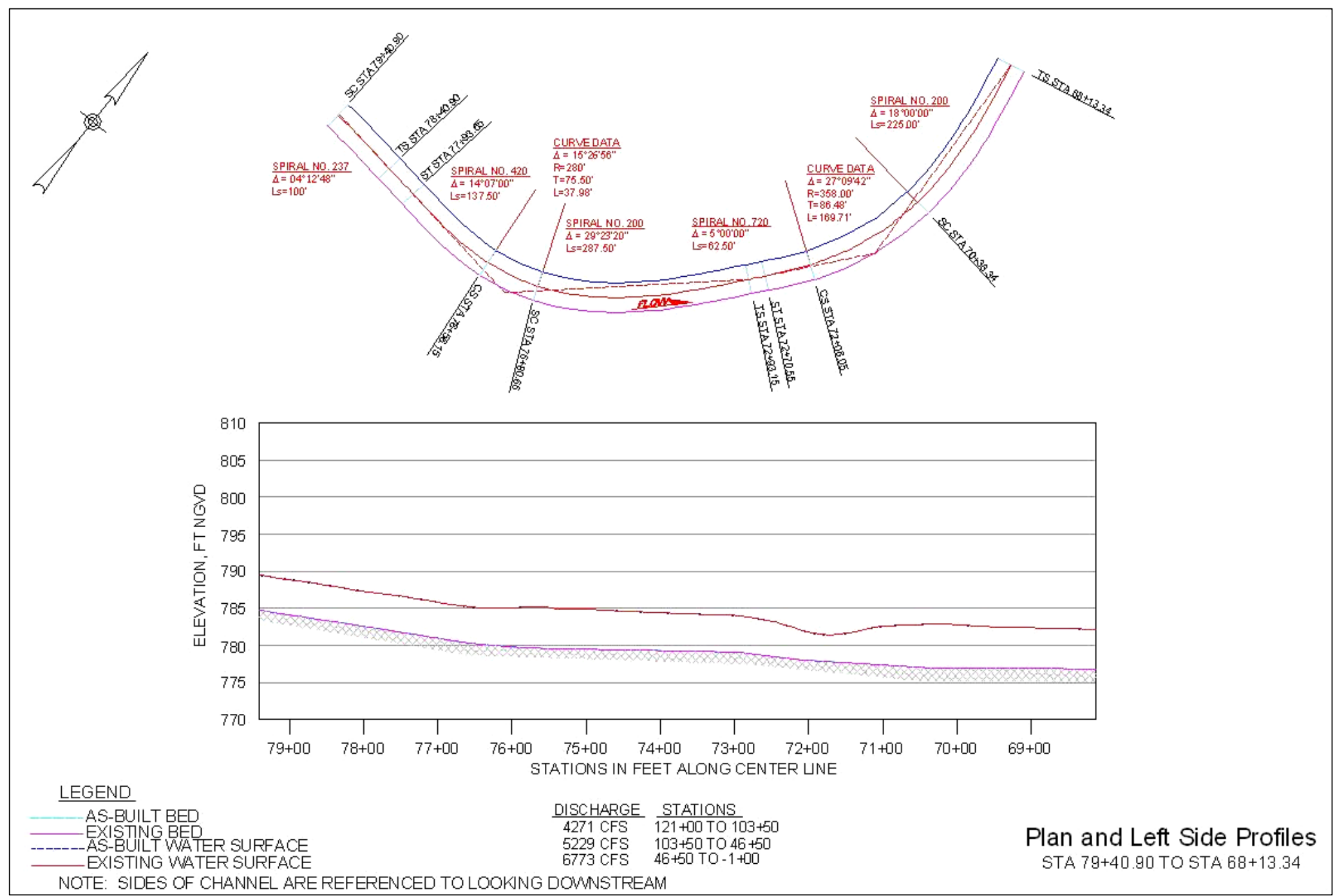

Figure 44. Existing and as-built conditions, plan and profiles, sta $79+40.9068+13.34$, left wall. 


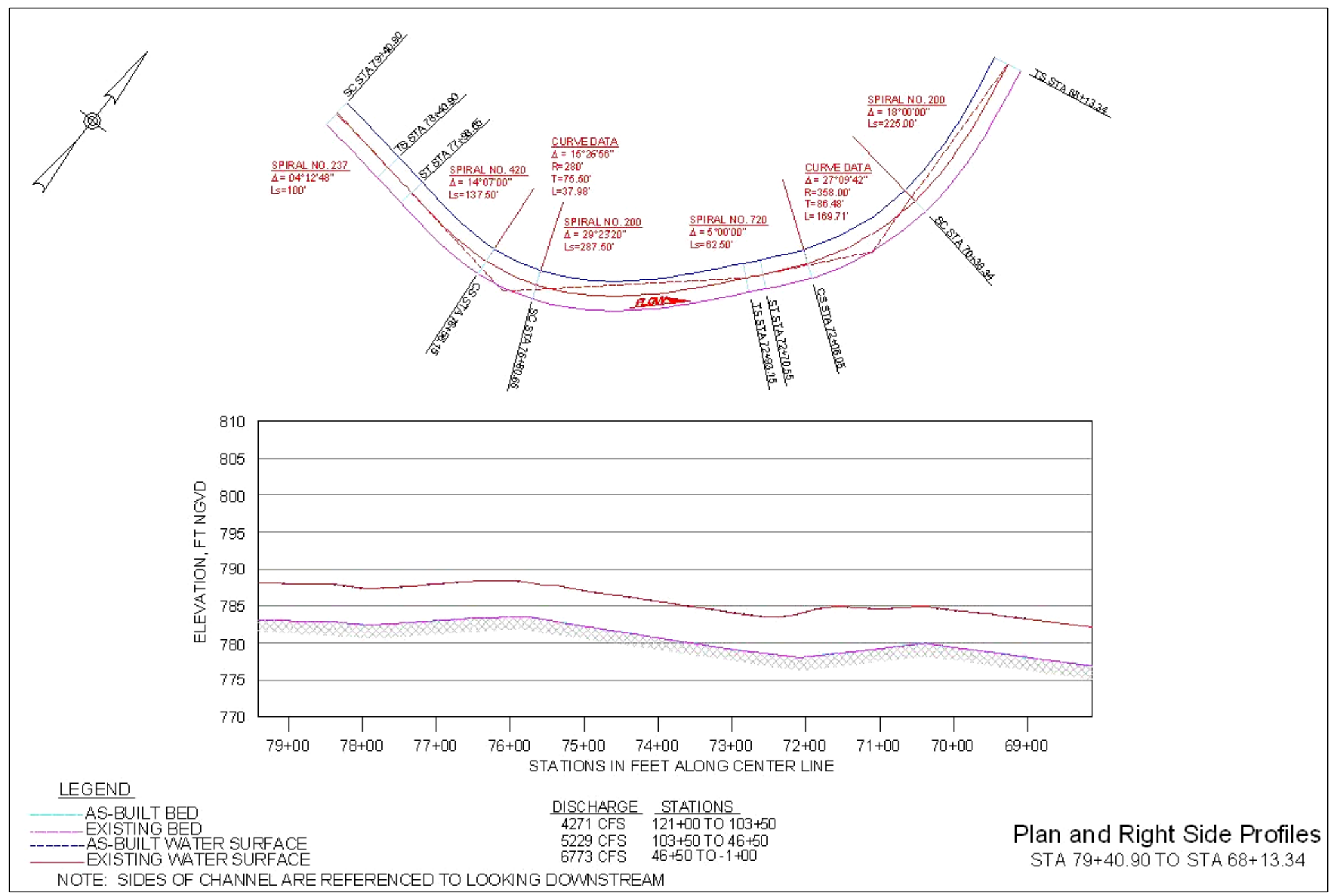

Figure 45. Existing and as-built conditions, plan and profiles, sta $79+40.9068+13.34$, left wall.

igure 45. Existing and as-built conditions, plan and profiles, sta $79+40.9068+13.34$, left wall. 


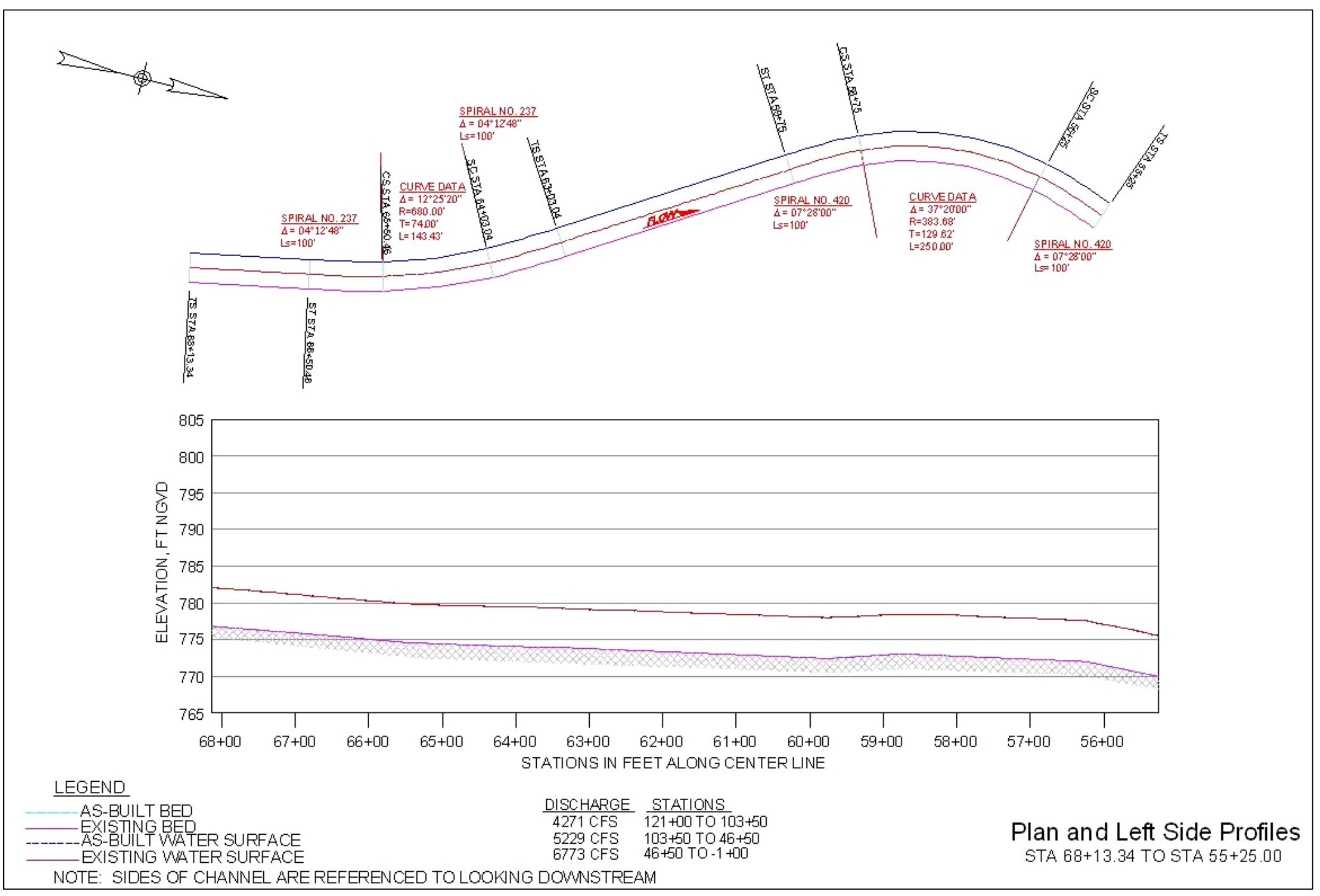

Figure 46. Existing and as-built conditions, plan and profiles, sta $68+13.34$ to $55+25.00$, left wall. 


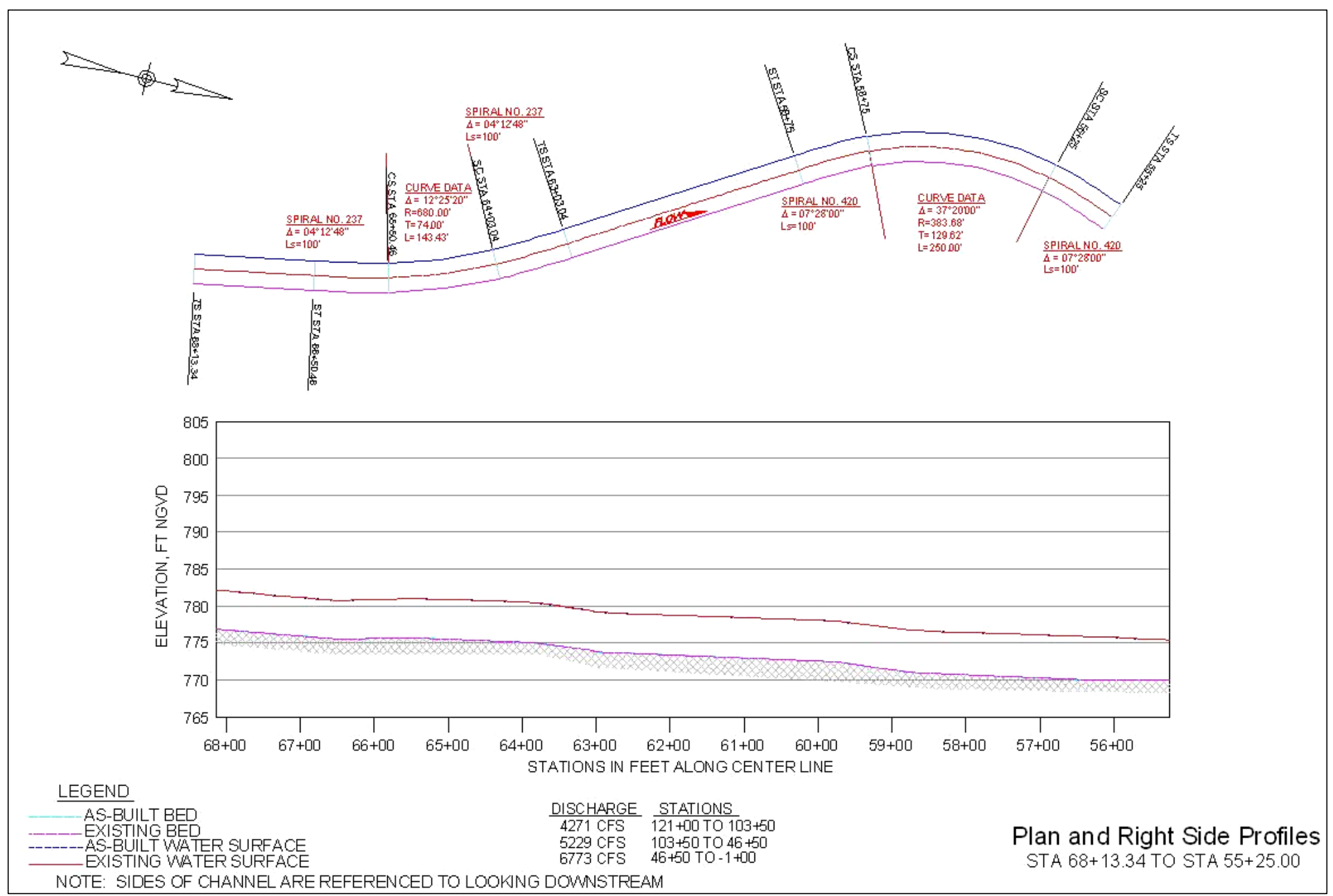

Figure 47. Existing and as-built conditions, plan and profiles, sta $68+13.34$ to $55+25.00$, right wall. 


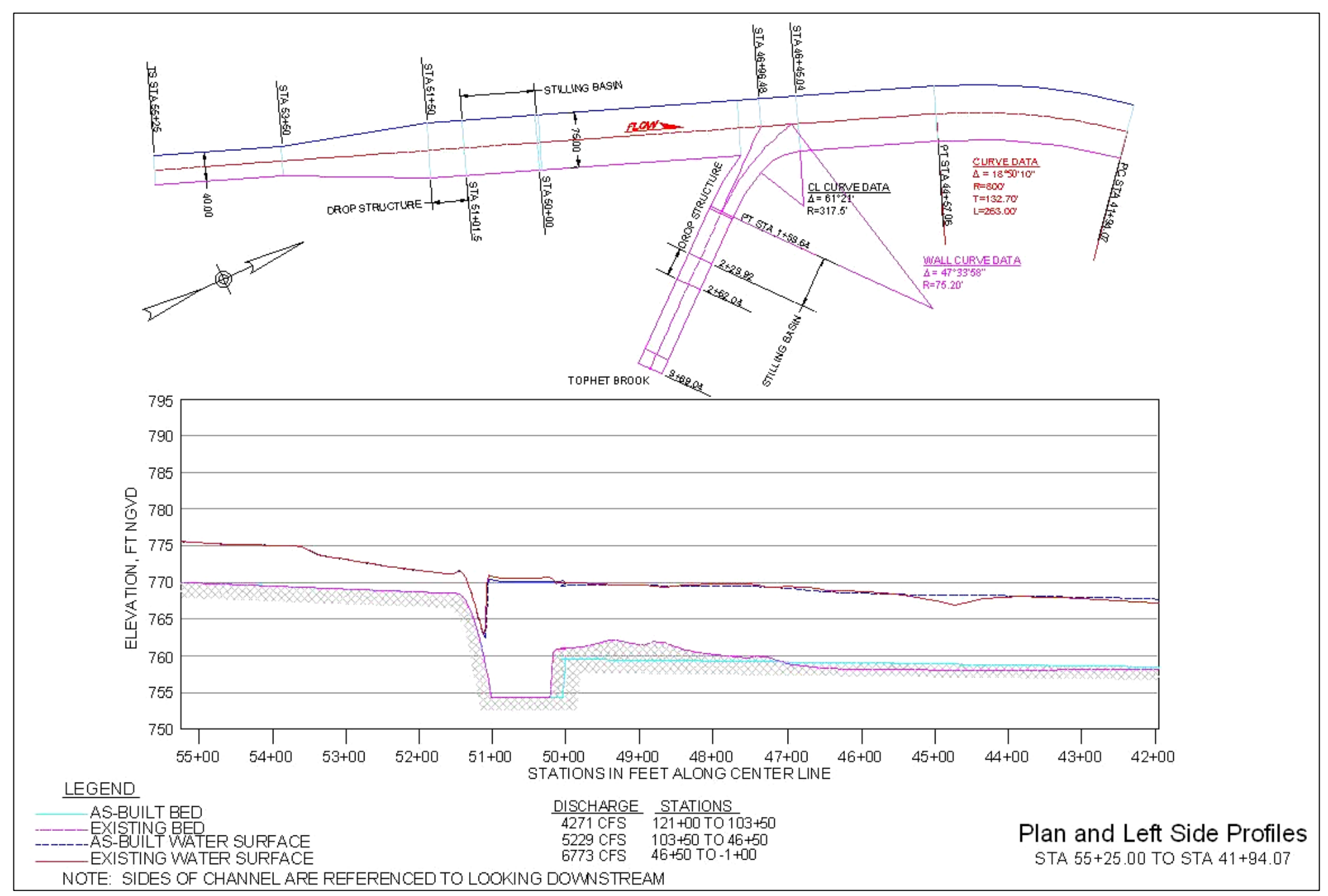

Figure 48. Existing and as-built conditions, plan and profiles, sta 55+25.00 to 41+94.07, left wall. 


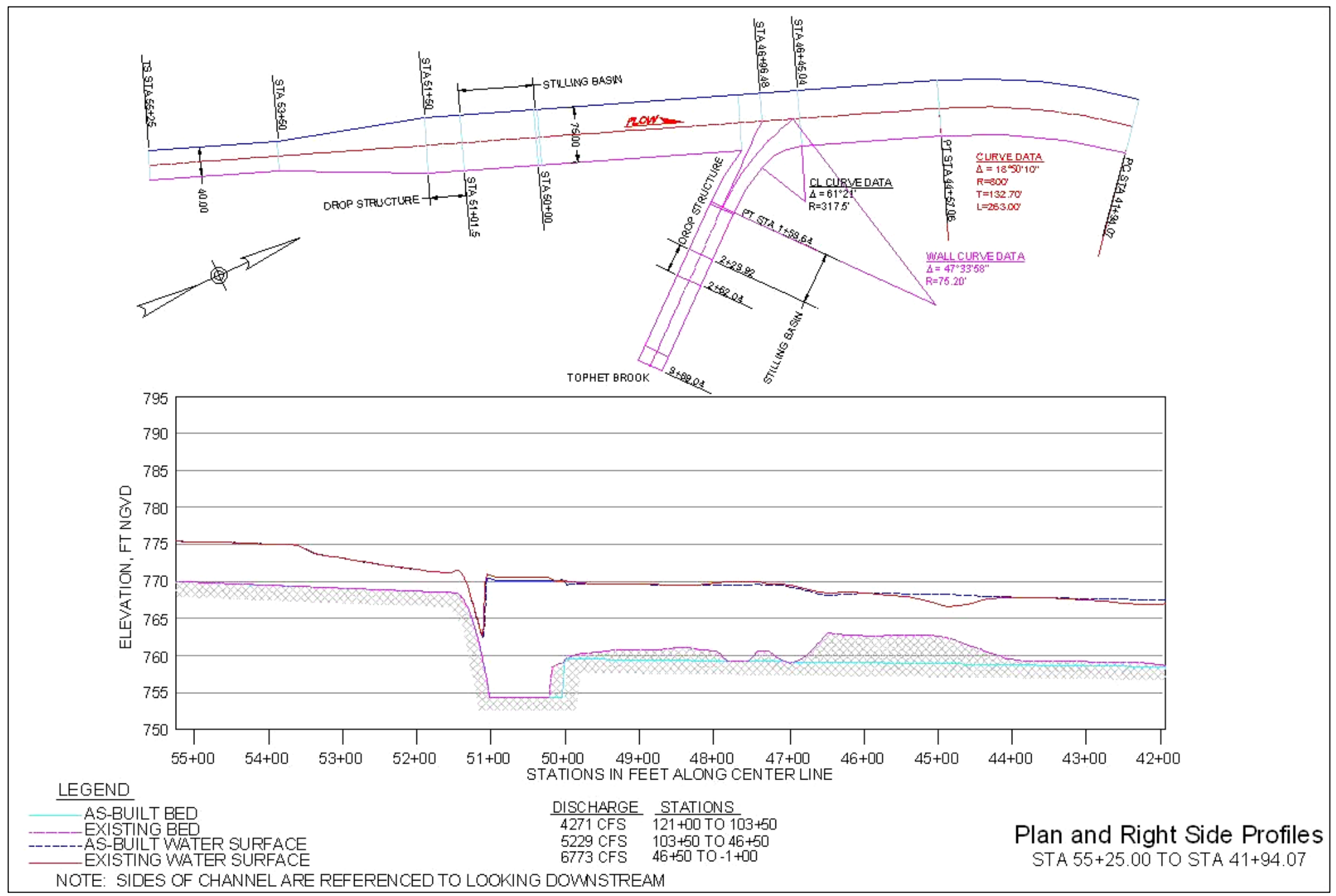

Figure 49. Existing and as-built conditions, plan and profiles, sta $55+25.00$ to $41+94.07$, right wall. 


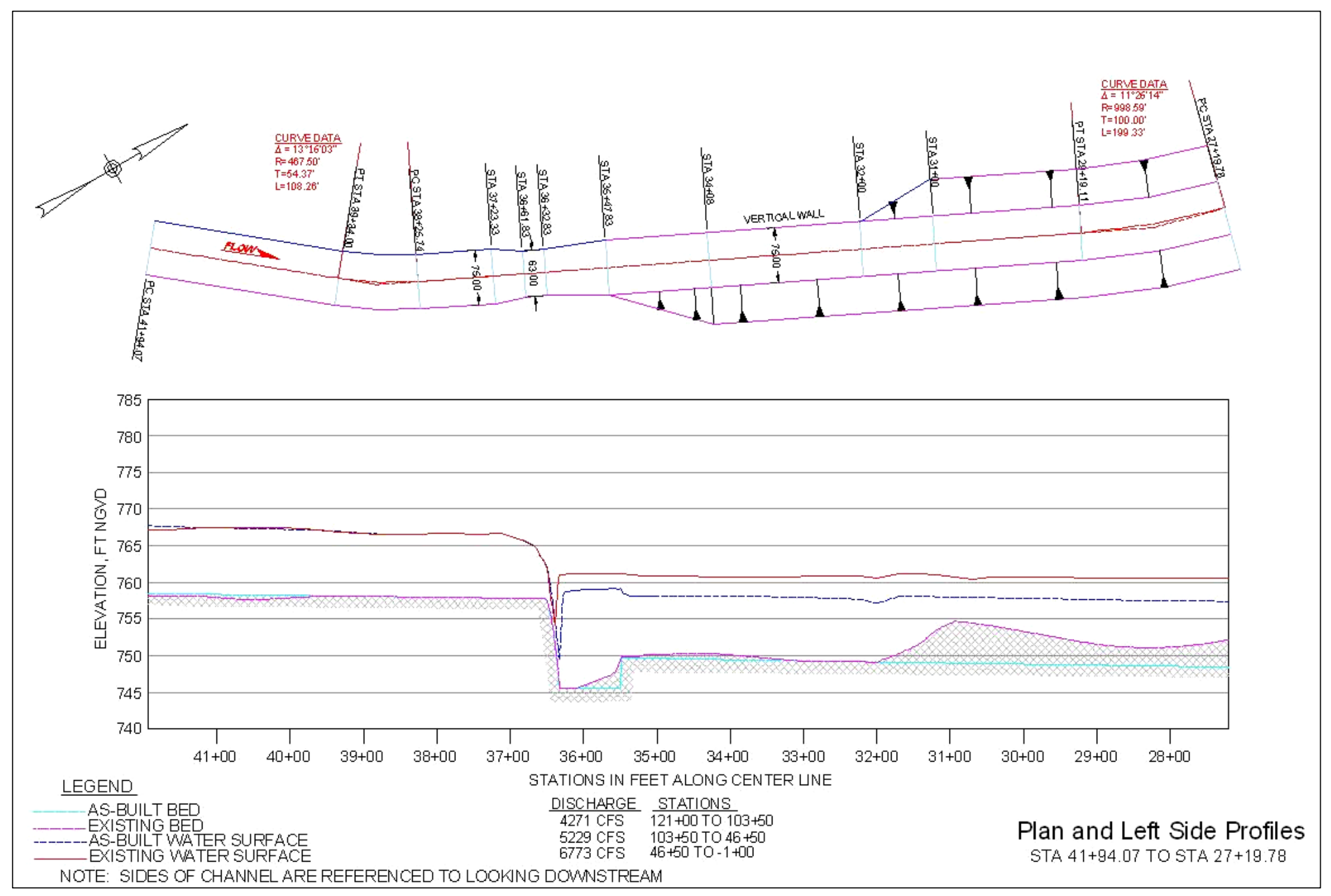

Figure 50. Existing and as-built conditions, plan and profiles, sta $41+94.07$ to $27+19.78$, left wall. 


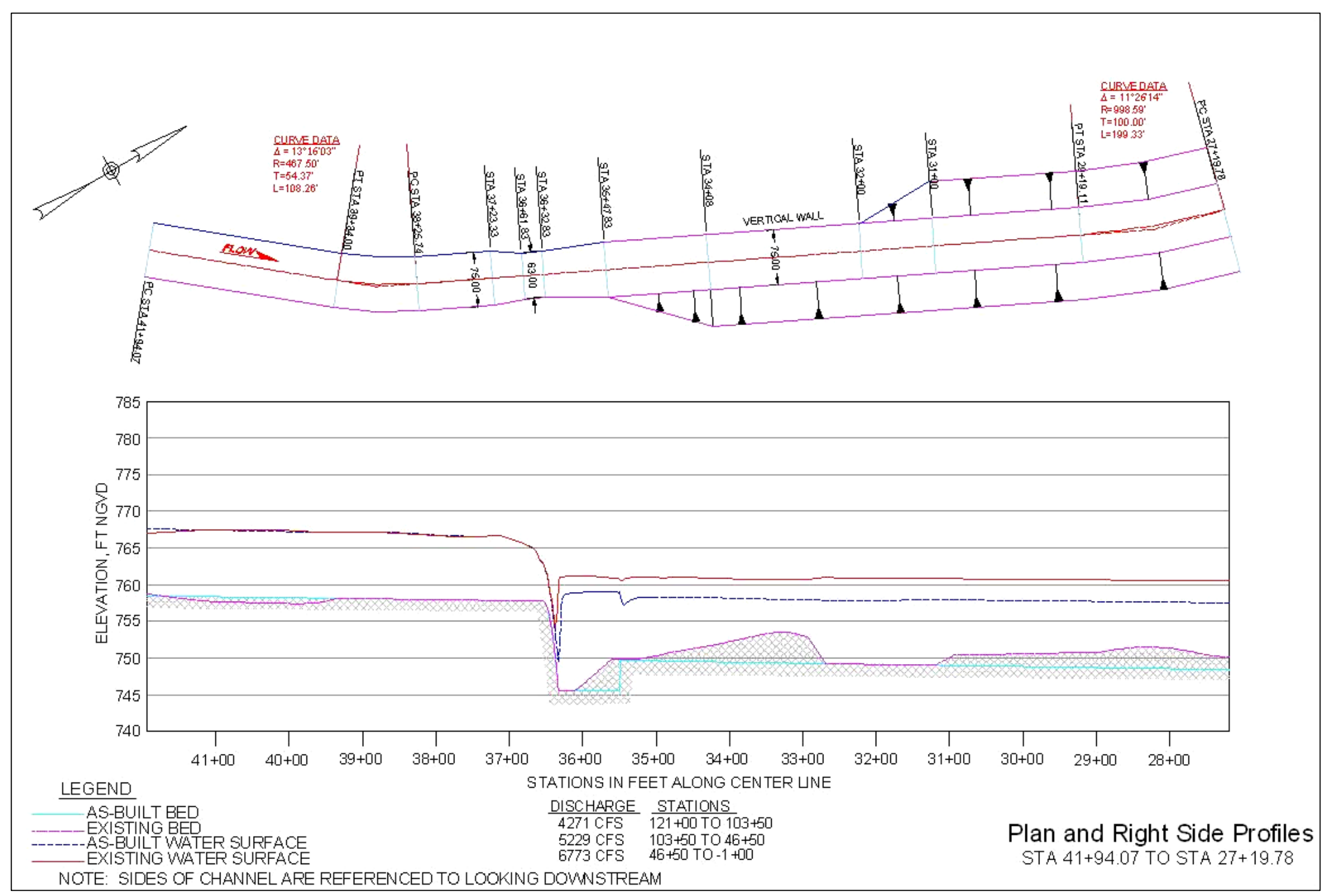

Figure 51. Existing and as-built conditions, plan and profiles, sta $41+94.07$ to $27+19.78$, right wall. 


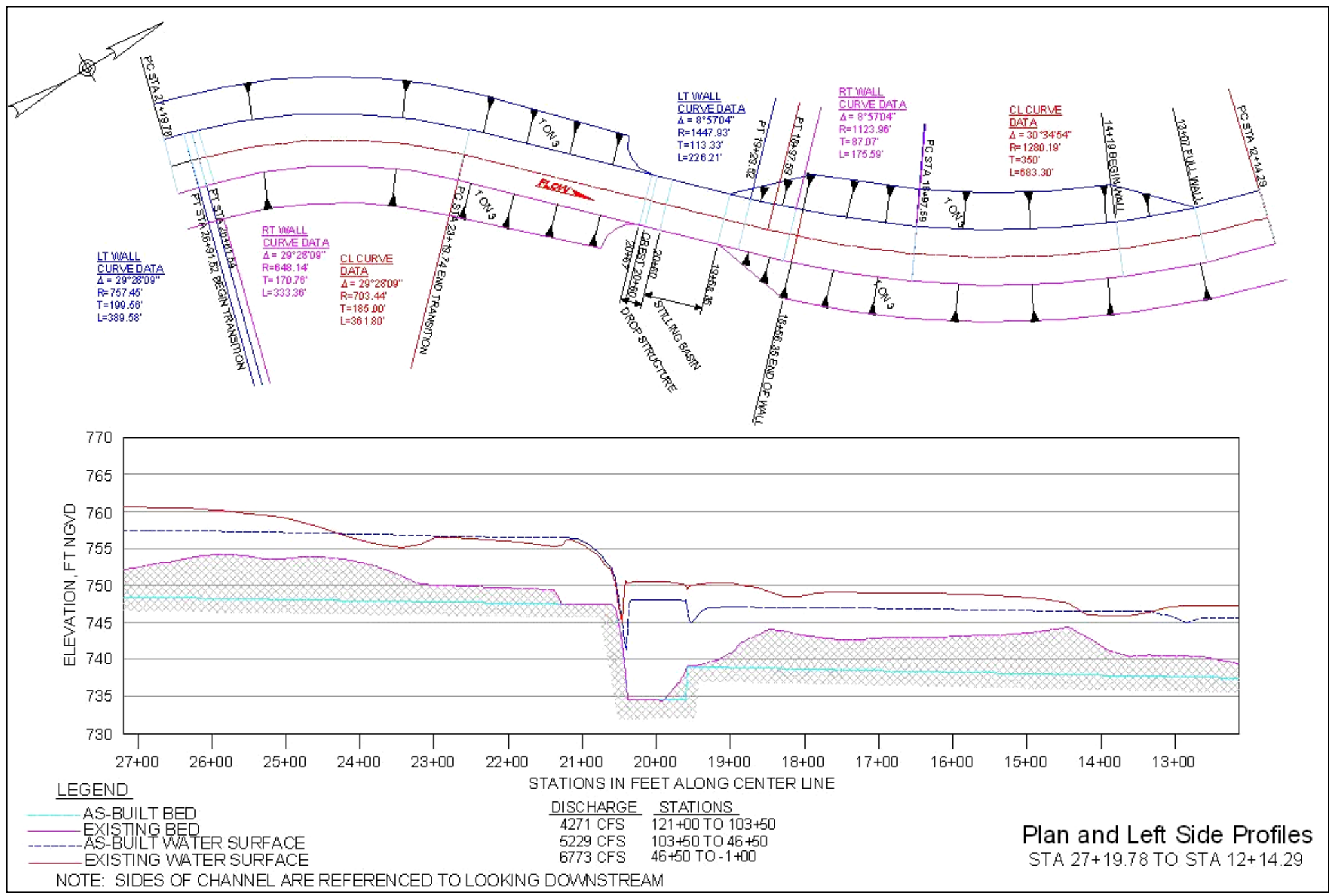

Figure 52. Existing and as-built conditions, plan and profiles, sta $27+19.78$ to $12+14.29$, left wall. 


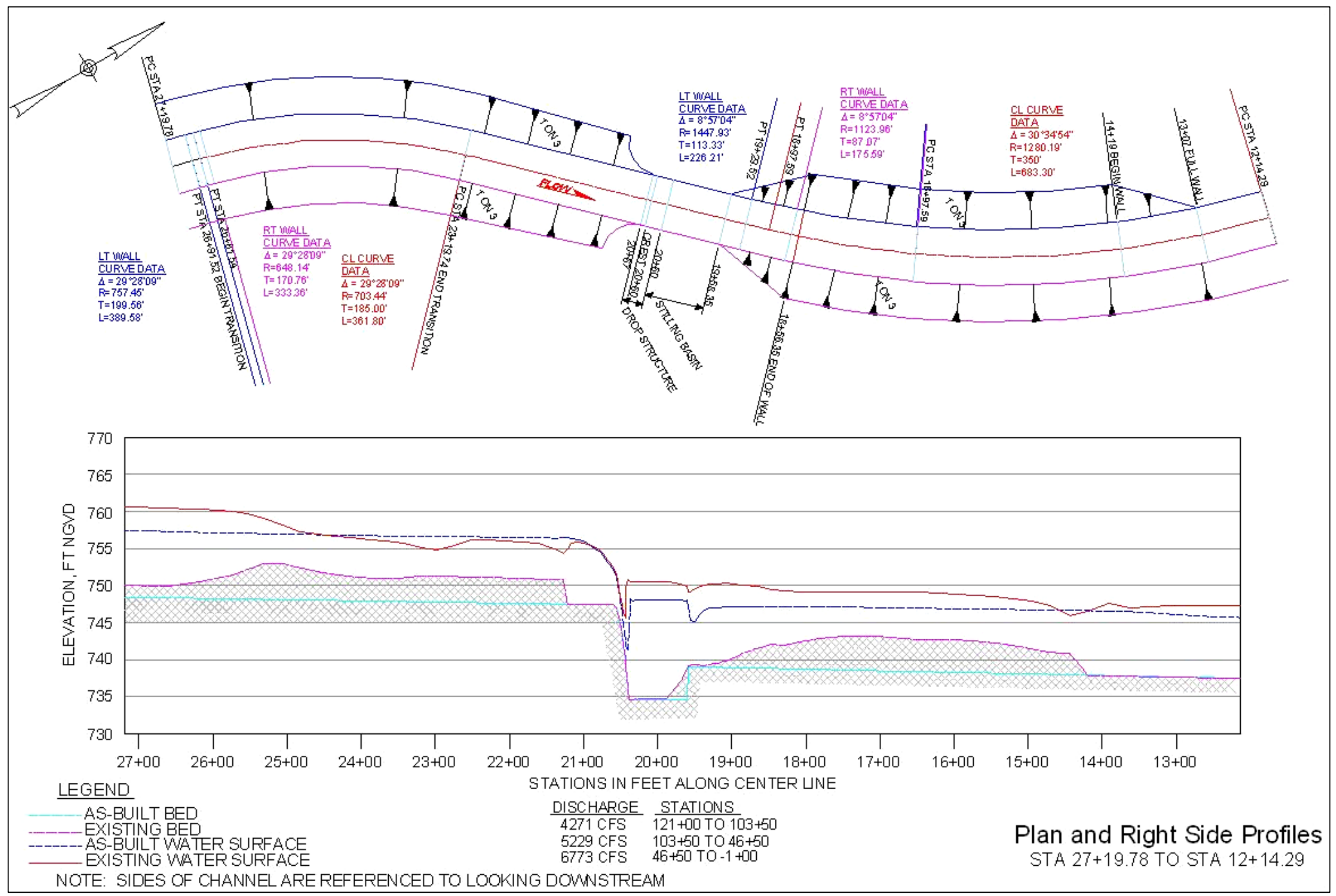

Figure 53. Existing and as-built conditions, plan and profiles, sta $27+19.78$ to $12+14.29$, right wall. 


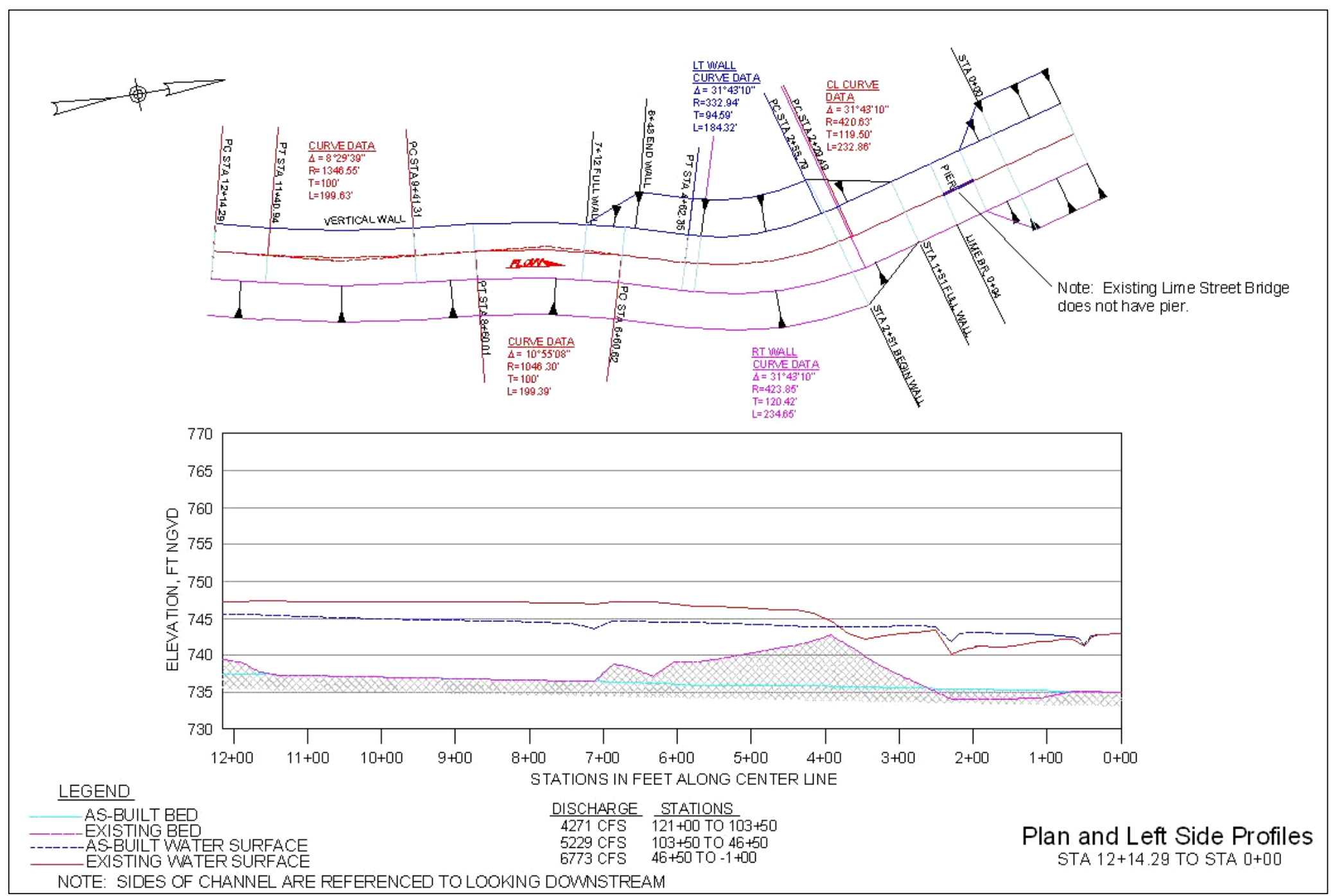

Figure 54. Existing and as-built conditions, plan and profiles, sta $12+14.29$ to $0+00$, left wall. 


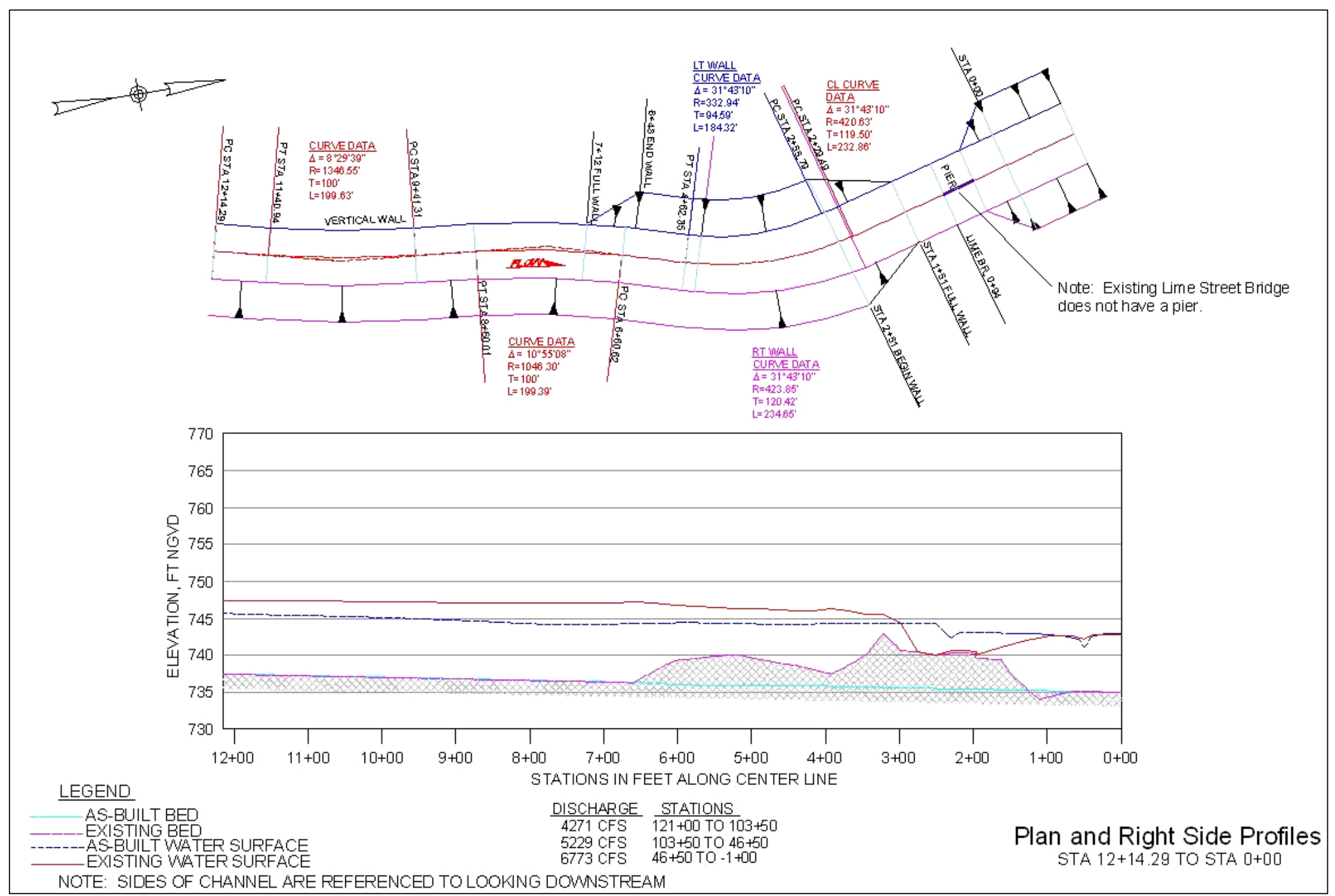

Figure 55. Existing and as-built conditions, plan and profiles, sta $12+14.29$ to $0+00$, right wall. 


\section{Restoration Models}

Chapter 1 explained that the upstream reach of the project consists of a rectangular concrete channel, whereas the downstream reach is a trapezoidal channel with riprap protection. The trapezoidal reach is a manmade earth channel that has a base width that varies from 65 to $90 \mathrm{ft}$. The Hoosic River flood-control project provides flood protection, but results in harsh conditions for fish and wildlife. However, a restoration plan has been proposed. The proposed plan, Section 1135 Ecosystem Restoration, is intended to restore fisheries and wildlife habitat to the Hoosic River project. Restoration ideas include reshaping of the trapezoidal riprap reach and modifying drop structures so that they are more conducive to fish passage. The idea is to add a winding low-flow channel within the trapezoidal section to create habitat. Pools and riffles would be formed with the low-flow channel.

The proposed modifications investigated in this report were changes to the downstream 5,000 ft of modeled reach. The proposed restoration modifications begin at the end sill of drop structure No. 2 (sta 50+00) and ends immediately upstream of the Lime Street Bridge (sta 1+50). Numerical flow models were used to evaluate the hydraulic performance of two restoration alternatives. The flow velocities and water-surface elevations resulting from the proposed modifications were computed and compared with those that the as-built design produced.

A temperature model was used by the NAN to size the low-flow channel. These results indicated that a 16 -ft-wide low-flow channel should be incorporated into the restoration plans. Therefore, a $16-\mathrm{ft}$ wide by 2- to $2.5-\mathrm{ft}-$ deep low-flow channel was added to the "Water Resources Development Project Section 1135 Ecosystem Restoration, Stream Temperature Alternative" designs provided by the NAN. The low-flow channel, which had $1 \mathrm{~V}$ on $3 \mathrm{H}$ side slopes, was cut into the existing bed. The low-flow channel meandered from the right- to the left-side-slope toe. The existing conditions model, discussed in the previous chapter, was modified to construct models of the two proposed plans titled Alternative A and Alternative B. 


\section{Alternative A model}

\section{Geometry and computational mesh}

The Alternative A restoration design had a meandering low-flow channel coupled with riffles and pools at the crossings and bends. Alternative A called for replacing the existing drop structures with ramps created by filling in the drops with stones. These ramps had an incised channel which would contain the daily low flows. These modifications to the existing drop structures were minimal. The existing concrete would be covered with stacked stones forming a sloped transition across the drop structure. Each rock ramp was $240 \mathrm{ft}$ long and placed on a 3-percent slope. These rock ramps were used to fill in drop structures No. 3 (crest at sta $36+54$ ) and No. 4 (crest at sta 20+67). The typical modification is shown in Figure 56 .

The computational mesh used to simulate the design discharge in the Alternative A channel is shown in Figure 57. The mesh had 10,496 nodes and 18,807 elements. The number of nodes and elements was less than that used to describe the as-built or existing conditions models because the rock ramps did not require as much resolution as the drop structures of

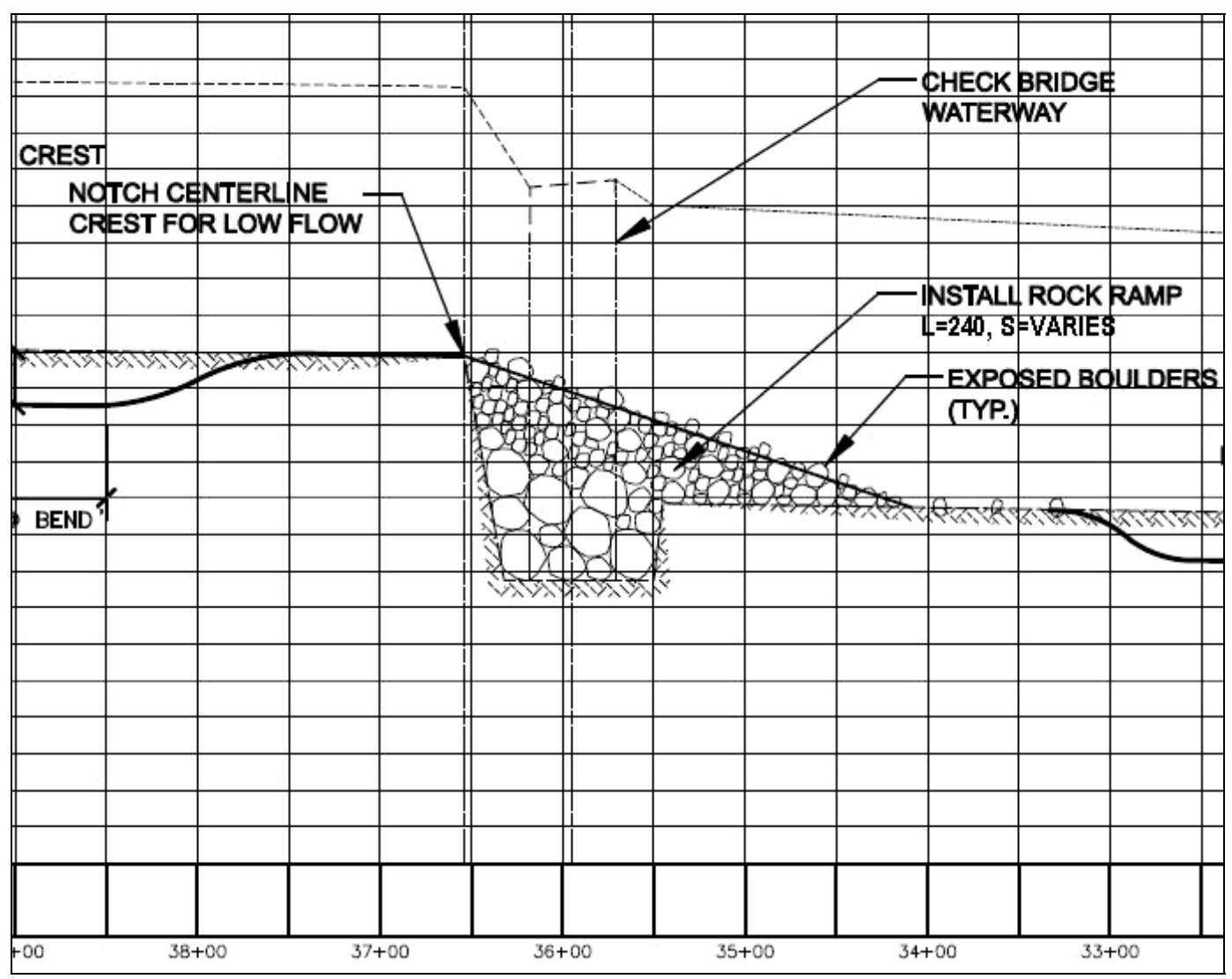

Figure 56. Typical drop structure modification used in the restoration alternatives. 


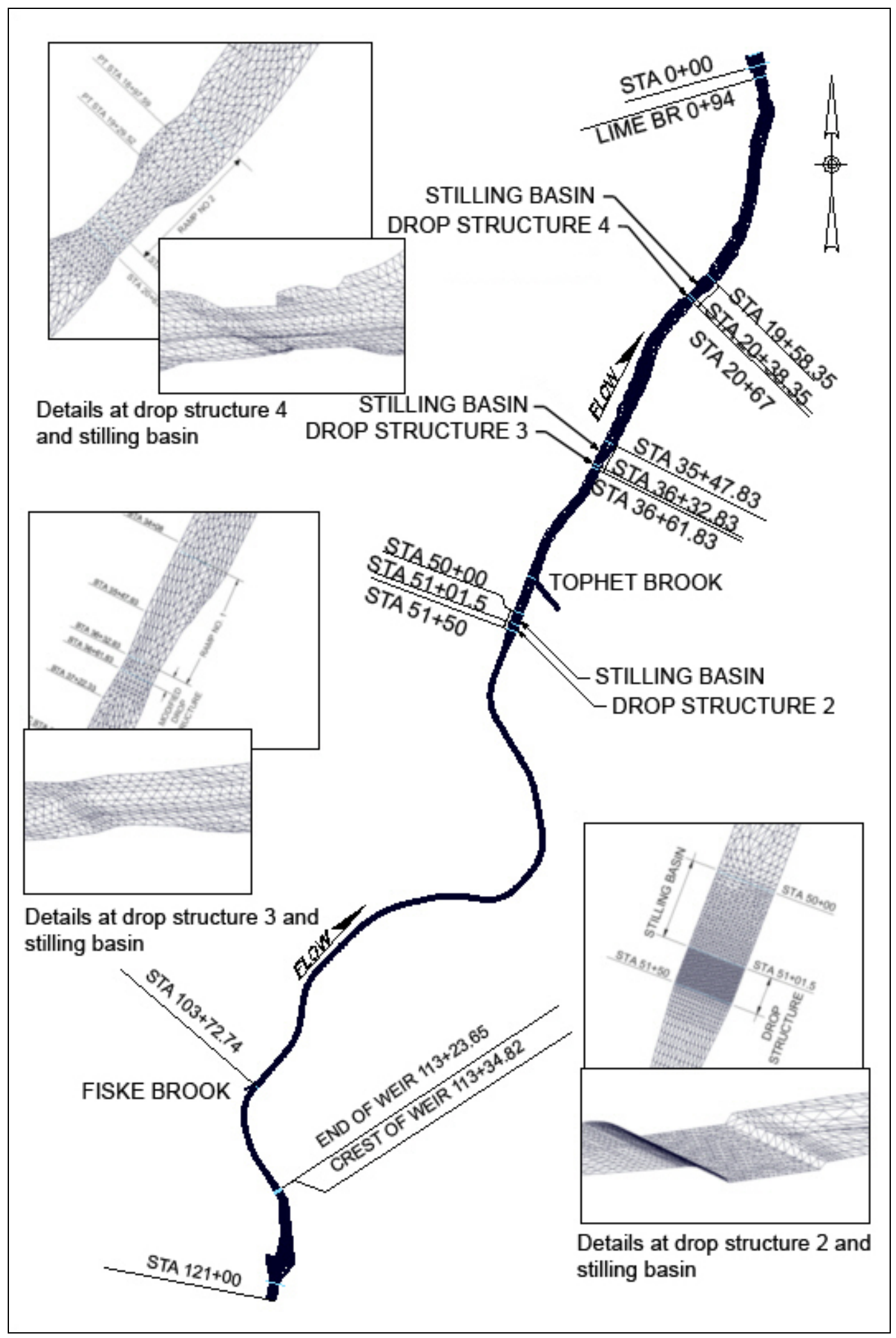

Figure 57. Alternative A, computational mesh details. 
the previous models. The Alternative A model included the concrete highvelocity channel upstream of the modified reach because the boundary conditions were established and the finite element mesh was already constructed. It was desirable to have models of the entire reach for each configuration; the as-built, existing, Alternative A, and Alternative B, in case future studies investigate discharges and/or conditions other than the ones described in this report.

Element sizes varied throughout the domain, but the primary reaches of the trapezoidal channel were described with elements that were about $20 \mathrm{ft}$ long by about $8 \mathrm{ft}$ wide. The width of the low-flow channel was usually described using 2 elements. The side slopes of the low-flow channel were described using one element on each side of the channel. The channel side slopes were described using similar sized elements. The effects of the cobble lateral bars and riffles were modeled with the elements' roughness.

The modeling process consisted of time marching from initial conditions of a level water-surface and quiescent flow to steady state produced by the boundary conditions. The mesh was converged by advancing in time from the original mesh's steady-state solution to a steady-state solution with two levels and three levels of adaption. The steady-state solution with two levels of adaption did not significantly differ from the three levels and therefore mesh convergence was obtained with two levels of adaption. The two levels of adaption were employed on the low-flow channel, the side slopes, the riffles, and the rock chutes at the drop structures. The automatic adaption process produced a mesh that had 10,904 nodes. This is 408 nodes more than the original mesh.

\section{Boundary conditions and model parameters}

The inflow discharges and tailwater elevation were those associated with the design discharge of 6,773 cfs (100-year frequency). The distribution of inflows is provided in Table 1 . These boundary conditions were identical to those used for the as-built and existing conditions models since the primary purpose of this study was to evaluate the affects that restoration modifications might have on the channel's ability to pass the design discharge. Simulations were run to evaluate design flow conditions resulting from various modifications to the lower end of the project. The model was used to determine what changes the restoration alterations would make to the water-surface elevations and flow distributions when the channel passed the design discharge. 
Roughness coefficients were assigned as with the previous models. A Manning's roughness coefficient, $n$, of 0.014 was used for concrete, 0.025 for the existing channel's gravel bed, 0.020 for the assumed sand bottomed low-flow channel, and o.o3o for the sloped grassy banks. The cobbles of the riffles and the stones of the fill slopes at the drop structures were assigned an $n$ value of 0.035 .

The flow at the model's outflow boundary was subcritical and therefore a tailwater boundary condition was set. A tailwater elevation at the outflow boundary was set to el 743.o. This is the water-surface elevation at the normal depth produced by the trapezoidal cross section with the design discharge of $6,773 \mathrm{cfs}$.

\section{Alternative A results}

Flow velocities at the two ramps that are currently drop structures, reached values near $19 \mathrm{fps}$. These ramps will require large size stone to resist erosion due to these high velocities. There was very little difference in the depth-averaged velocity at the low-flow channel as compared with the main channel. Although the velocity was slightly slower in the shallow area near the waterline, the flow distribution at the design discharge was generally uniform across a cross section. Velocity magnitude contours are shown in Figures 58-62. Along the length of the Alternative A, the flow was no less than $5 \mathrm{ft}$ deep and so the 2-ft added depth in the low-flow channel did not change the depth-averaged velocity distribution significantly.

Between the Tophet Brook confluence and drop structure No. 3 (crest at sta $36+54$ ), the depth-averaged velocity varied from about 9 fps to $12.5 \mathrm{fps}$ (Figures 58 and 59). The velocities through the reach from drop structure No. 3 to drop structure No. 4 varied from about $6 \mathrm{fps}$ at sta $31+50$ to $16 \mathrm{fps}$ near sta 24+0o (Figures 59 and 60). Downstream of drop structure No. 4 the largest velocity is about 12.5 fps near sta $3+00$ (Figures 60-62).

Alternative A produced a water-surface elevation along the reach between the Tophet Brook confluence and drop structure No. 3 that was about $1 \mathrm{ft}$ lower than that produced with the as-built design (Figures 63-66). However, downstream of sta $36+00$, the profiles in Figures $65-70$ show that Alternative A resulted in water-surface elevations that were as large as $2.5 \mathrm{ft}$ higher than the as-built conditions. 


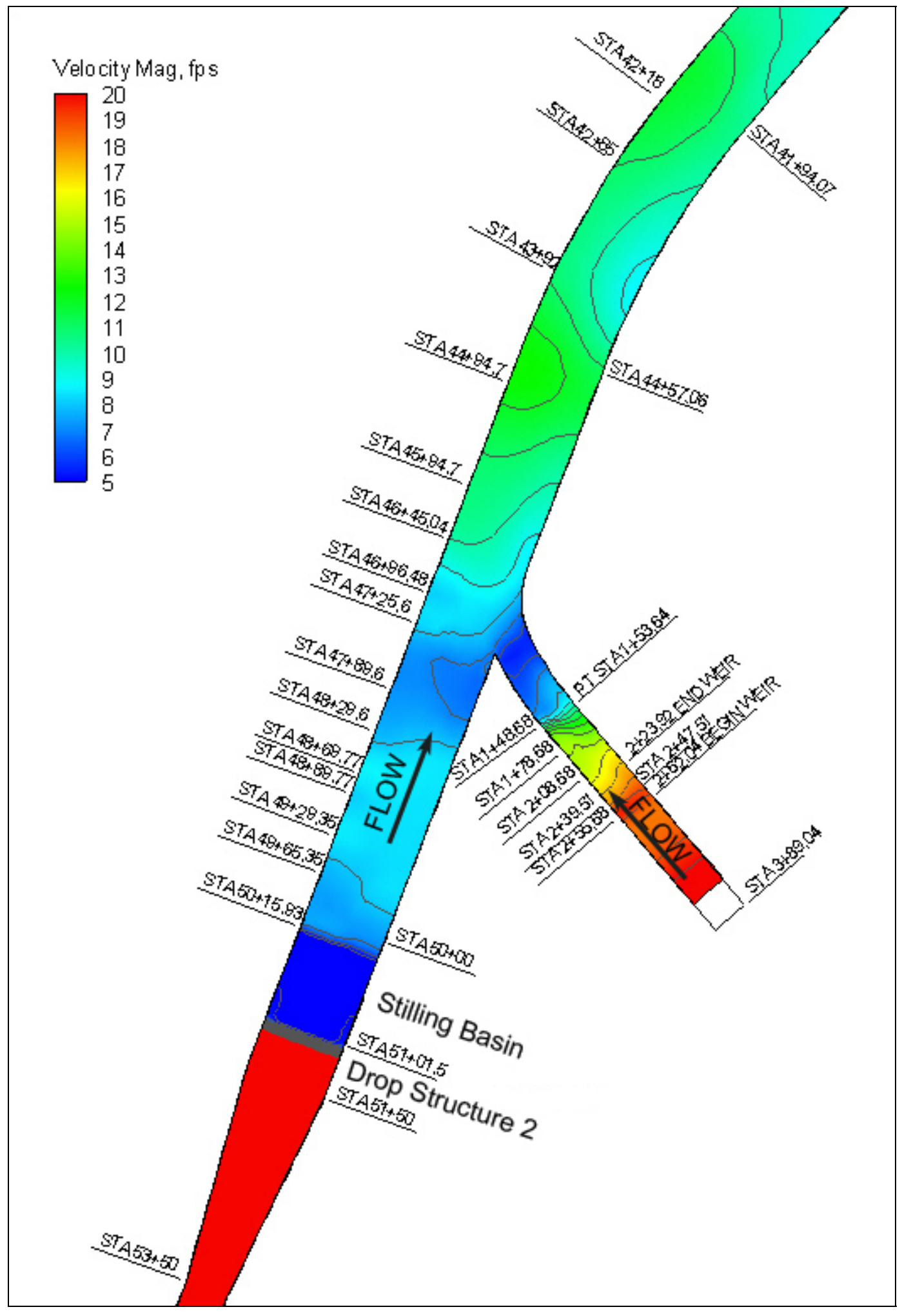

Figure 58 . Alternative A, velocity magnitude contours, sta $53+50$ to $41+94.07$. 


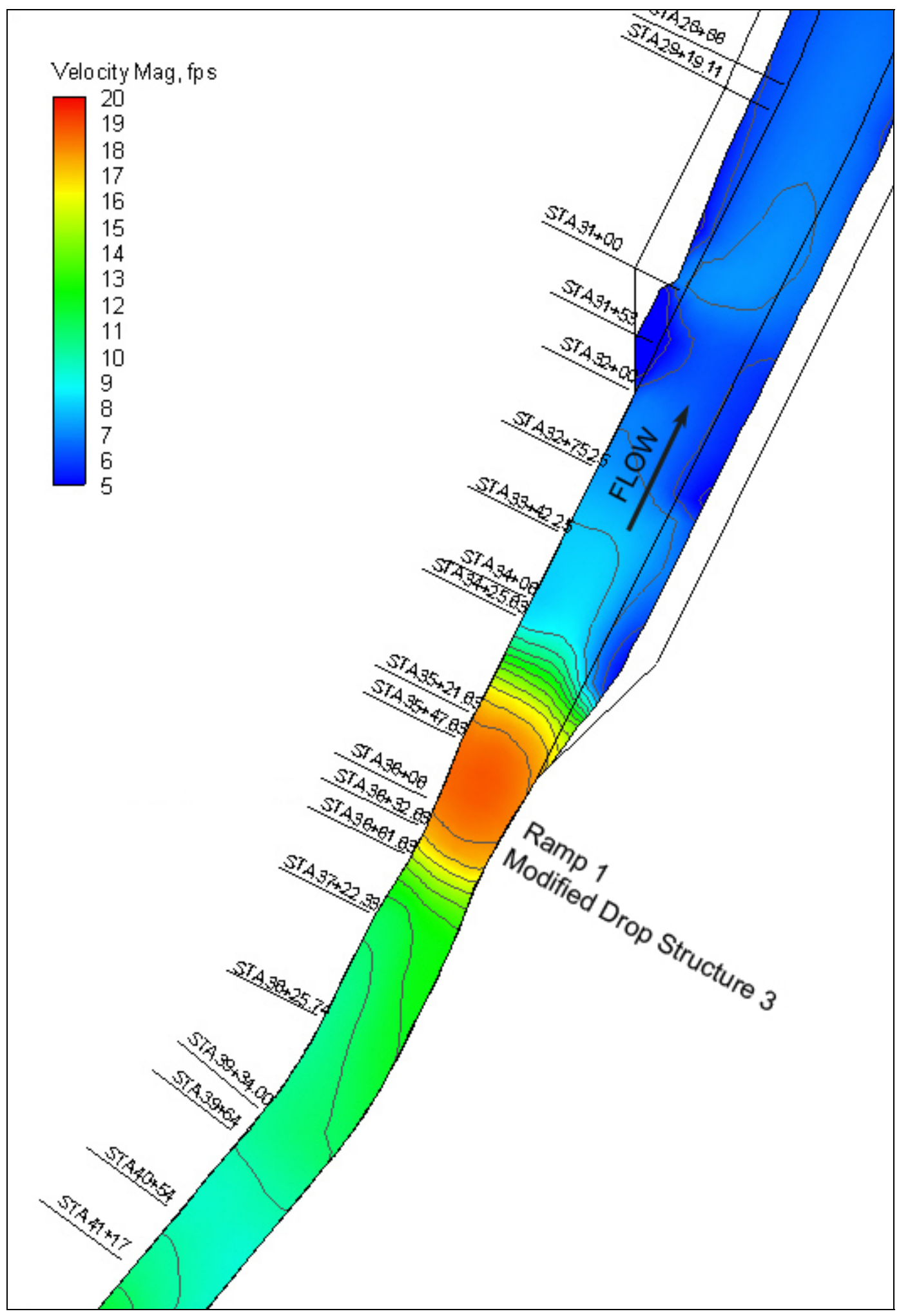

Figure 59. Alternative A, velocity magnitude contours, sta $41+17$ to $29+11$. 


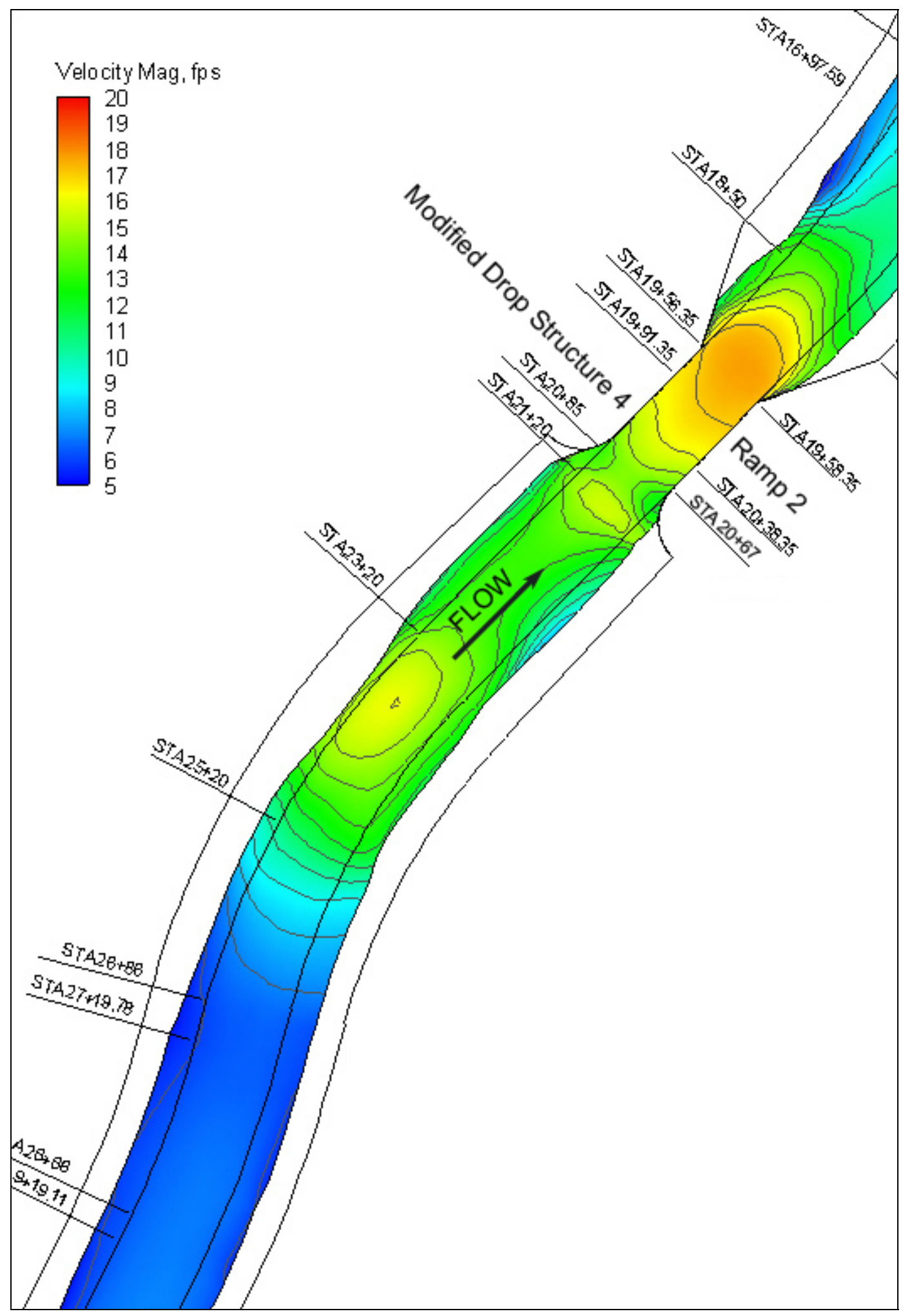

Figure 60 . Alternative A, velocity magnitude contours, sta $29+11$ to $17+50$. 


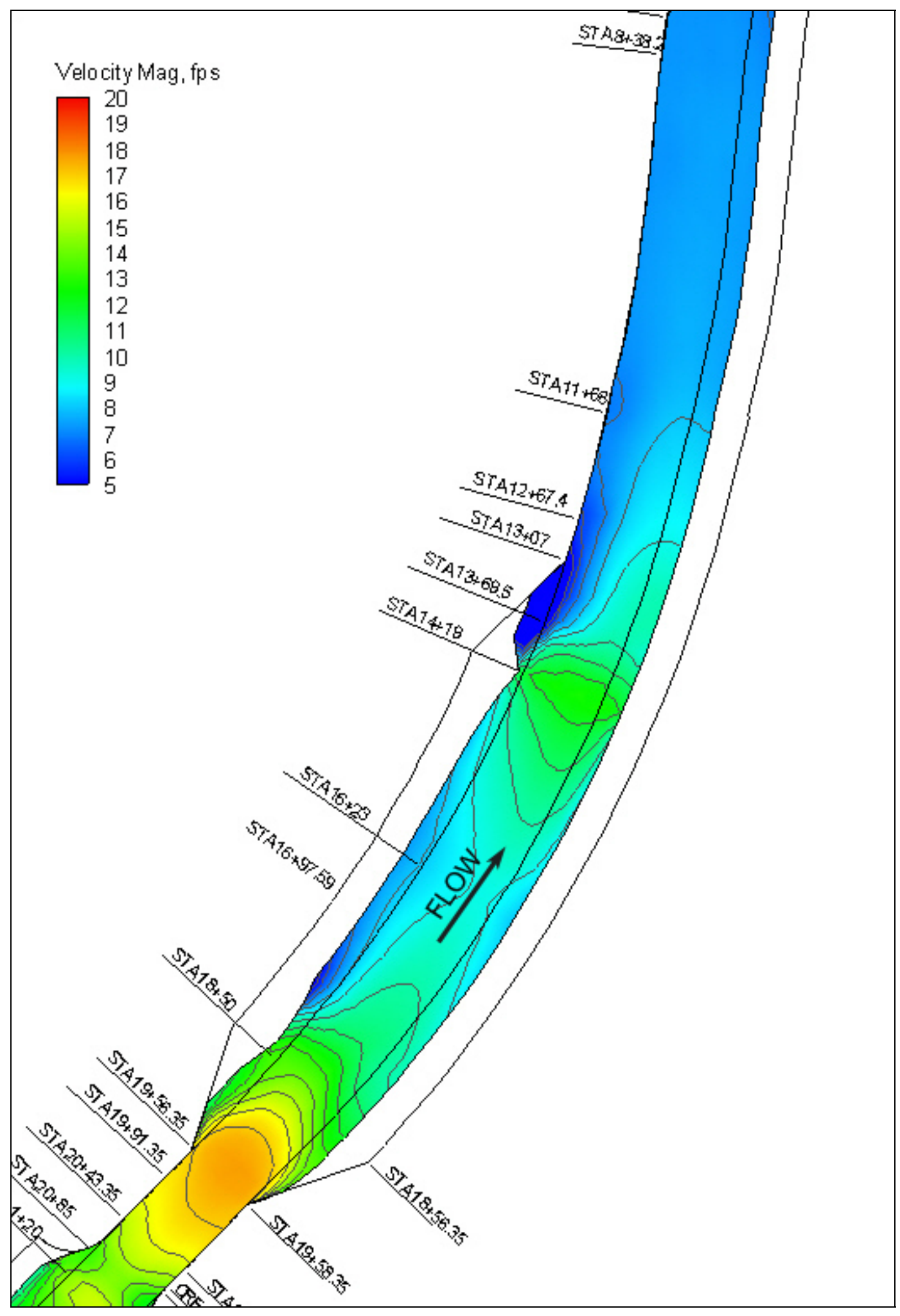

Figure 61 . Alternative A, velocity magnitude contours, sta $20+67$ to $8+38.2$. 
Velocity Mag, fps

20
19
18
17
16
15
14
13
12
11
10
9
8
7
6
5

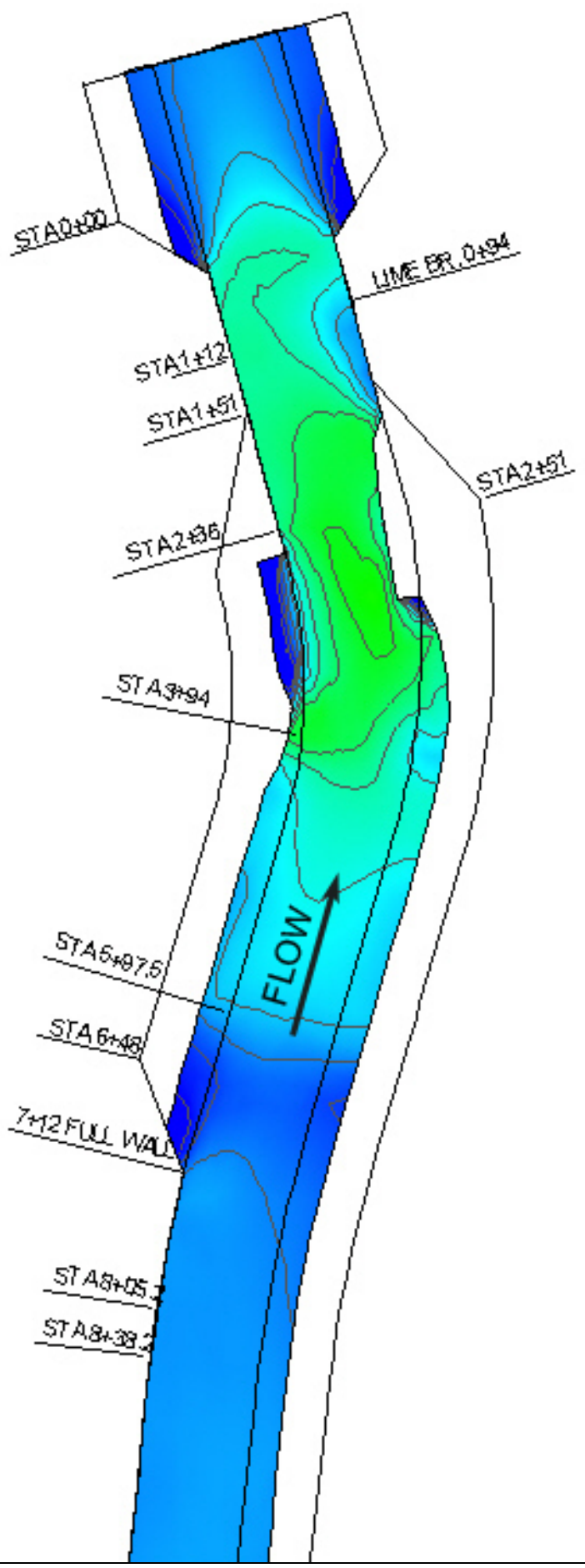

Figure 62. Alternative A, velocity magnitude contours, sta $39+00$ to $-1+00$. 


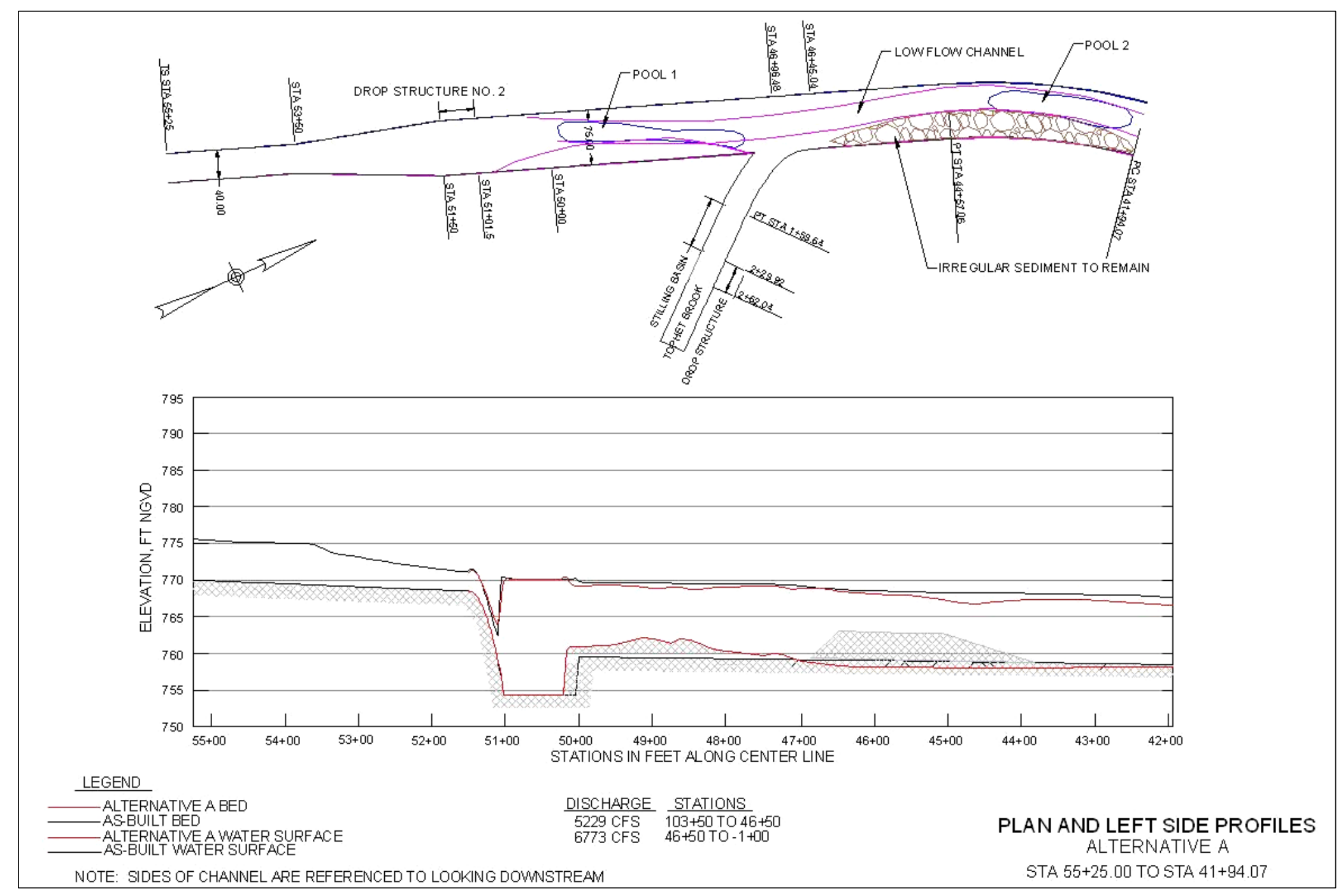

Figure 63. Alternative A, plan and profiles, sta $55+25.00$ to $41+94.07$, left wall. 


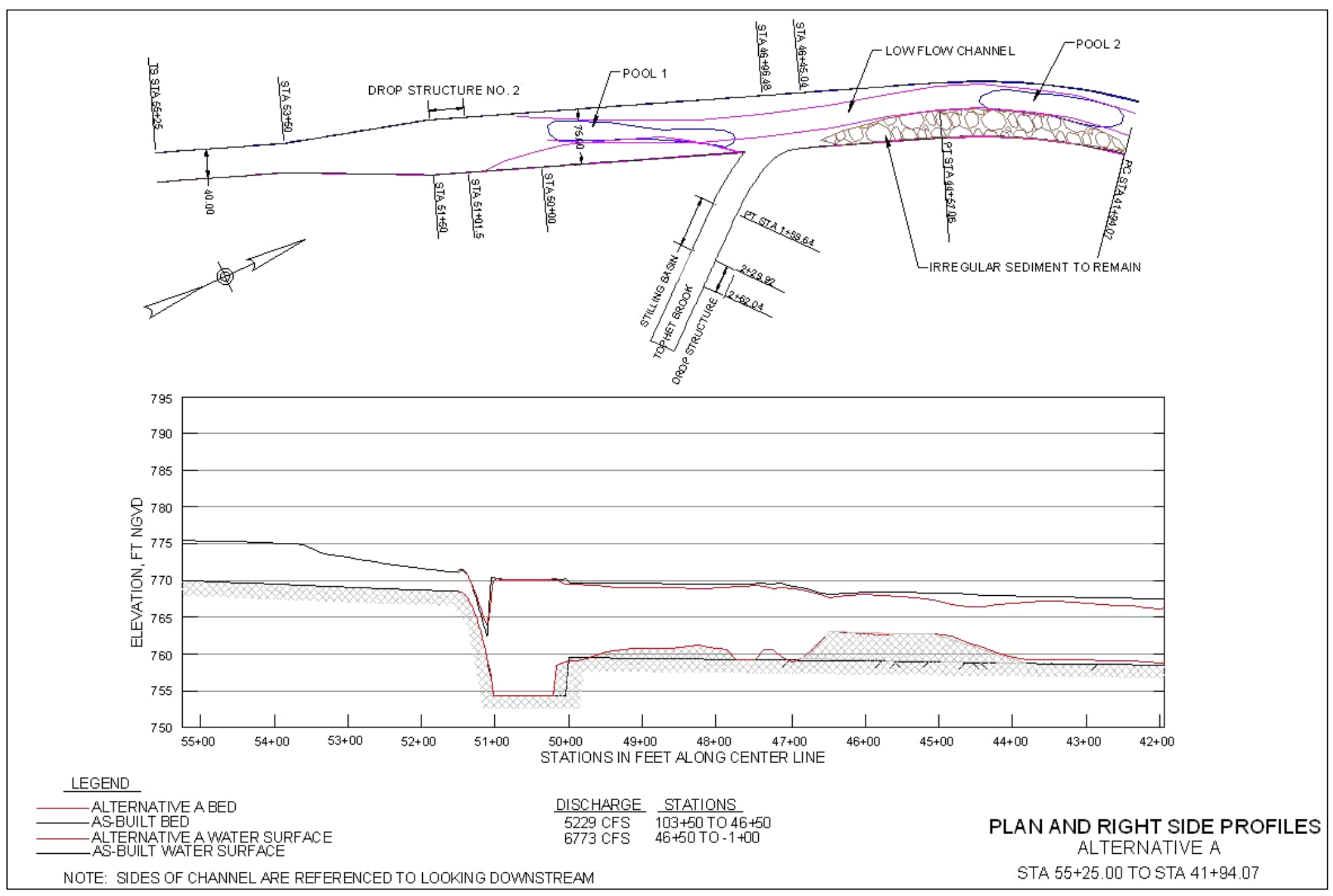

Figure 64. Alternative A, plan and profiles, sta $55+25.00$ to $41+94.07$, right wall. 


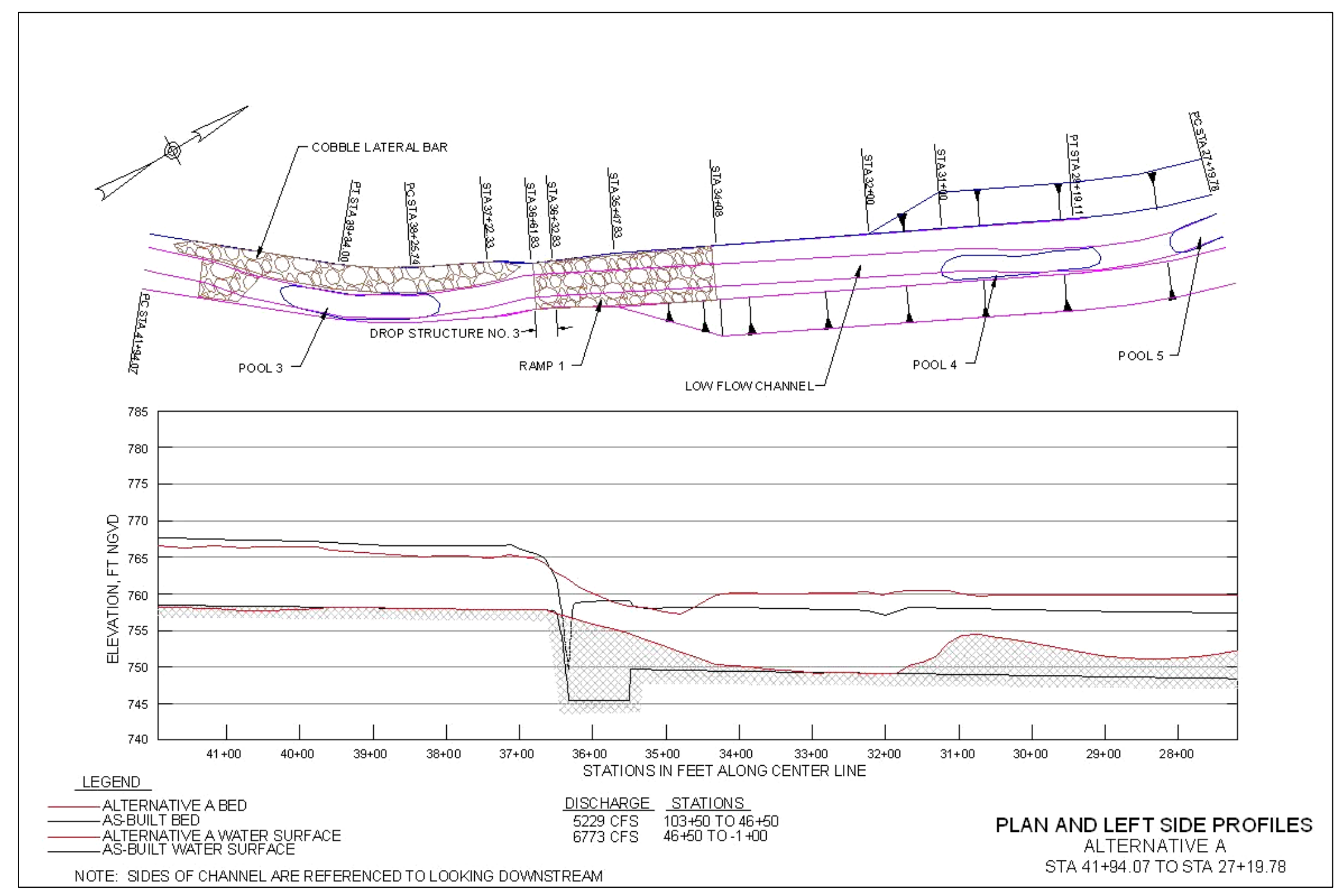

Figure 65. Alternative A, plan and profiles, sta $41+94.07$ to $27+19.78$, left wall. 


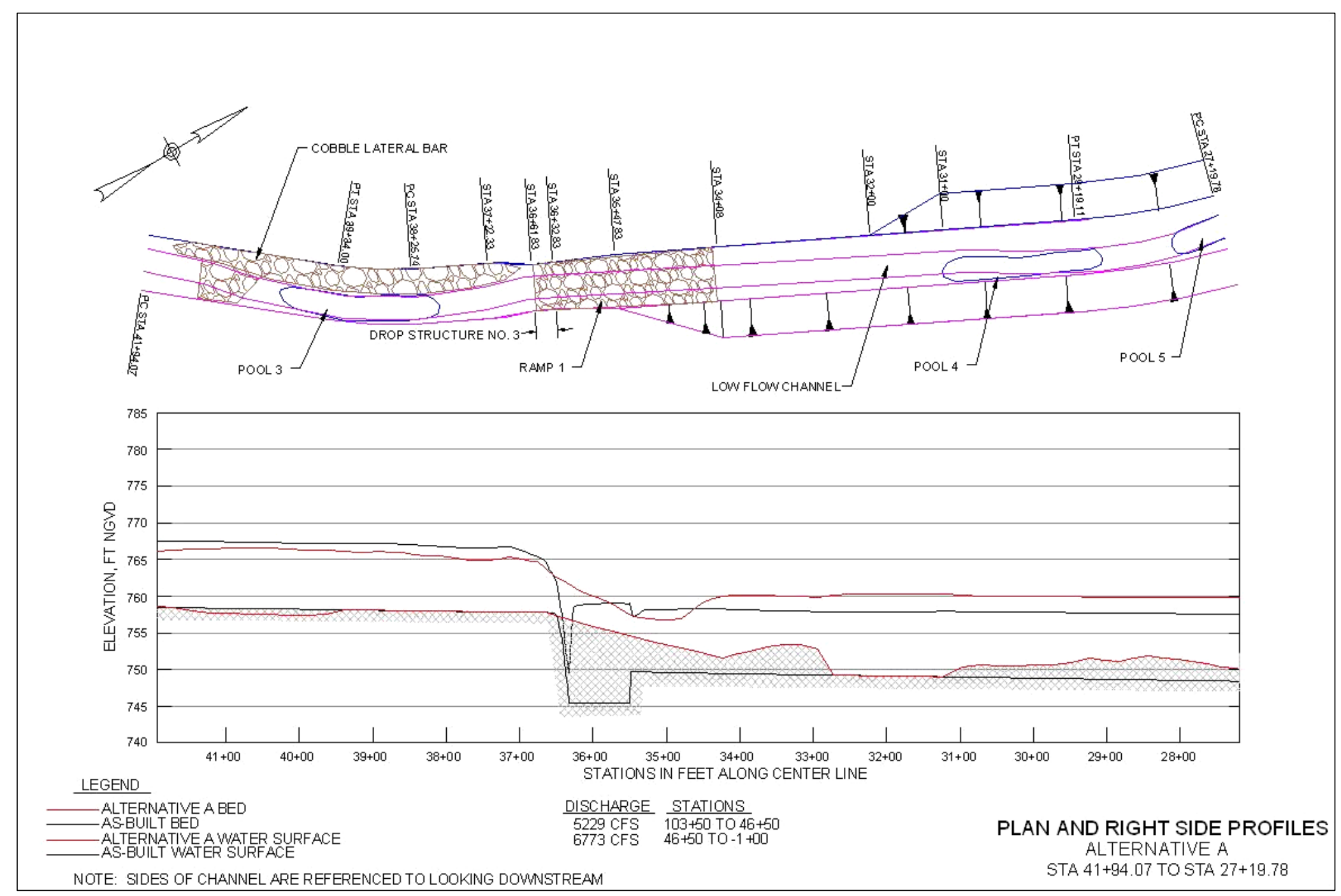

Figure 66 . Alternative A, plan and profiles, sta $41+94.07$ to $27+19.78$, right wall. 


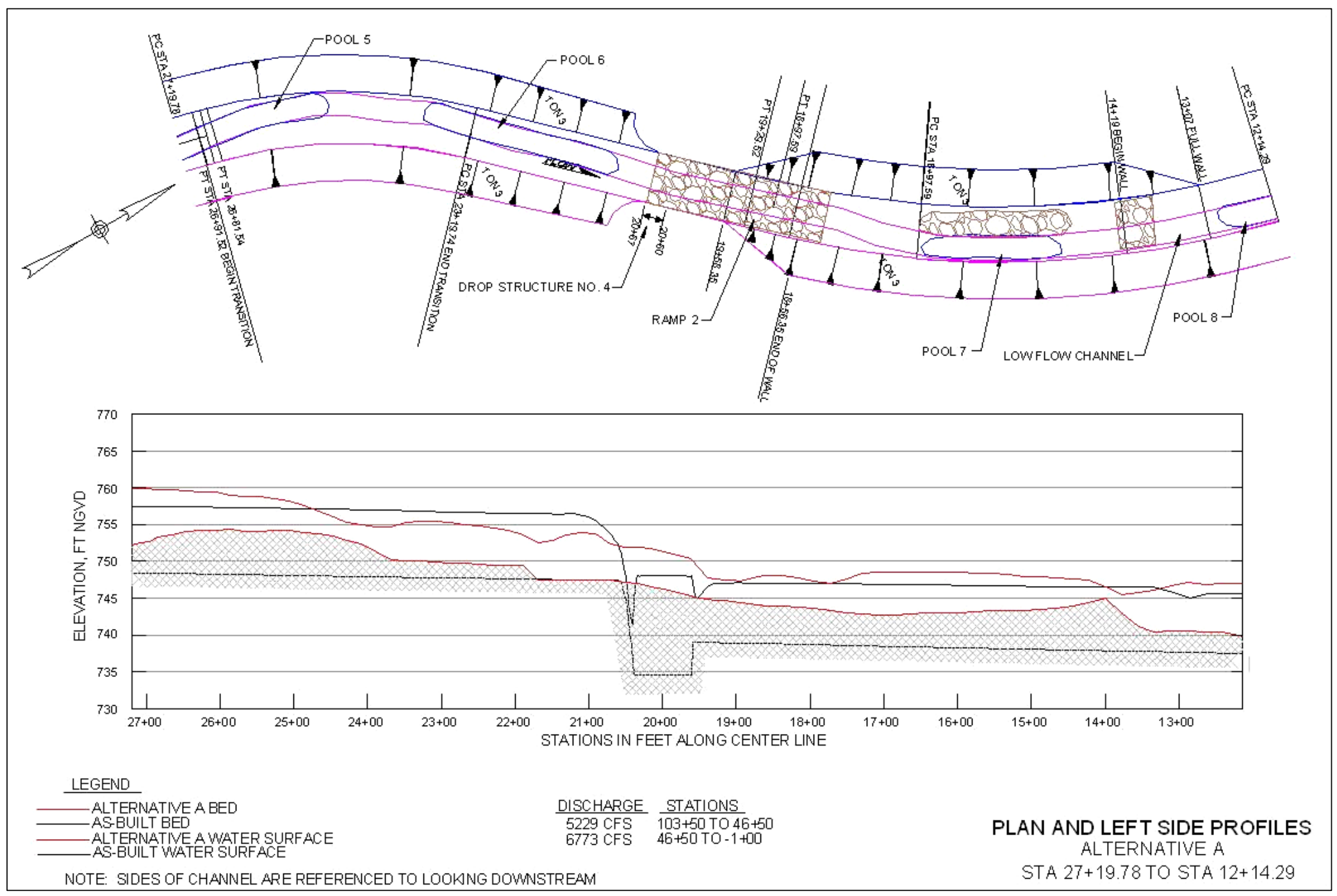

Figure 67. Alternative A, plan and profiles, sta $27+19.78$ to $12+14.29$, left wall. 


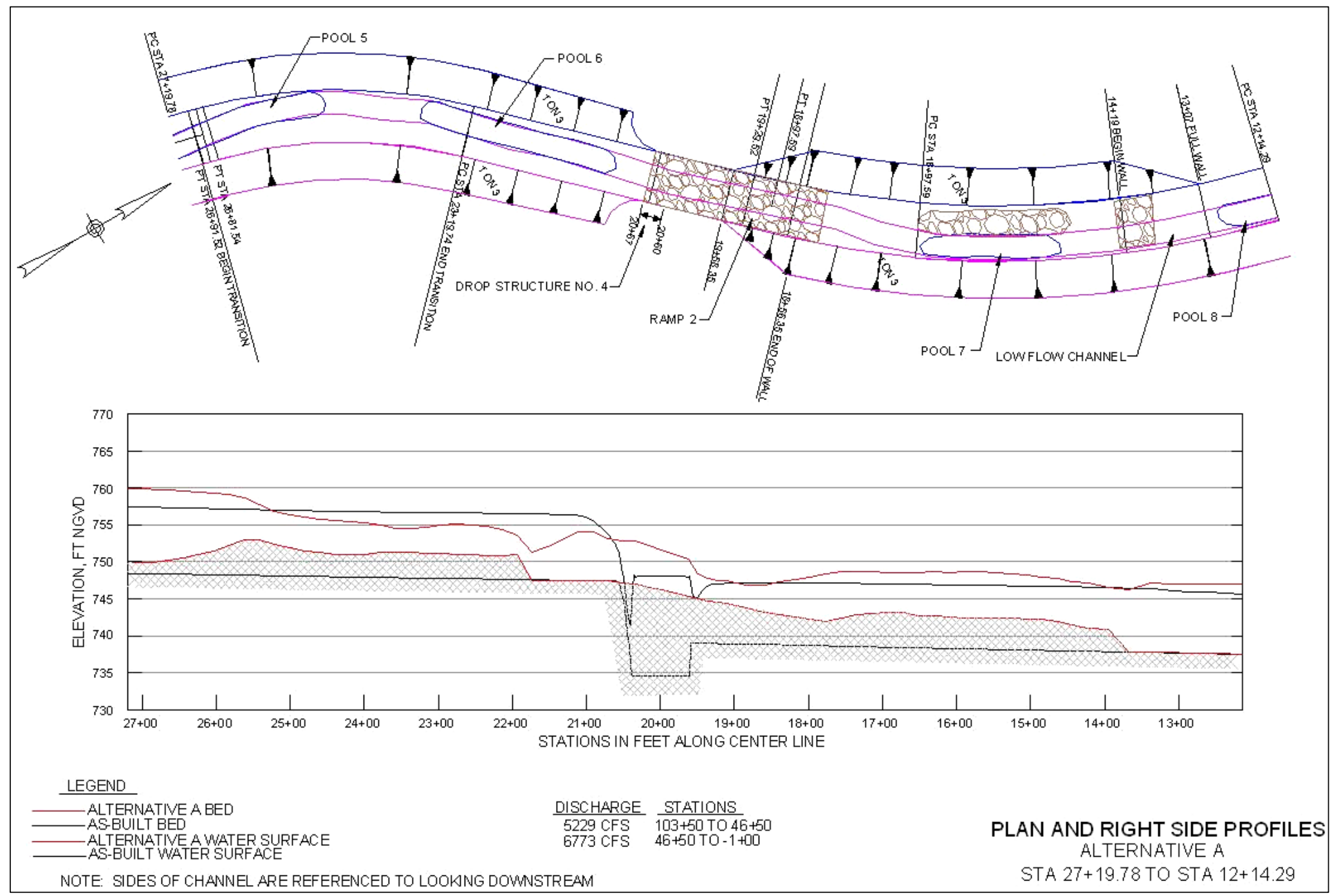

Figure 68. Alternative A, plan and profiles, sta $27+19.78$ to $12+14.29$, right wall. 


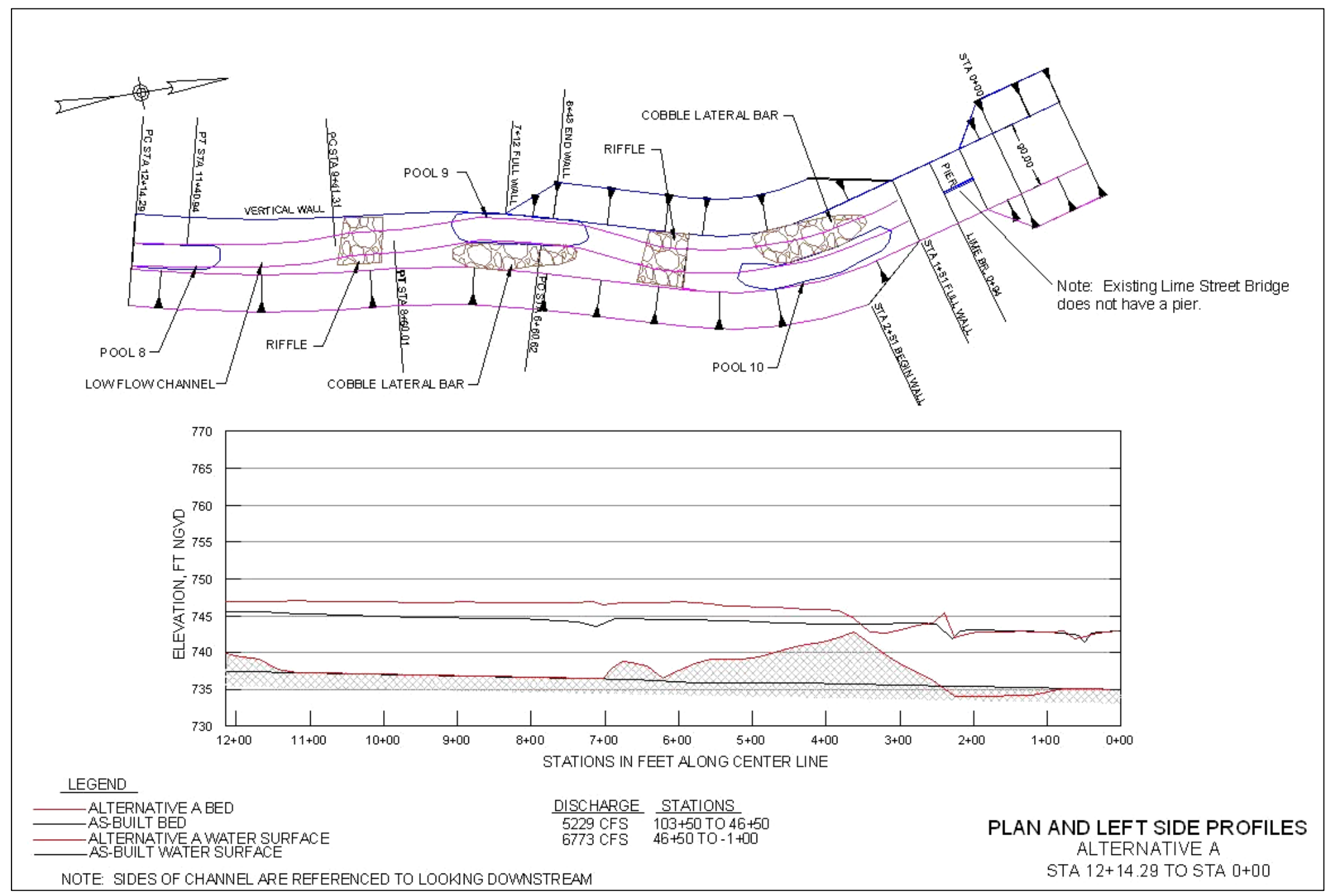

Figure 69. Alternative A, plan and profiles, sta $12+14.29$ to $0+00$, left wall. 


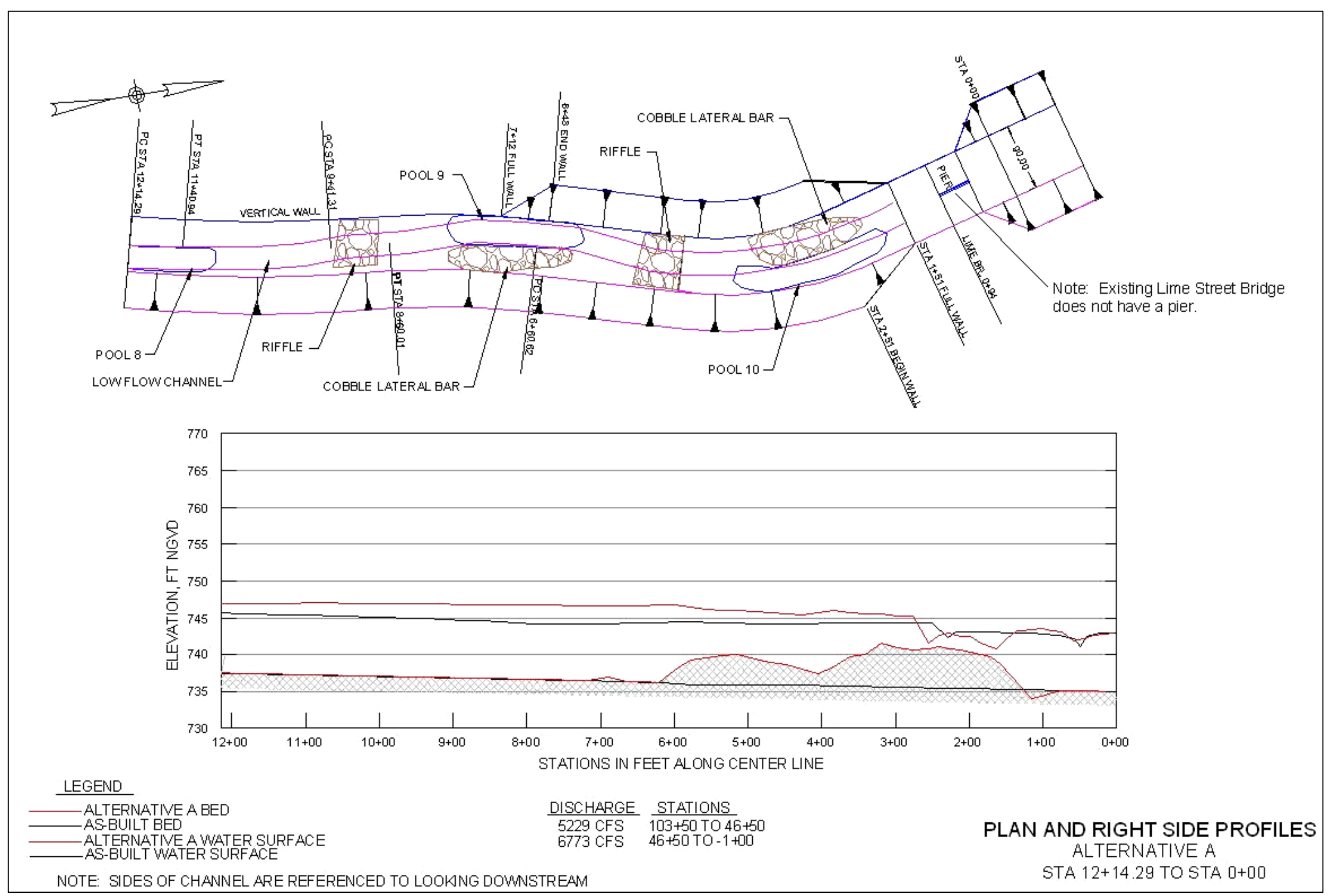

Figure 70. Alternative A, plan and profiles, sta $12+14.29$ to $0+00$, right wall. 


\section{Alternative B model}

\section{Geometry and computational mesh}

The Alternative B called for cutting the concrete of the existing drop structures. The invert at the crest of the existing drop structures would be cut $4 \mathrm{ft}$. The remaining drop would then be filled with rock to form a $240-\mathrm{ft}-$ long ramp having a 1.5-percent slope. This alternative would change the entire longitudinal slope of the Hoosic River between drop structure No. 2 (crest at sta 51+50) and No. 4 (crest at sta 20+67).

The Alternative B design replaced the rectangular cross section between sta $51+01.5$ and sta $44+50$ with a trapezoidal cross section. The existing vertical concrete walls through this reach were replaced with $1 \mathrm{~V}$ on $3 \mathrm{H}$ side slopes armored with rock. The toe of the side slopes were at the base of the existing walls so that the Alternative B channel was significantly wider than the existing channel through this reach.

A low-flow channel similar to Alternative A was cut into the existing channel bed in a pattern similar to Alternative A. Pools and riffles were formed as the low-flow channel crossed from side to side of the bed. The primary difference in the beds of Alternative A and B is that Alternative B removed the drop structures and that the resulting bed slope was steeper than the slopes between the drop structures of Alternative A. The purpose of the existing drop structures was to reduce the bed slope to ensure that the flow is subcritical. Alternative B lowered the existing bed along the upstream $3,100 \mathrm{ft}$ (sta $49+00$ to sta $18+00$ ) of the restoration project. Alternative $\mathrm{B}$ was similar to Alternative A downstream of sta $18+00$ where the low-flow channel is cut into the existing trapezoidal channel.

Alternative B called for "bank plantings" along both side slopes. The restoration line drawings showed that these plantings would include bushes and trees. The bank plantings were not simulated in the Alternative B model. The U.S. Army Corps of Engineers' guidance requires a vegetationfree zone (Headquarters, U.S. Army Corps of Engineers (USACE) 2000) such that for trapezoidal channels, trees can be planted no closer than $15 \mathrm{ft}$ from the toe of the outside levee (USACE 2009). Therefore, the roughness coefficients did not reflect the presence of these plantings, but rather were of the same value as those used to represent the roughness of Alternative A side slopes. 
The Alternative B mesh had 10,962 nodes and 19,775 elements. Element sizes and mesh resolution were similar to those used to model the Alternative A conditions. Details of the Alternative B mesh are shown in Figure 71. Two levels of adaption were employed on the low-flow channel, the side slopes, the riffles, and the rock chutes at the drop structures. Adaption resulted in an addition of 347 nodes to the original mesh to establish the steady-state solution.

\section{Boundary conditions and model parameters}

The boundary conditions were identical to those used to model Alternative A. The design discharge of $6,773 \mathrm{cfs}$ was the cumulative inflow and a tailwater of el 743.0 was set at the outflow.

The roughness coefficients were the same as those used in the Alternative A model. A Manning's roughness coefficient, $n$, of 0.014 was used for concrete, 0.025 for existing channel's gravel bed, 0.020 for the assumed sand bottomed low-flow channel, 0.030 for the sloped grassy banks, and 0.035 for the riffles and the stones of the fill slopes at the drop structures.

\section{Alternative B results}

Contours of velocity magnitudes with Alternative B are shown in Figures 72-76. The velocity immediately downstream of the Tophet Brook confluence was not significantly different between the two alternatives. However, the Alternative B was wider between drop structure No. 2 and sta $44+50$ and the Tophet Brook flow crossed the main channel flow more than the Alternative A flow. The wider cross section of the Alternative B design resulted in depth-averaged velocities being about $0.5 \mathrm{fps}$ lower than those produced with Alternative A.

The Alternative B had milder longitudinal slopes (1.5 percent) over the existing drop structures than Alternative A (3 percent) and so the velocities were slightly lower. The maximum velocity at the drop structures was about 16 fps with Alternative B compared to $19 \mathrm{fps}$ with the Alternative A. The Alternative B flow at the existing drop structures is about $0.5 \mathrm{ft}$ to 1.0 $\mathrm{ft}$ deeper than Alternative A. 


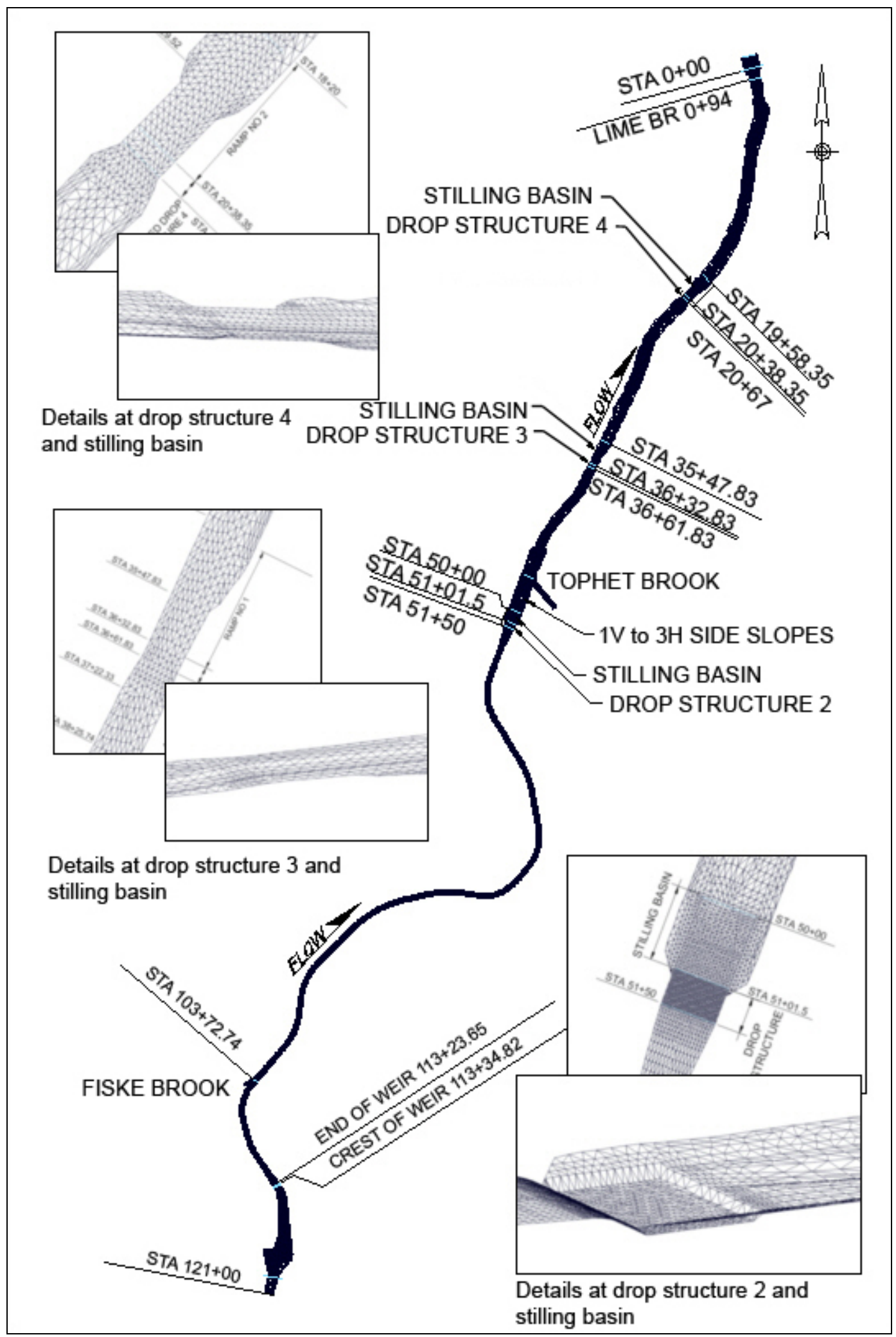

Figure 71. Alternative B, computational mesh details. 


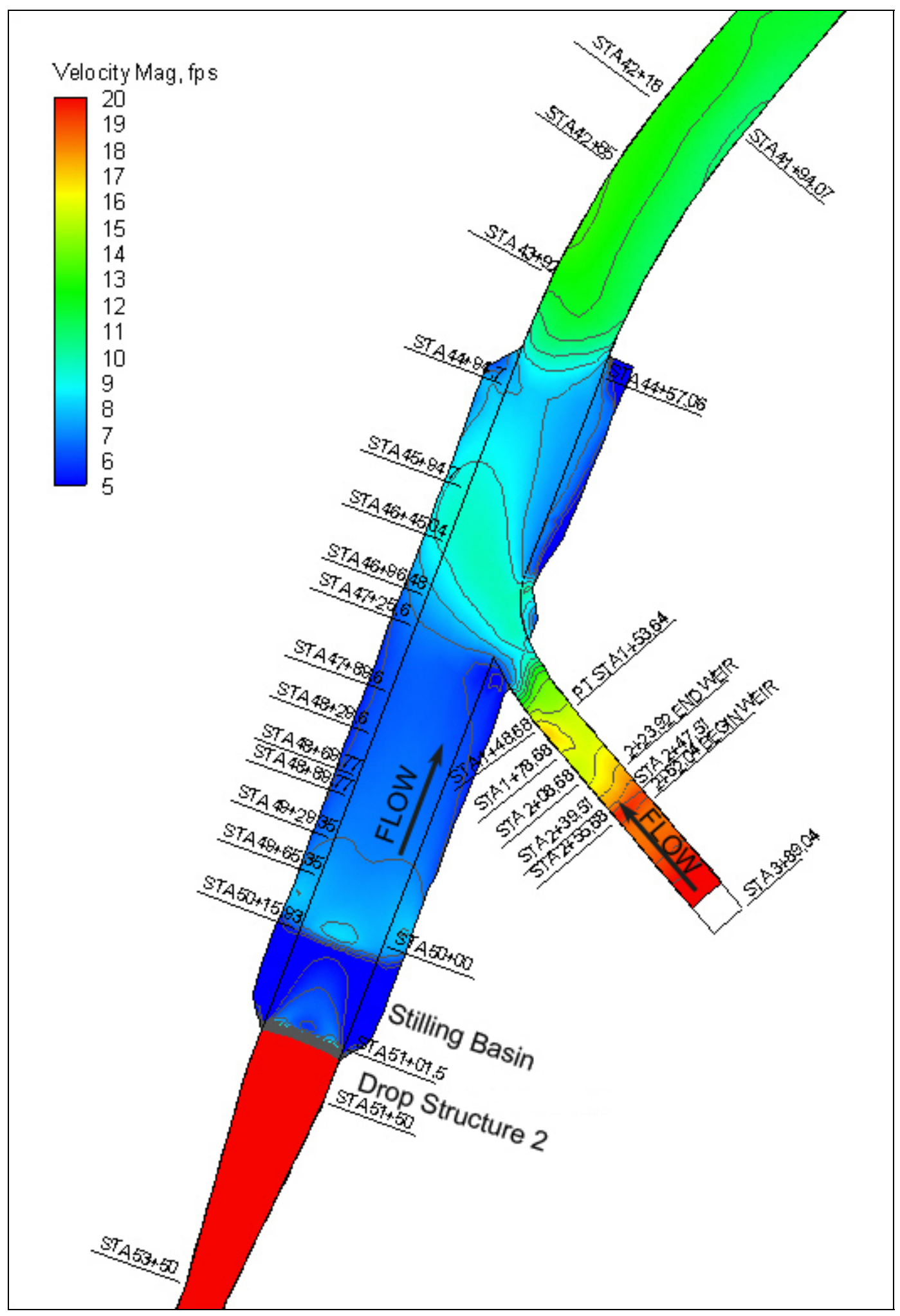

Figure 72 . Alternative $B$, velocity magnitude contours, sta $53+50$ to $41+94.07$. 


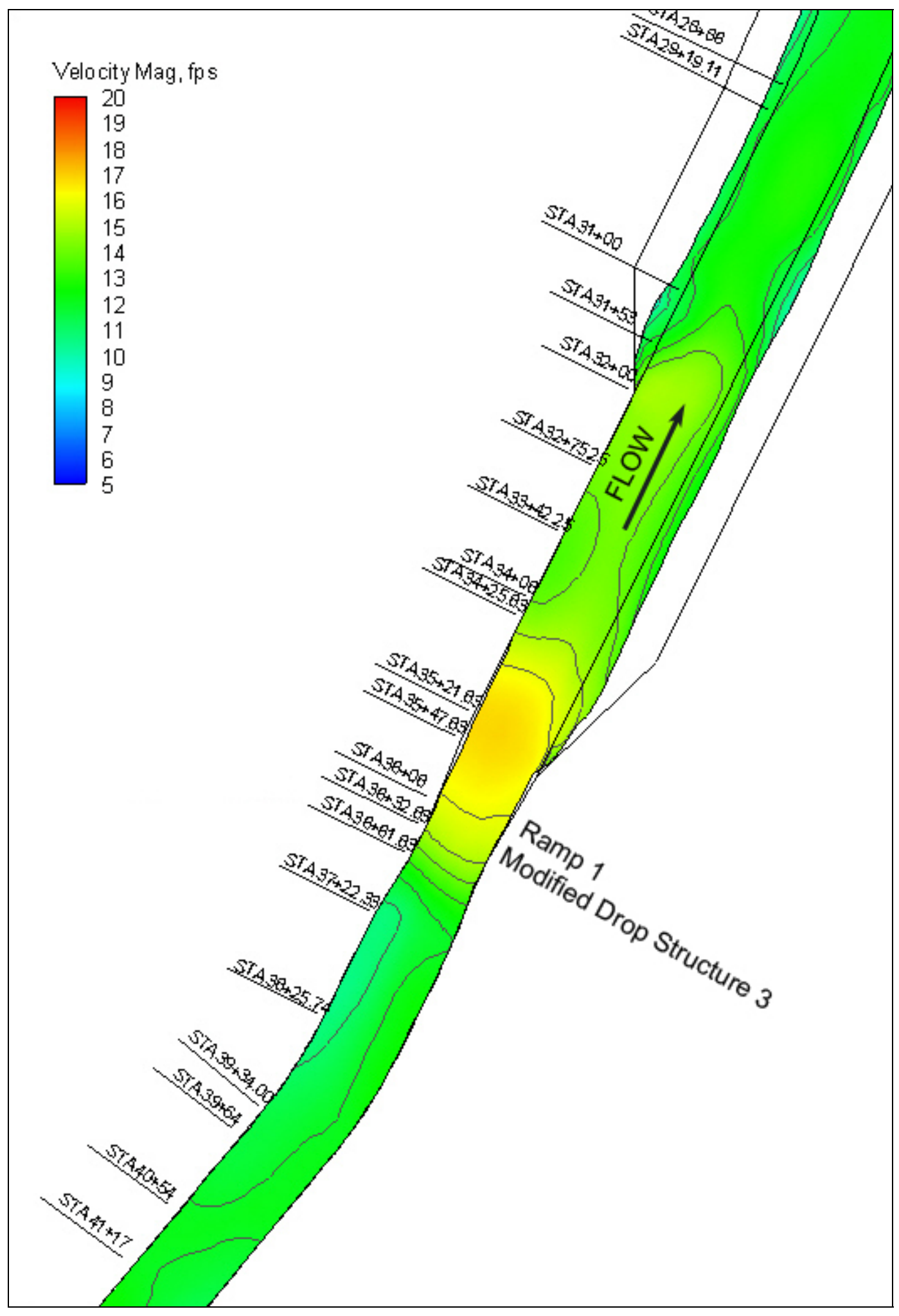

Figure 73 . Alternative B, velocity magnitude contours, sta $41+17$ to $29+11$. 


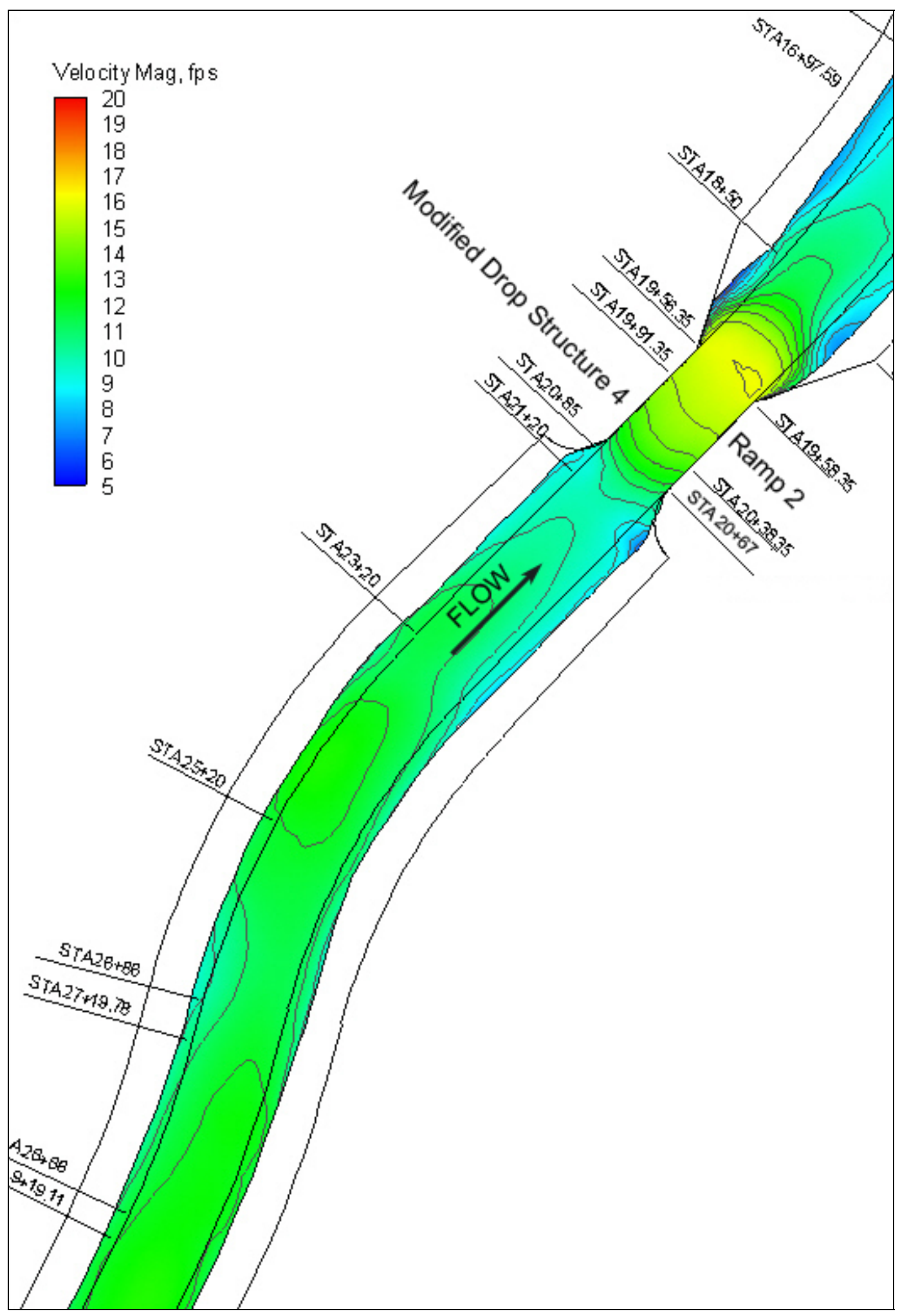

Figure 74 . Alternative $B$, velocity magnitude contours, sta $29+11$ to $17+50$. 


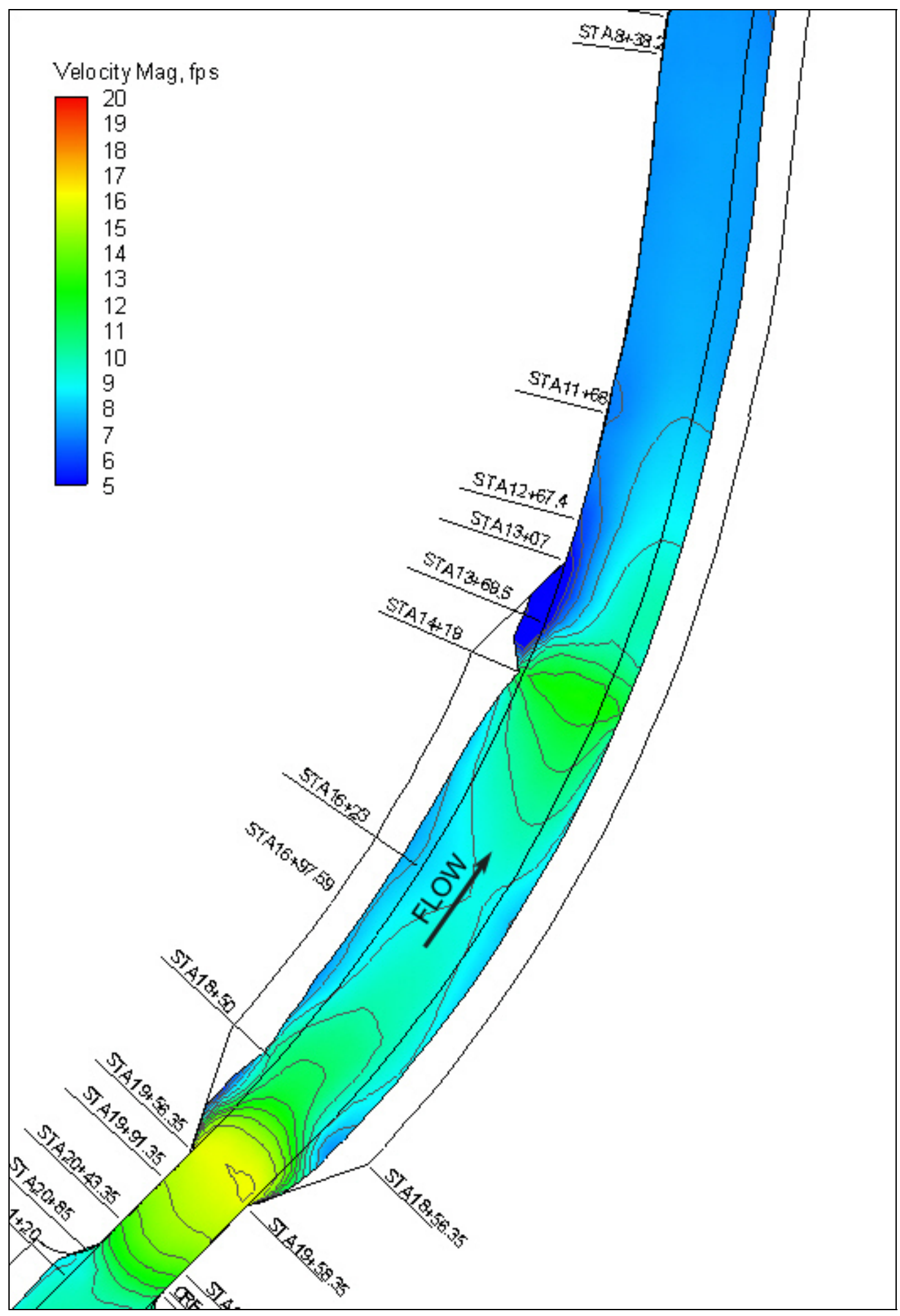

Figure 75 . Alternative B, velocity magnitude contours, sta $20+67$ to $8+38.2$. 
Velocity Mag, fps

20
19
18
17
16
15
14
13
12
11
10
9
8
7
6
5

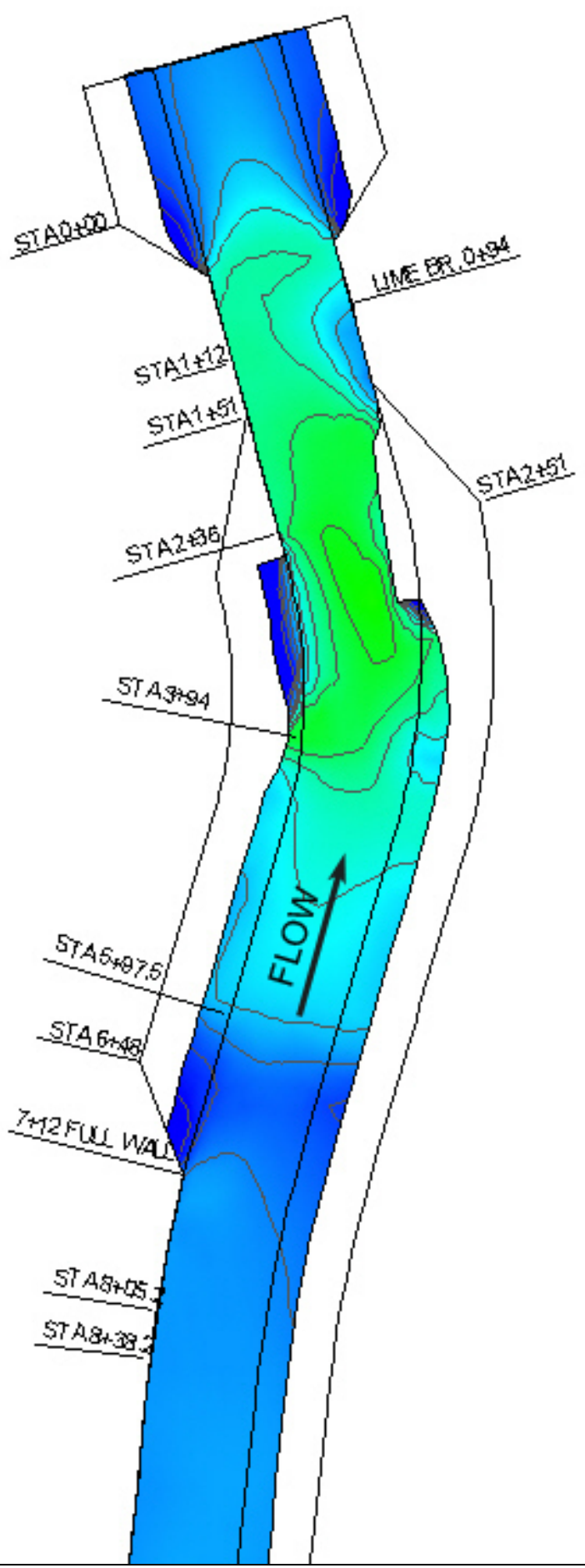

Figure 76 . Alternative $B$, velocity magnitude contours, sta $39+00$ to $-1+00$. 
The overall longitudinal bed slope of Alternative B was steep enough to produce flow that is near the critical condition. The critical flow condition is where the Froude number nears unity. Channels flowing near the critical condition will experience unstable flow with an undulating water surface. The numerical model results are steady-state conditions and do not reflect the instability associated with flow near critical (Froude number near unity). The design manual EM 1110-2-1601 (USACE 1991) notes that when flow nears the critical condition "a relatively large change of depth may occur with a very small variation of specific energy. Flow in this region is unstable and excessive wave action or undulations of the water surface may occur."

Corps of Engineers' guidance (USACE 1991) recommends that channels be designed to avoid Froude numbers between 0.86 and 1.13. It is noted that the numerical model results presented in this report do not consider the undulations of the water surface that may occur.

Alternative B produced water-surface elevations lower than the as-built design because the channel was bed was lower and steeper (and wider in the reach where side slopes replaced vertical walls). The profiles provided in Figures 77-84 show that the water-surface elevations from drop structure No. 2 (crest at sta $51+00$ ) down to drop structure No. 4 (crest at sta $20+67$ ) were significantly lower than the as-built design. This is because the bed of the Alternative B was lower than the as-built design. Downstream of sta $17+00$, the water-surface profiles with the Alternative B were essentially the same as those produced with Alternative A since the designs were similar through this reach. 


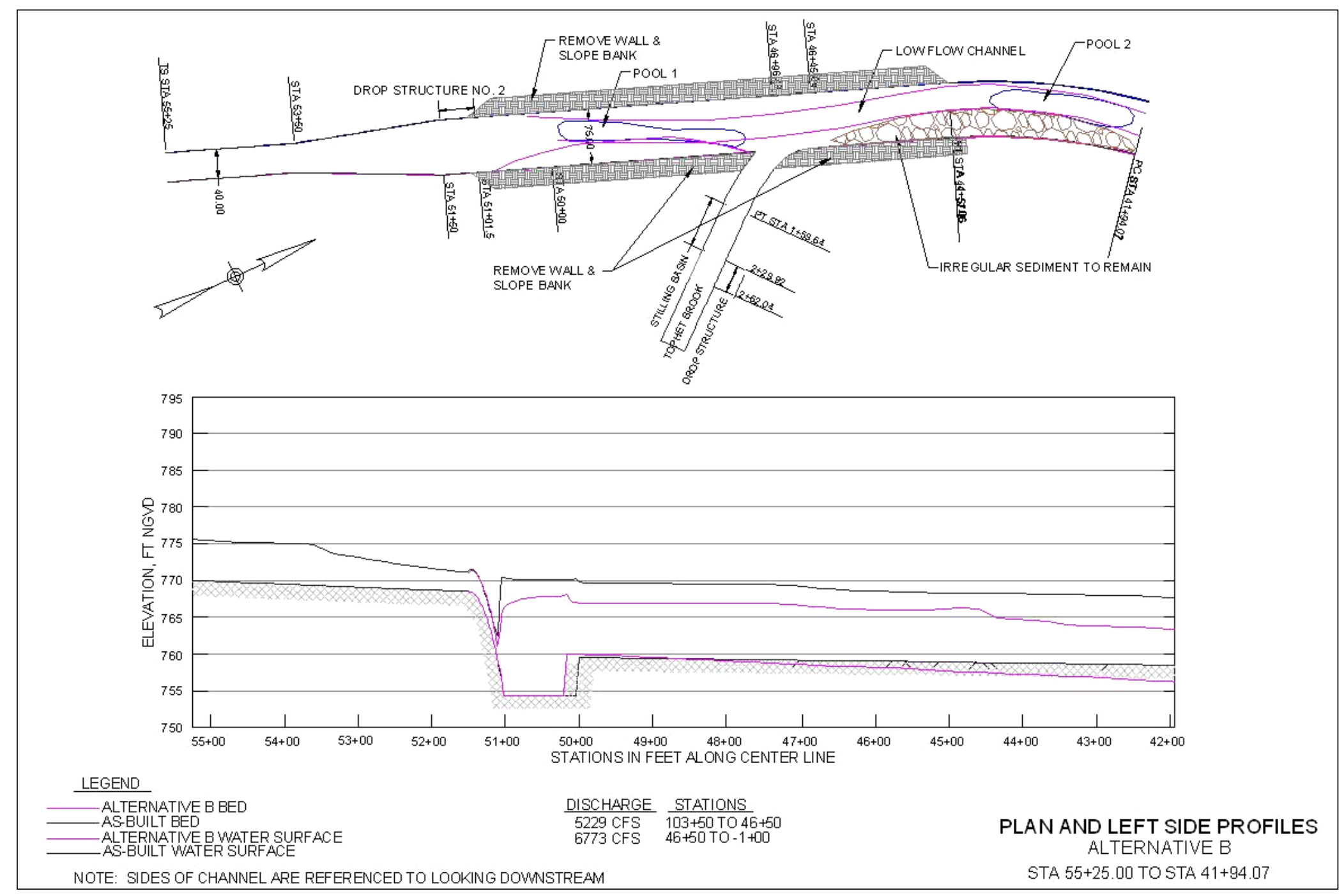

Figure 77. Alternative B, plan and profiles, sta $55+25.00$ to $41+94.07$, left wall. 


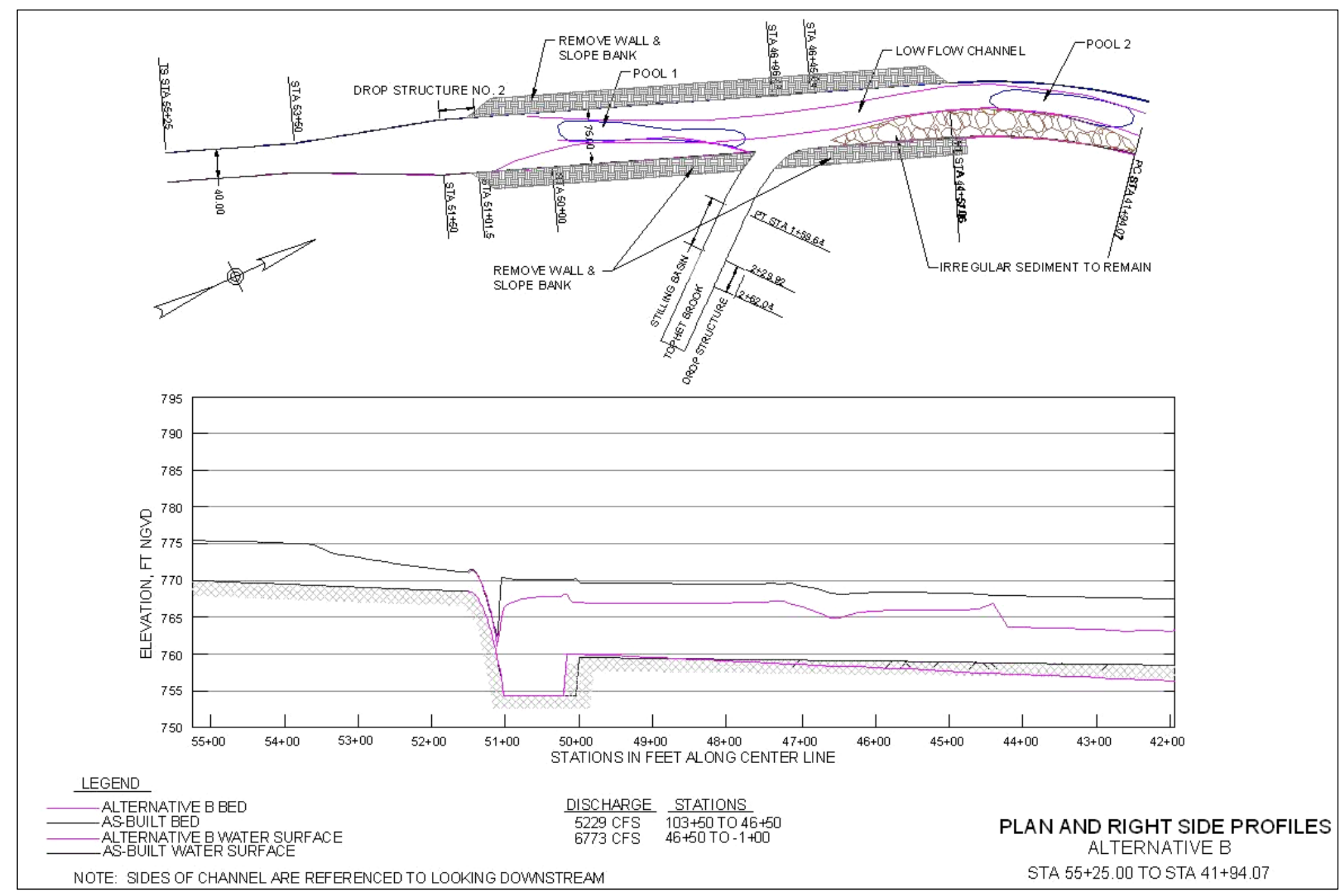

Figure 78. Alternative B, plan and profiles, sta $55+25.00$ to $41+94.07$, right wall. 


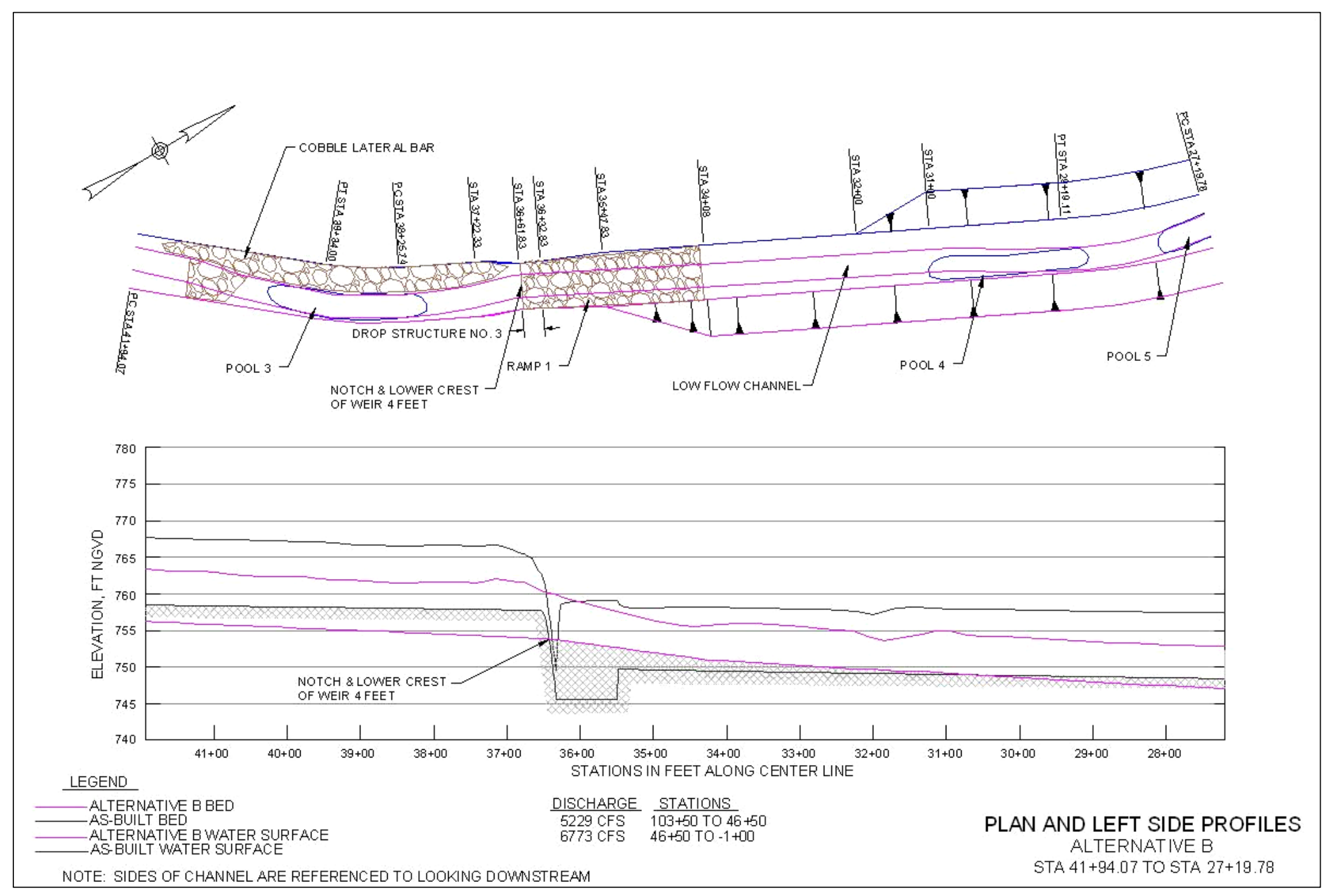

Figure 79. Alternative B, plan and profiles, sta $41+94.07$ to $27+19.78$, left wall. 


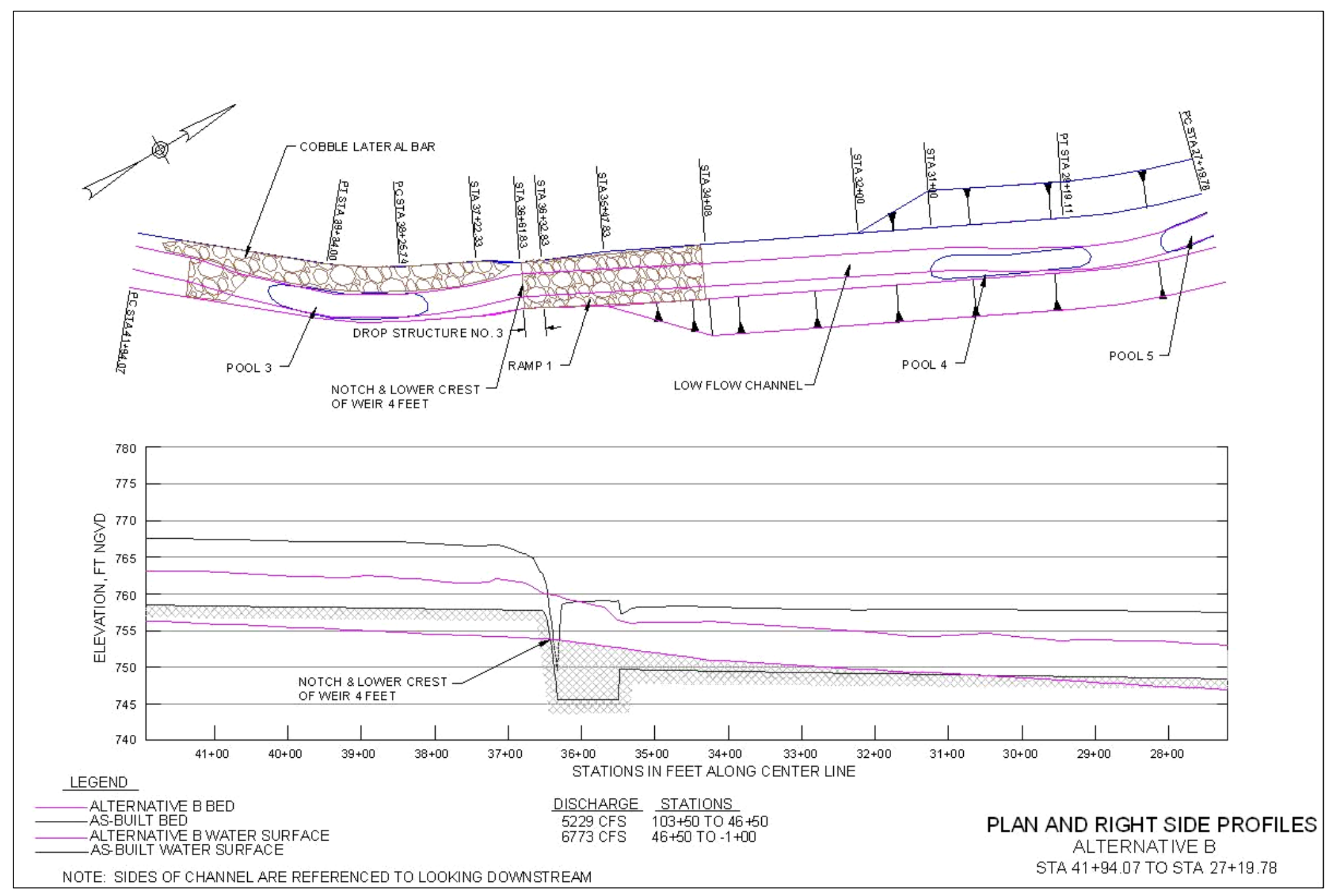

Figure 80 . Alternative B, plan and profiles, sta $41+94.07$ to $27+19.78$, right wall. 

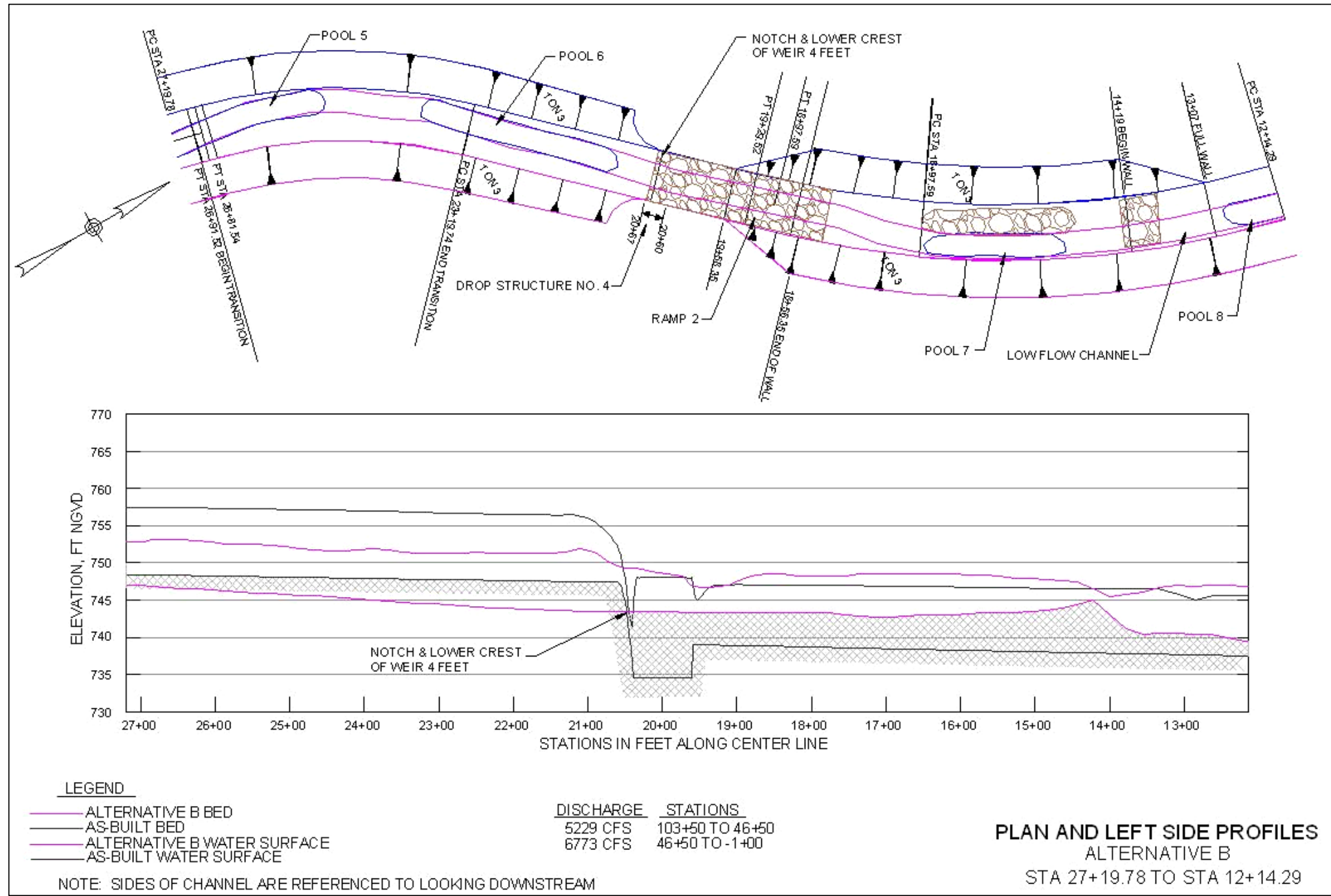

Figure 81 . Alternative B, plan and profiles, sta $27+19.78$ to $12+14.29$, left wall. 


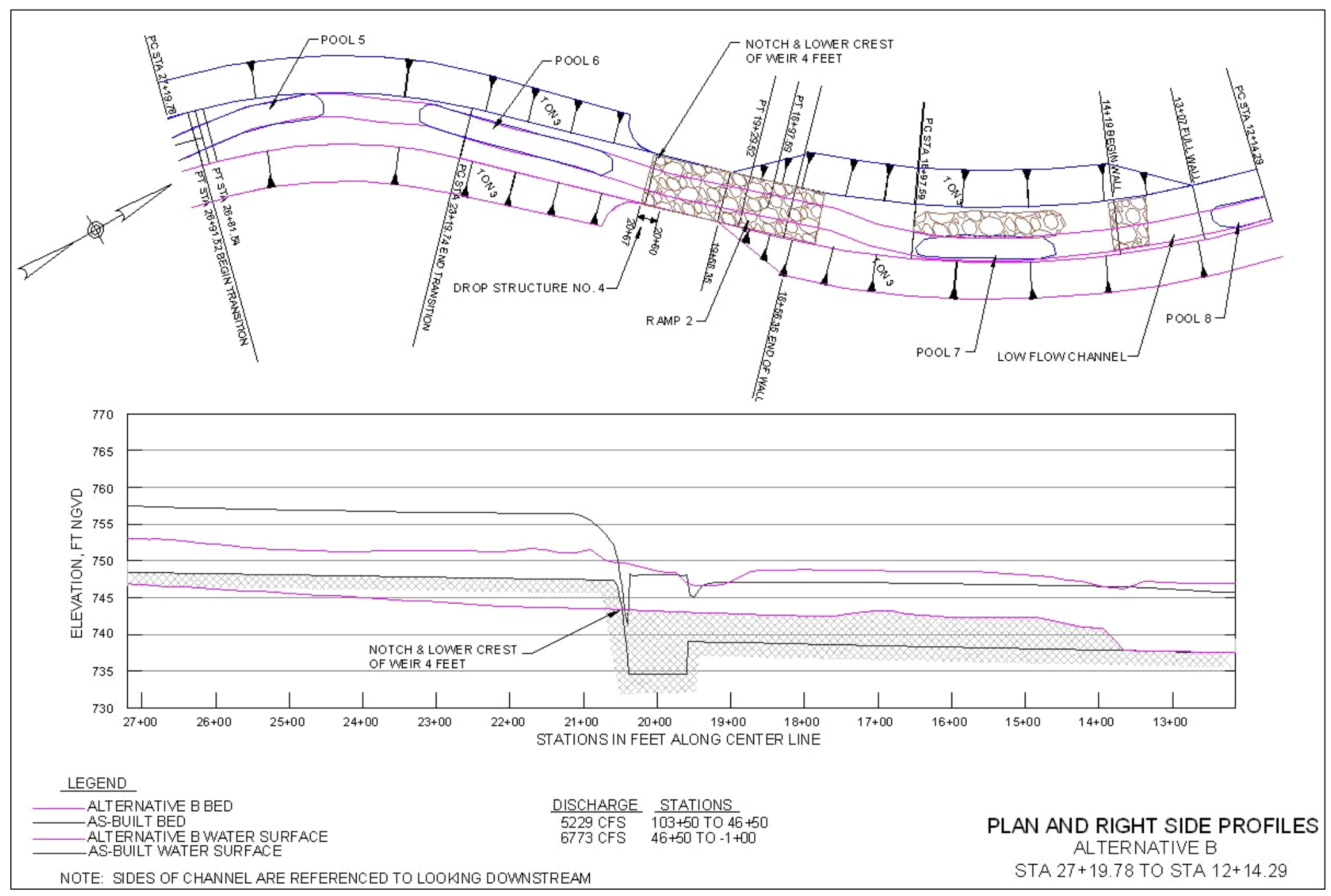

Figure 82. Alternative B, plan and profiles, sta $27+19.78$ to $12+14.29$, right wall. 


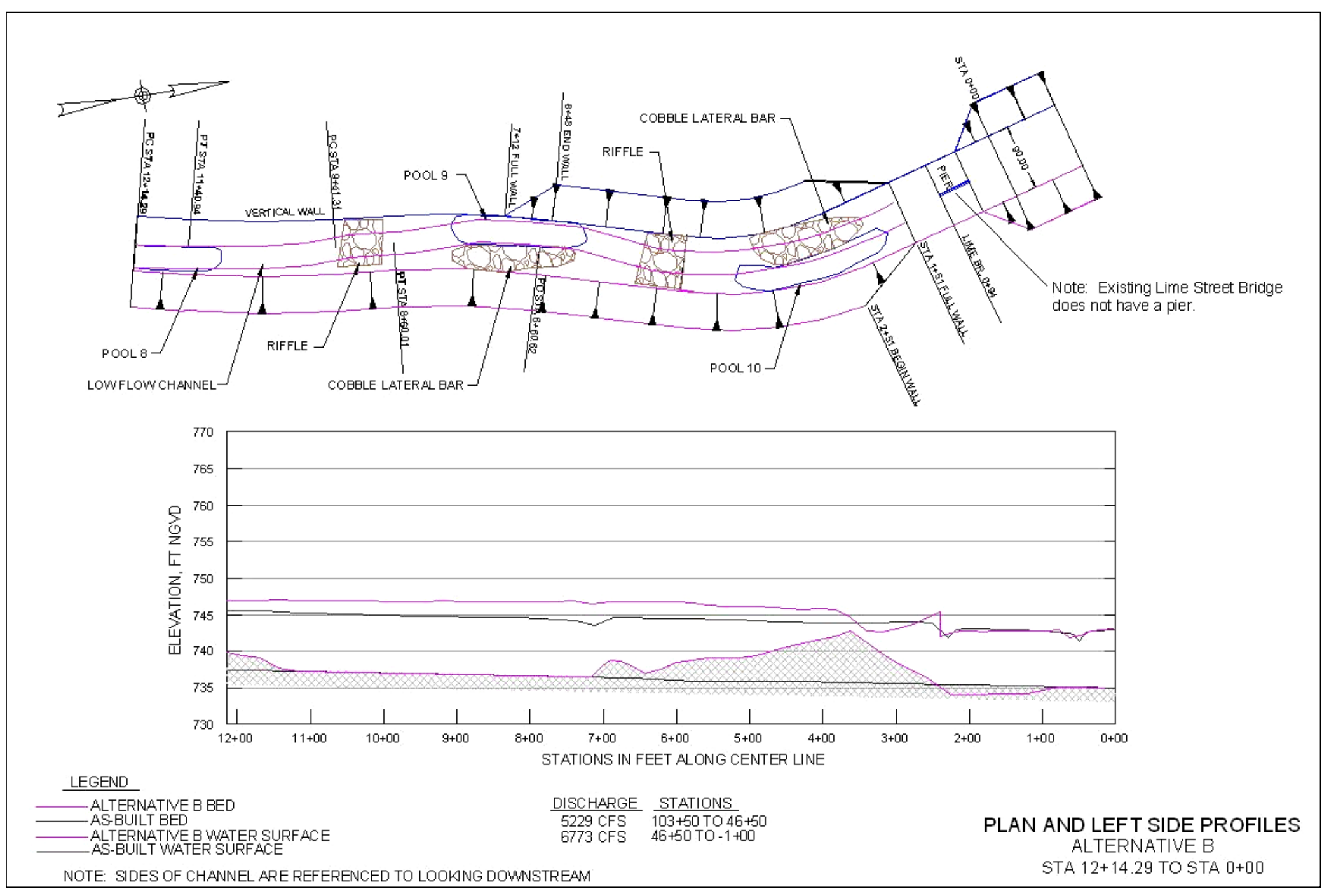

Figure 83. Alternative B, plan and profiles, sta $12+14.29$ to $0+00$, left wall. 


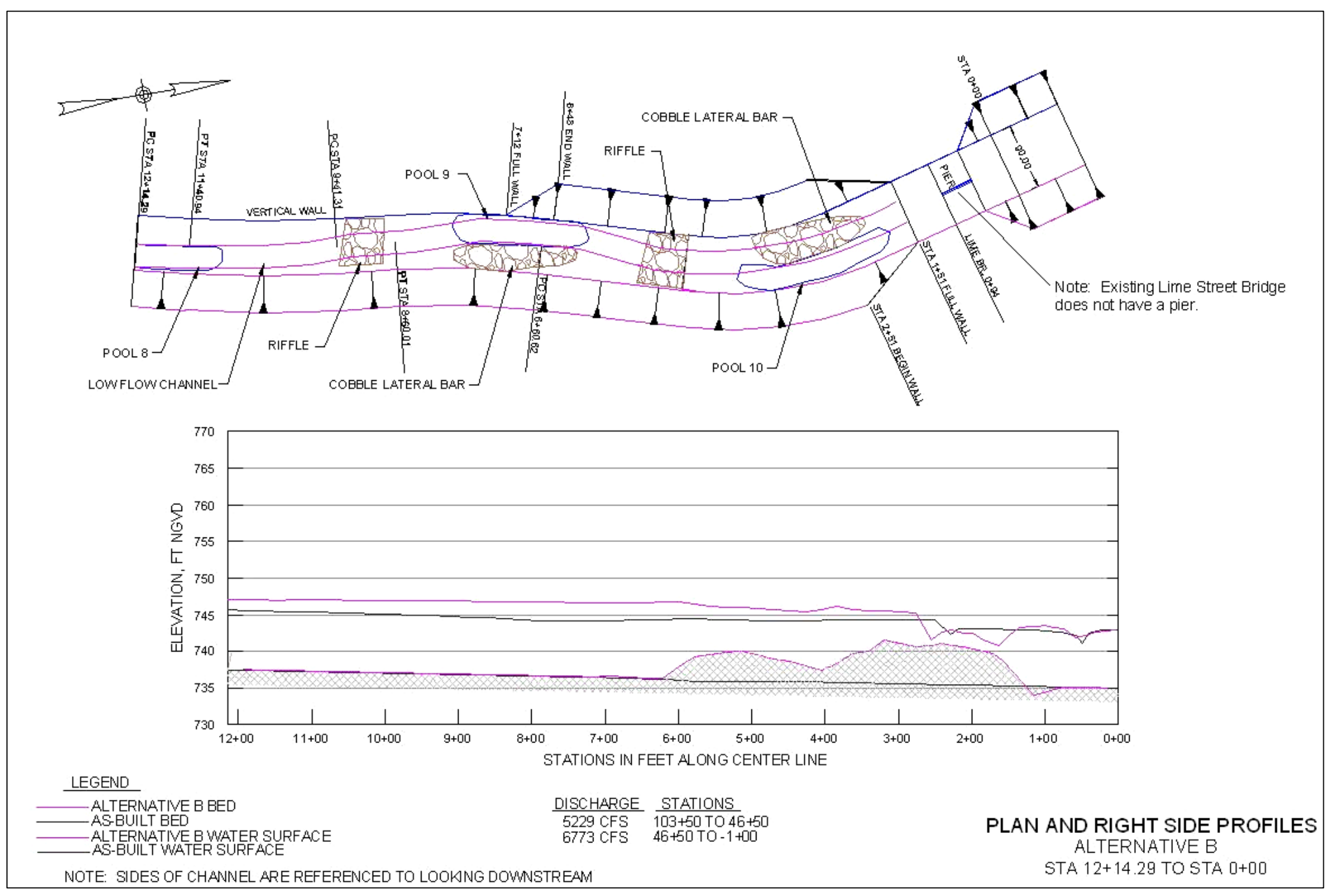

Figure 84. Alternative B, plan and profiles, sta $12+14.29$ to $0+00$, right wall. 


\section{Summary}

This study determined the design-flow conditions in the man-made reach of the Hoosic River that forms the flood-control project for Adams, MA. Flow conditions were simulated with the 2-D depth-averaged flow code, $\mathrm{ADH}$. These simulations were conducted to determine water-surface elevations and flow velocities along the river from upstream of the weir near sta $205^{+96.03}$ where the project is a rectangular concrete channel to the Lime Street Bridge where it is a trapezoidal riprap channel.

The model was validated by comparing with previously published physical model data for the Hoosic River Flood-Control Channel through North Adams, MA. Simulation results showed that the 2-D ADH model is an appropriate tool to use in evaluating flow conditions in the Hoosic River Flood-Control Channel.

As-built and existing conditions were modeled primarily to determine the consequences of the sediment deposition in the lower reach. Water-surface elevations produced during the 100-year frequency flow were compared. The water-surface elevations produced with the existing conditions were more than $2 \mathrm{ft}$ in areas of the channel where deposits of sediment obstructed the flow.

The primary purpose of the study was to evaluate proposed channel restoration modifications to the lower end. The model determined whether restoration alterations changed water-surface elevations associated with the design discharge. Restoration designs included a 16 -ft-wide by $2-$ to 2.5 -ft-deep low-flow channel with pools and riffles. Two restoration configurations were studied.

Alternative A, downstream of sta $36+00$, produced water-surface elevations that were in some areas $2.5 \mathrm{ft}$ higher than the as-built conditions at the design discharge. However, some reaches of Alternative A resulted in water-surface elevations that were lower than the as-built conditions.

Although Alternative B produced water-surface elevations that were lower than the as-built conditions, the design discharge produced flow near critical depth. This opposes Corps of Engineers' guidance (USACE 1991) which 
recommends that channels be designed to avoid Froude numbers near unity. The numerical model results presented in this report do not consider the undulations of the water surface that may occur. Alternative A provided better hydraulic conditions than Alternative B because the later resulted in flow near critical conditions. 


\section{References}

Headquarters, U.S. Army Corps of Engineers (USACE). 1991. Hydraulic design of flood control channels. Engineer Manual 1110-2-1601. Washington, DC: Headquarters, U.S. Army Corps of Engineers.

Headquarters, U.S. Army Corps of Engineers (USACE). 2000. Guidelines for landscape planting and vegetation management at floodwalls, levees, and embankment dams. Engineer Manual 1110-2-301. Washington, DC: Headquarters, U.S. Army Corps of Engineers.

Headquarters, U.S. Army Corps of Engineers (USACE). 2009. Guidelines for landscape planting and vegetation management at levees, floodwalls, embankment dams, and appurtenant structures. Engineer Technical Letter 1110-2-571. Washington, DC: Headquarters, U.S. Army Corps of Engineers.

U.S. Army Engineer District, Los Angeles. 1948. Modified spiral curve tables. Los Angeles, CA: U.S. Army Corps of Engineers.

U.S. Army Engineer Waterways Experiment Station. 1952. Flood-control project, Hoosic River, North Adams, Massachusetts, Report No. 1, Model investigation of stilling basin and junction section. Technical Memorandum 2-338. Vicksburg, MS: U.S. Army Engineer Waterways Experiment Station.

U.S. Army Engineer Waterways Experiment Station. 1957. Flood-control project, Hoosic River, Adams, Massachusetts, Report No. 2, Model investigation of phase II of improvement works. Technical Memorandum No. 2-339. Vicksburg, MS: U.S. Army Engineer Waterways Experiment Station.

U.S. Army Engineer Waterways Experiment Station. 1987. Hydraulic design criteria. Vicksburg, MS: U.S. Army Engineer Waterways Experiment Station. http://chl.erdc.usace.army.mil/hdc. 


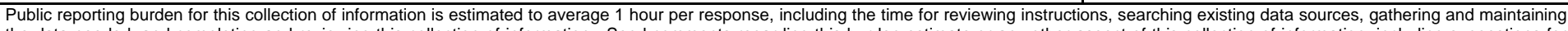

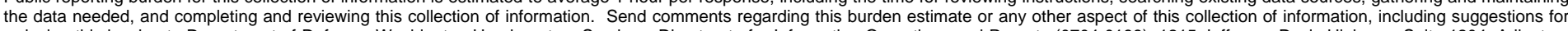

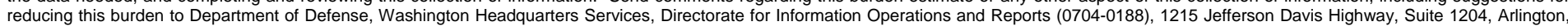

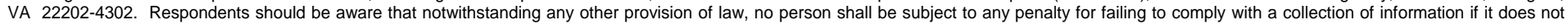
display a currently valid OMB control number. PLEASE DO NOT RETURN YOUR FORM TO THE ABOVE ADDRESS.
1. REPORT DATE (DD-MM-YYYY)
2. REPORT TYPE
3. DATES COVERED (From - To)

Final report

February 2010

4. TITLE AND SUBTITLE

Numerical Model of the Hoosic River Flood-Control Channel, Adams, MA

5a. CONTRACT NUMBER

5b. GRANT NUMBER

5c. PROGRAM ELEMENT NUMBER

\section{AUTHOR(S)}

Richard L Stockstill, Jane M. Vaughan, and Keith Martin

5d. PROJECT NUMBER

5e. TASK NUMBER

5f. WORK UNIT NUMBER

\section{PERFORMING ORGANIZATION NAME(S) AND ADDRESS(ES)}

8. PERFORMING ORGANIZATION REPORT NUMBER

U.S. Army Engineer Research and Development Center

Coastal and Hydraulics Laboratory

ERDC/CHL TR-10-1

3909 Halls Ferry Road

Vicksburg, MS 39180-6199

9. SPONSORING I MONITORING AGENCY NAME(S) AND ADDRESS(ES)

10. SPONSOR/MONITOR'S ACRONYM(S)

U.S. Army Engineer District, New York

Jacob K. Javits Federal Building

26 Federal Plaza, Room 2109

New York, NY 10278-0090

11. SPONSOR/MONITOR'S REPORT NUMBER(S)

\section{DISTRIBUTION / AVAILABILITY STATEMENT}

Approved for public release; distribution is unlimited.

\section{SUPPLEMENTARY NOTES}

\section{ABSTRACT}

A numerical model study of the Hoosic River Flood-Control Channel was conducted to determine the flow conditions with the channel as it presently exists as compared with the as-built conditions. Sediment has accumulated in certain portions of the channel resulting in relatively large areas of deposited material that may inhibit flood-flow conveyance. The two-dimensional depth-averaged module of the Adaptive Hydraulics (ADH) finite element flow solver was used to obtain velocity information and water-surface elevations. Validation of the numerical modeling system was completed by comparing simulation results with published physical model data. The model was then used to evaluate the flow conditions associated with the as-built channel configuration. The existing channel conditions were then simulated to determine the water-surface elevations that are to be expected with design discharge and the channel in the present day condition. Finally, the flow conditions with two alternative channel modifications were evaluated. These modifications were proposed channel restoration configurations designed to improve habitat and aesthetics.

\begin{tabular}{|ll|}
\hline 15. SUBJECT TERMS & High-velocity channels \\
Finite element & Hoosic River \\
Flood control & Numerical models \\
\hline
\end{tabular}

16. SECURITY CLASSIFICATION OF:

\begin{tabular}{|l|l|}
\hline a. REPORT & b. ABSTRACT \\
UNCLASSIFIED & UNCLASSIFIED \\
\hline
\end{tabular}

c. THIS PAGE

UNCLASSIFIED
River restoration

Shallow-water equations

Two-dimensional

\begin{tabular}{l|c|l|}
$\begin{array}{l}\text { 17. LIMITATION } \\
\text { OF ABSTRACT }\end{array}$ & $\begin{array}{l}\text { 18. NUMBER } \\
\text { OF PAGES }\end{array}$ & $\begin{array}{l}\text { 19a. NAME OF RESPONSIBLE } \\
\text { PERSON }\end{array}$ \\
\cline { 3 - 3 } & 112 & $\begin{array}{l}\text { 19b. TELEPHONE NUMBER (include } \\
\text { area code) }\end{array}$ \\
& &
\end{tabular}

